WHOI-98-11

A Deep Sea Docking Station for ODYSSEY Class Autonomous Underwater Vehicles

by

M. F. Bowen, D. B. Peters

Woods Hole Oceanographic Institution
Woods Hole, Massachusetts 02543

June 10, 1998

Technical Report

Funding was provided by the Office of Naval Research under Grant No. N000-14-95-1-1316

Reproduction in whole or in part is permitted for any purpose of the United States Government. This report should be cited as Woods Hole Oceanog. Inst. Tech. Rept., WHOI-98-11

Approved for public release; distribution unlimited.

Approved for Distribution:
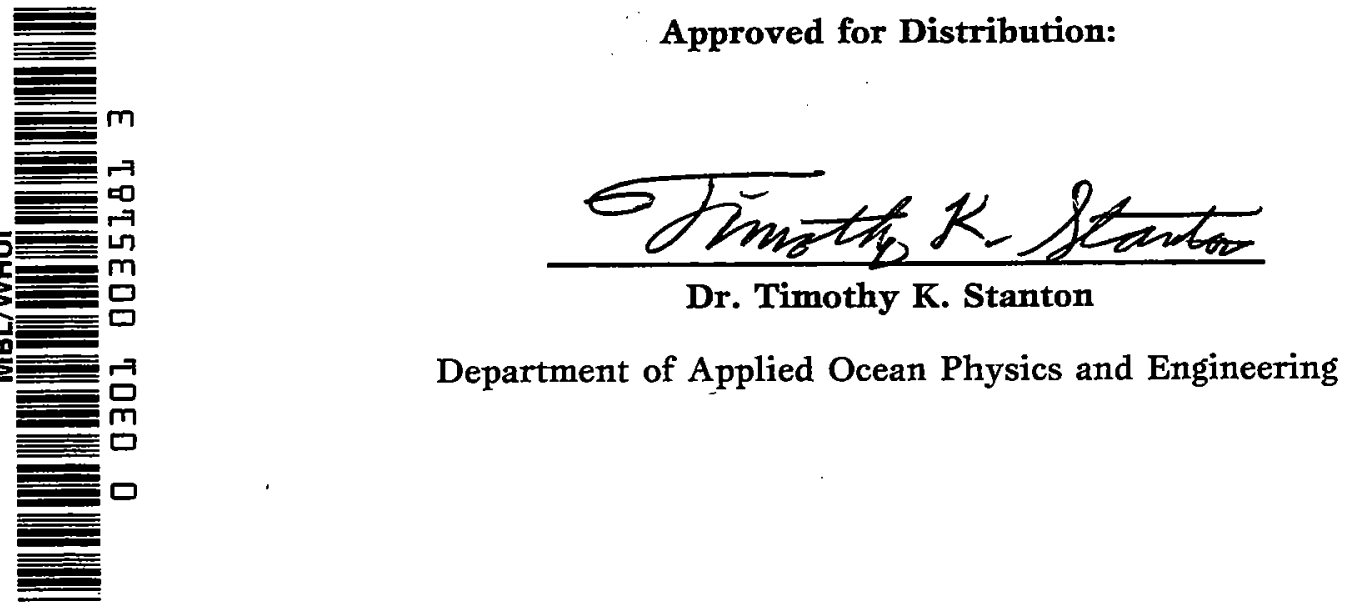


\section{A Deep Sea Docking Station for ODYSSEY Class Autonomous Underwater Vehicles}

Electro-Mechanical Design, Fabrication and Operation for the MIT Sea Grant

Autonomous Ocean Sampling Network (AOSN)

Prepared By:

M. F. Bowen, D. B. Peters

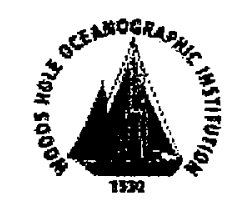

Version 1.0

10 June 1998

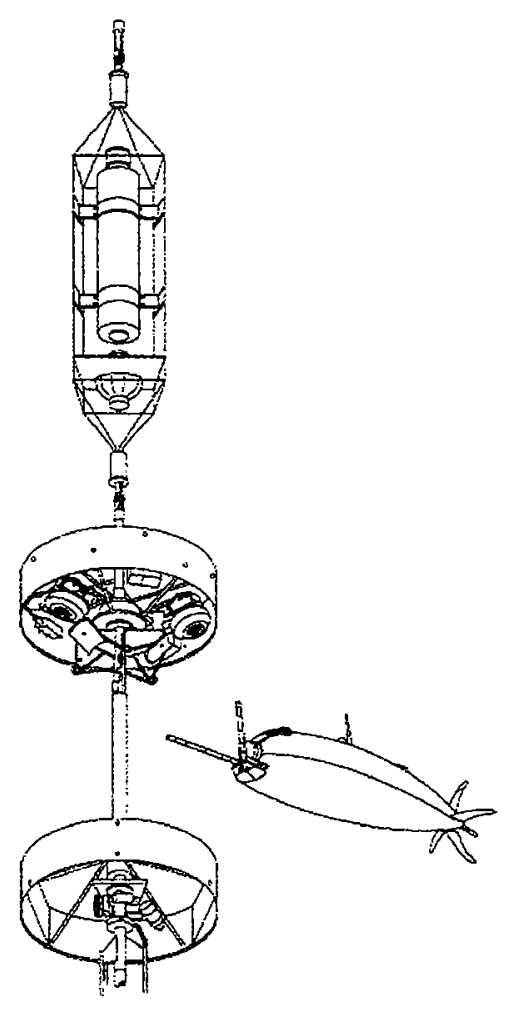




\section{A Deep Sea Docking Station for ODYSSEY Class AUVs}

\section{Electro-Mechanical Design, Fabrication and Operation for the MIT Sea Grant Autonomous Ocean Sampling Network (AOSN)}

\section{Version 1.0}

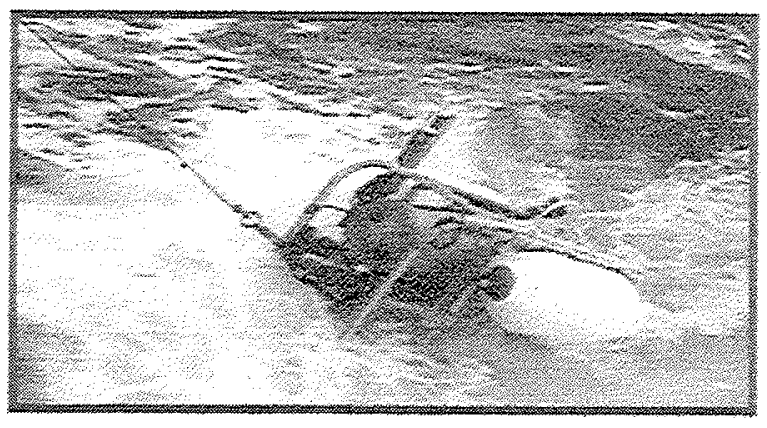

\section{Contents}

Abstract 3

1.0 Introduction 4

2.0 Mooring Background 4

3.0 Docking Station 5

3.1 Dock Controller

3.1.1 Housing

3.1.2 Chassis Layout

3.1.3 Chassis Wiring

3.1.4 Wet Harnessing

3.2 Moving Carriage and Docking Pole

3.2.1 Drive Mechanism

3.2.2 Guide Aprons

3.2.3 Magnetic Switch Harness

3.3 Inductive Link

3.3.1 Male Core Mounting, Docking Station Side

3.3.2 Female Core Mounting, Vehicle Side

3.4 Housing Frame

3.4.1 Battery Housings

3.4.2 External Sensors

3.4.2.1 Utility Acoustic Modem (UAM)

3.4.2.2 Acoustic Doppler Velocimeter (ADV)

3.4.2.3 Seabird RS232 Temperature Probe (SBE)

3.4.2.4 Long-baseline Remote Transducer Head (LBL)

3.4.2.5 Digiquartz Intelligent Depth Sensor (PARO)

3.4.3 Collapsible Flotation

3.5 Performance Analysis

3.5.1 Moving Carriage Fault

3.5.2 Battery Connector Leak

3.5.3 LBL Transmitter Fault

3.5.4 Carriage Motor Flooding 6 6 6 7 7 8 8

$-8$
9

posed Improvements

3.6.1 Split Station Modification___ 15

3.6.2 Pinch Capstan Modification 15

3.6.3 Edgetech Correction 15

3.6.4 Carriage Motor Compensation 15

3.6.5 Slow Scan Video System Addition__ 15 


\section{Figures}

Figure [1] AOSN Mooring Components on the Fantail of RN KNORR

Figure [ 2] Mooring and Docking Station, Block Diagram___ 5

Figure [ 3 ] Docking Station (circled) and 2 AUVs___ 6

Figure [ 4] Doccon Chassis, Mechanical Layout_ 6

Figure [ 5 ] Doccon Chassis Wiring (See Drawing 156-97-100)_ 7

Figure [6] Doccon External Connections and Wet Harnessing___ 7

Figure [ 7 ] Moving Carriage and Docking Pole (shown sideways as stowed)___ 8

Figure [ 8 ] Docking Station, Magnetic Switch Locations 9

Figure [ 9] Male Inductive Core Mount, Docking Station Side__ 10

Figure [ 10] Female Inductive Core Mount, AUV Side__ 10

Figure [ 11$]$ Battery Housing, Purgable Endcap, Dock Frame, and Polyform Float __ 11

Figure [ 12] Utility Acoustic Modem Housing___ 12

Figure [ 13] Acoustic Doppler Velocimeter___ $\_12$

Figure [ 14 ] Collapsible Polyform Flotation___ 12

Figure [ 15 ] Carriage Drive Motor, Housing and Compensation Bladder 14

Figure [ 16 ] Proposed Separation of Battery Frame and Docking Pole__ 15

Figure [ 17 ] Odyssey Labrador Sea Mooring Detail, AEL Revision $4 \_16$

\section{Addendums}

Dock Controller Chassis Wiring

$17-20$

Mechanical Drawings

$21-68$

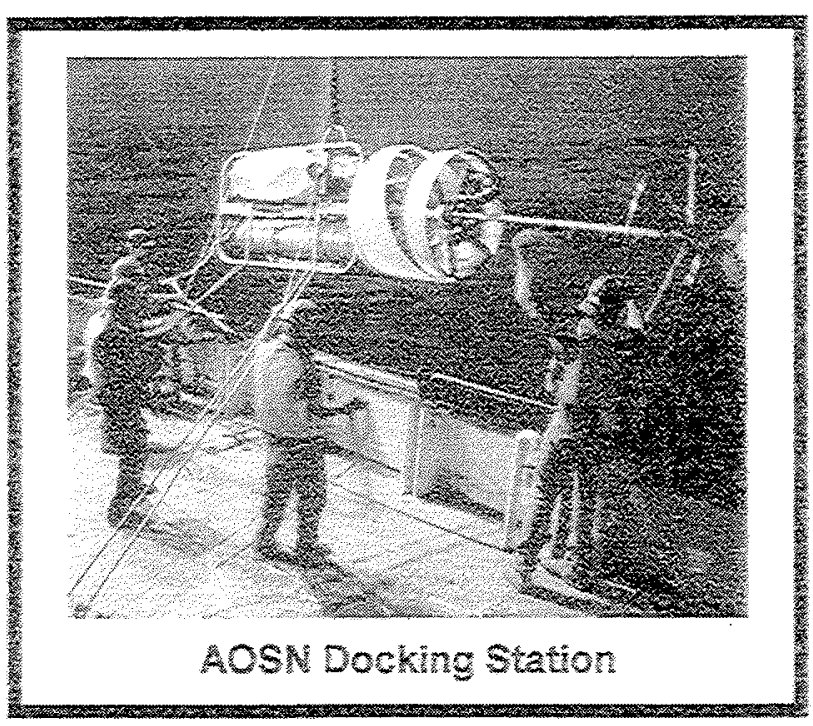

Abstract

Under subcontract to the Massachusetts Institute of Technology's (MIT) Sea Grant Autonomous Ocean Sampling Network (AOSN) program, engineers and researchers at the Woods Hole Oceanographic Institution (WHOI) designed, fabricated and operated a deep sea Docking Station for ODYSSEY-class autonomous underwater vehicles (AUVs). The docking station provides shelter as well as power transfer and data exchange services for an AUV that is between autonomous midwater missions. The Station is integrated into the main tension member of a deep sea mooring system. A large subsea flotation sphere supports the mass of the Station above the seafloor. A surface expression connected by an umbilical to the Station was capable of bi-directional satellite or radio frequency communications. Primary subsystems of the docking Station described in this report include a dock controller with multi-sensor support, long-duration battery packs, a docking pole with a moving carriage, an inductive link for power and data transfer, and information about how the Station was deployed, operated and recovered. (159) Keywords: AUV, docking, mooring. 


\subsection{Introduction}

The AOSN Deep AUV Docking Station was designed and built for MIT Sea Grant by the Deep Submergence Laboratory and the Applied Engineering Laboratory of WHOI and Electronic Design Consultants of North Carolina. The Station was fabricated in the summer of 1997, bench tested, wet tested, deployed to a depth of 500 meters in October 1997 during a test cruise to Site D off the New Jersey coast, revised at WHOl, and retested in preparation for an extended deployment. The Station was sealed and powered up again on 17 January for the (now-completed) 1998 AOSN cruise to the Labrador Sea on the R/V KNORR.

The Docking Station has not experienced a crippling failure since 17 January and has not been powered down since that date. The station was deployed a second time to a depth of 500 meters on 28 January for 14 days in the Labrador Sea and recovered successfully. A minimum of 30 days of on-board battery power has been consumed at the writing of this report.

\subsection{Mooring Background}

Three major mooring components appear in Figure [1]. The detailed design appears in Figure [24]

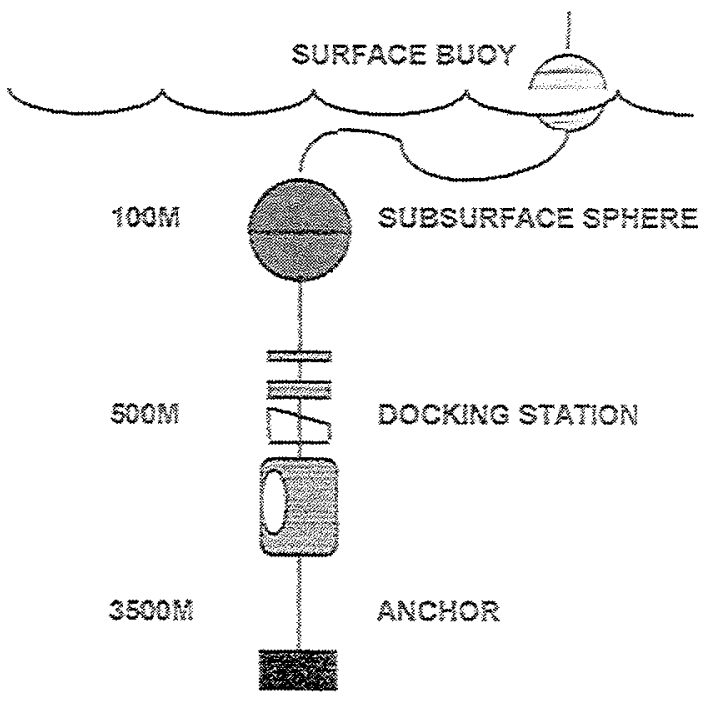

Except for the Docking Station itself, the remainder of the components and hardware making up the Labrador Sea AOSN Mooring have recognized histories of reliability and field longevity. The use of heavy duty strain reliefs, proven electro-mechanical terminations, a compliant s-tether configuration, pulltested wire rope, new hardware and accurate ballast and buoyancy programs allowed mooring designers at WHOl to provide AOSN with a deep-sea system that was virtually trouble-free on two deep deployment opportunities, one in October 1997 and again this year in the Labrador Sea.

Data to and from the mooring, transmitted via satellite communications, are processed by electronics housed in the surface expression. Data transfer between the surface expression and the Docking Station occurs by a hardwired RS485 link. Data transfer between Station and AUV is accomplished by inductive link and acoustics.

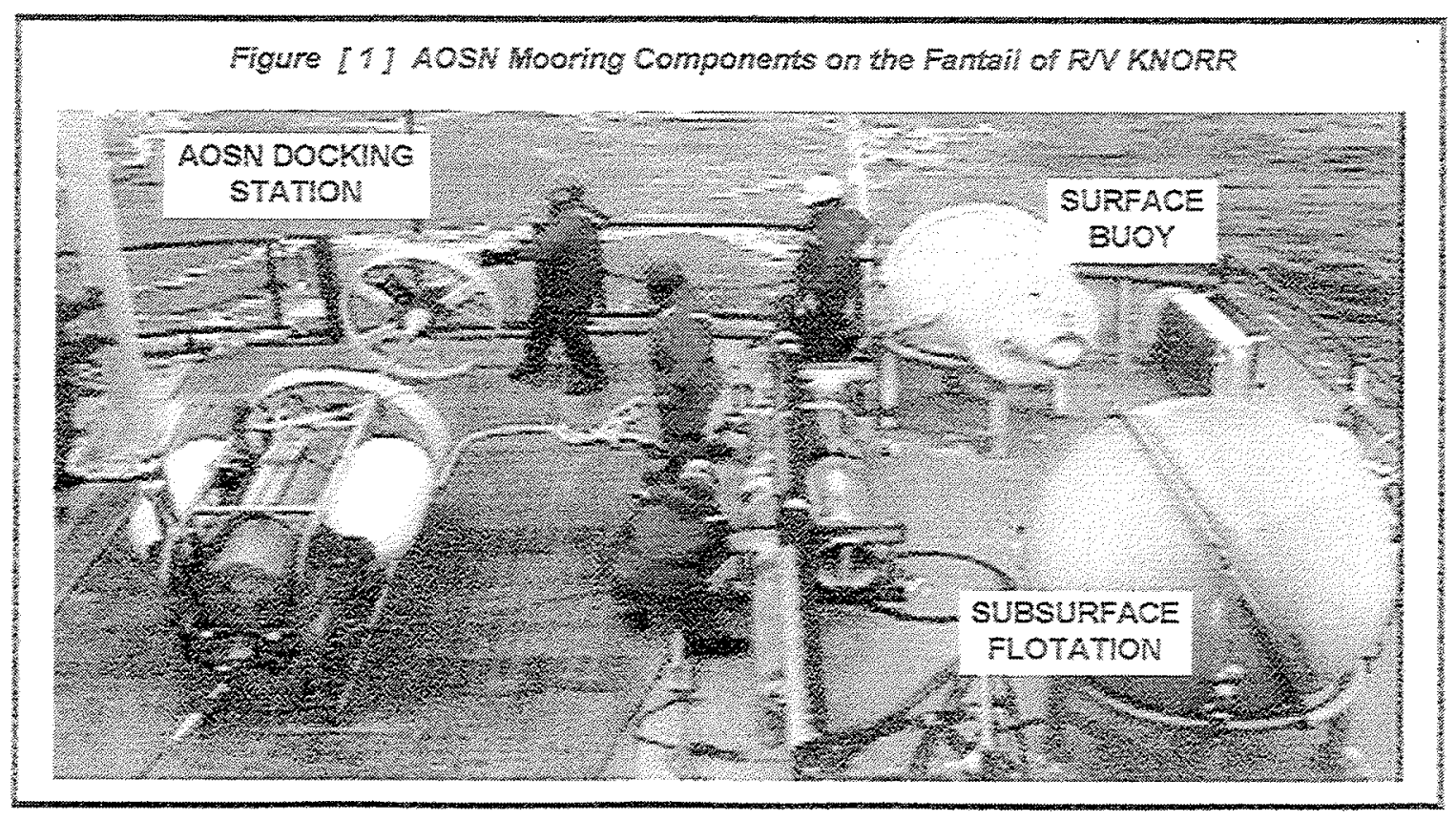




\subsection{The Docking Station}

A block diagram of the AOSN Labrador Sea Mooring and integral Docking Station appears in Figure [2] The Docking Station is a tension-bearing device that provides services for an Odyssey class autonomous vehicle between data gathering missions. The Station is also capable of gathering data independent of the vehicle. It can withstand a five-knot mooring deployment transient and static tension through the frame of 3,000 lbs. Its mechanical components consist of a one-atmosphere aluminum frame, two battery housings, a dock controller housing, a docking pole, a moving carriage and motor, external sensors including magnetic switches, collapsible flotation, and wet hamessing. The Station components are pressure tested to 2,000 psig and the complete system is rated to a safe working depth of 1,000 meters. It weighs $2,512 \mathrm{lbs}$. in air and $930 \mathrm{lbs}$. at working depth. It is neutrally buoyant at the surface. For testing purposes, the Station can be deployed in water as shallow as 33 meters. A picture of the Station taken during mobilization and being lifted by its side bail appears in Figure [ 3 ].

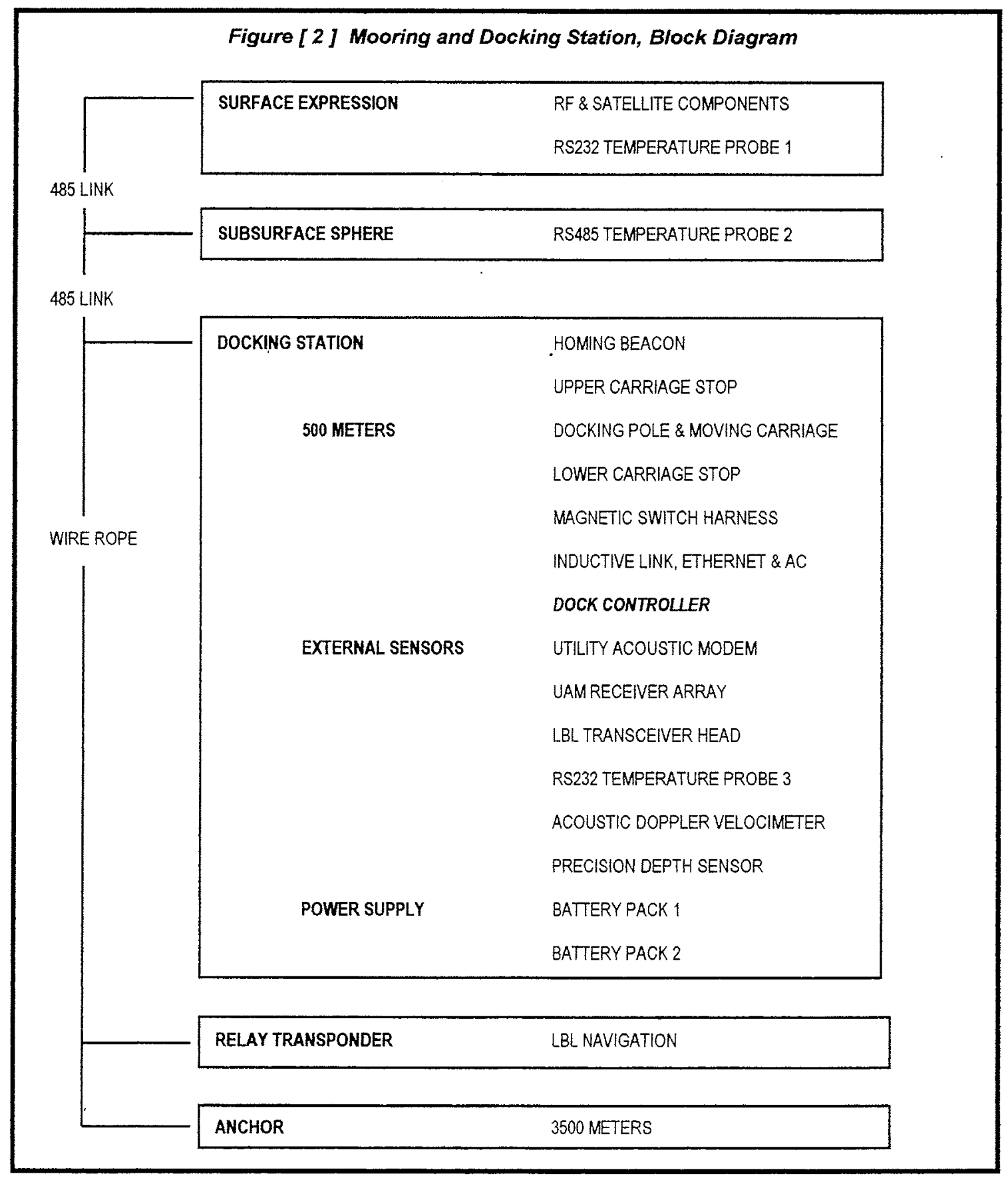




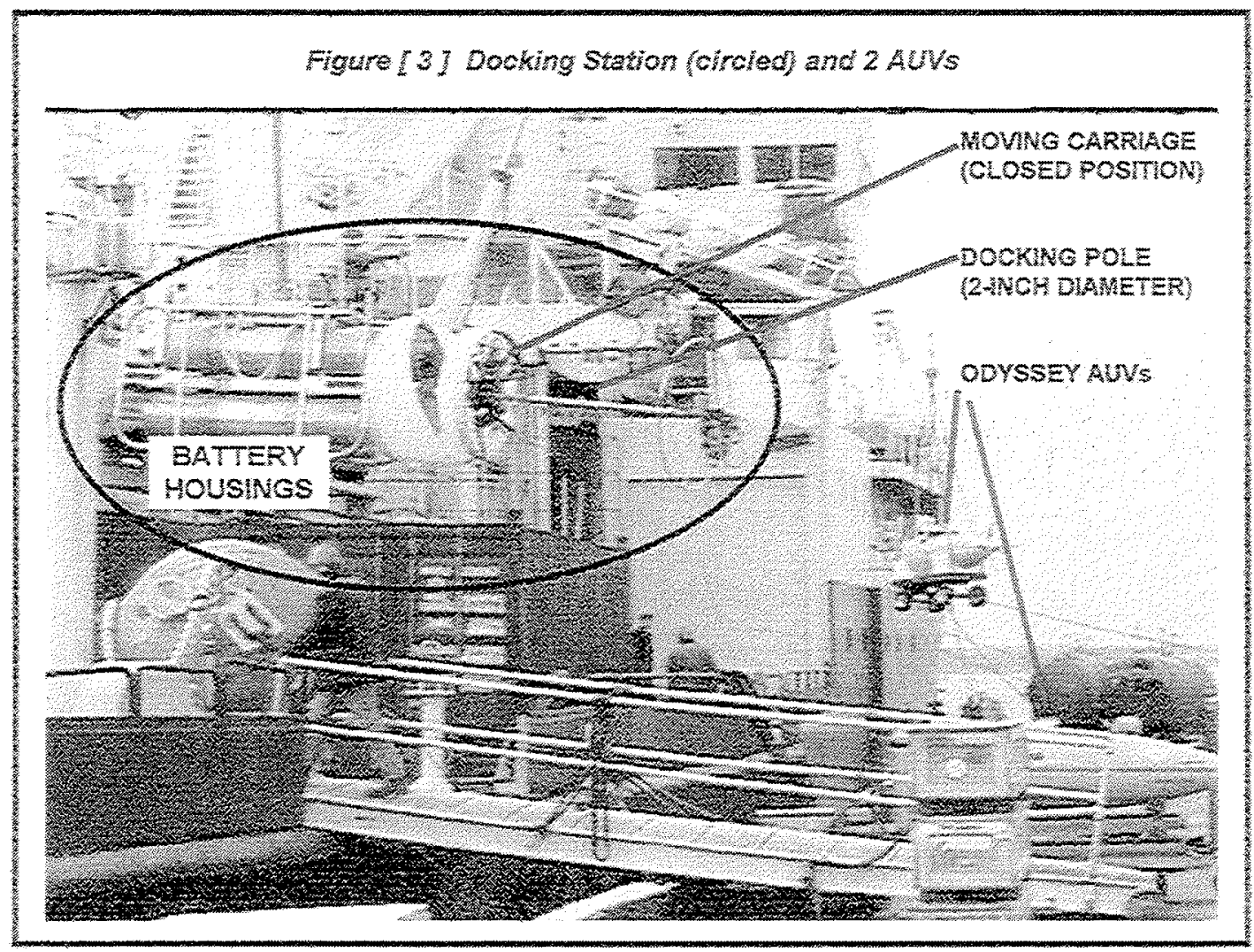

\subsection{Docking Station Controller}

\subsubsection{Housing}

The Docking Station Controller (Doccon) is a pressure-proof, cylindrical housing rated to 2,000 psig. The material used for the two endcaps and housing tube is a 6061-T6 aluminum alloy. Other materials used in the construction of the Doccon include Detrin, 300 series stainless steel, and various forms of poly plastics. The aluminum is cathodically protected from corrosion by strategically placed zinc anodes. The housing is nine inches in outside diameter (ten inches with hardware) and fifty-two inches long. It weighs $95 \mathrm{lbs}$. in air. When seaied, a minimum of ten, ten-gram desiccant packets are added to the volume to ensure humidity control.

\subsubsection{Chassis Layout}

The Doccon chassis layout appears in Figure [ 4 ]. The chassis framework is made up of adjustable aluminum shelves mounted at four corners to perforated aluminum channel. The channel is secured to one endcap only, allowing easy removal of the entire chassis and associated feedthroughs from the housing tube. The chassis is 7.5 inches in diameter. All power conductors are twisted pairs. High voltage circuitry is shielded and/or drained. Craftsmanship in construction meets and exceeds the best commercial practices.

Figure [4] Doccon Chassis, Mechanical Layout

\begin{tabular}{|c|c|c|c|c|c|c|c|}
\hline $\begin{array}{l}\text { BLKHD } \\
\text { CONNS, } \\
68 \text { COND }\end{array}$ & $\begin{array}{l}485 \\
\text { LINK } \\
\& \text { CHSS }\end{array}$ & $\begin{array}{l}\text { INDCTV } \\
\text { LINK } \\
\text { INVRTR }\end{array}$ & $\begin{array}{l}\text { PC104 } \\
\text { STACK } \\
10-C H\end{array}$ & $\begin{array}{l}\text { KVH } \\
\text { LBL CPU } \\
\text { LBL XCVR }\end{array}$ & $\begin{array}{l}\text { LBL MODEM } \\
\text { ADV CPU } \\
\text { MIO STACK }\end{array}$ & $\begin{array}{l}5 / 12 / 12 / 24 / \\
48 \text { VDC } \\
\text { PWR BUS }\end{array}$ & $\begin{array}{l}\text { PRESSURE } \\
\text { HOUSING, } \\
9 \text { IN OD } \times 52 \text { IN L }\end{array}$ \\
\hline
\end{tabular}




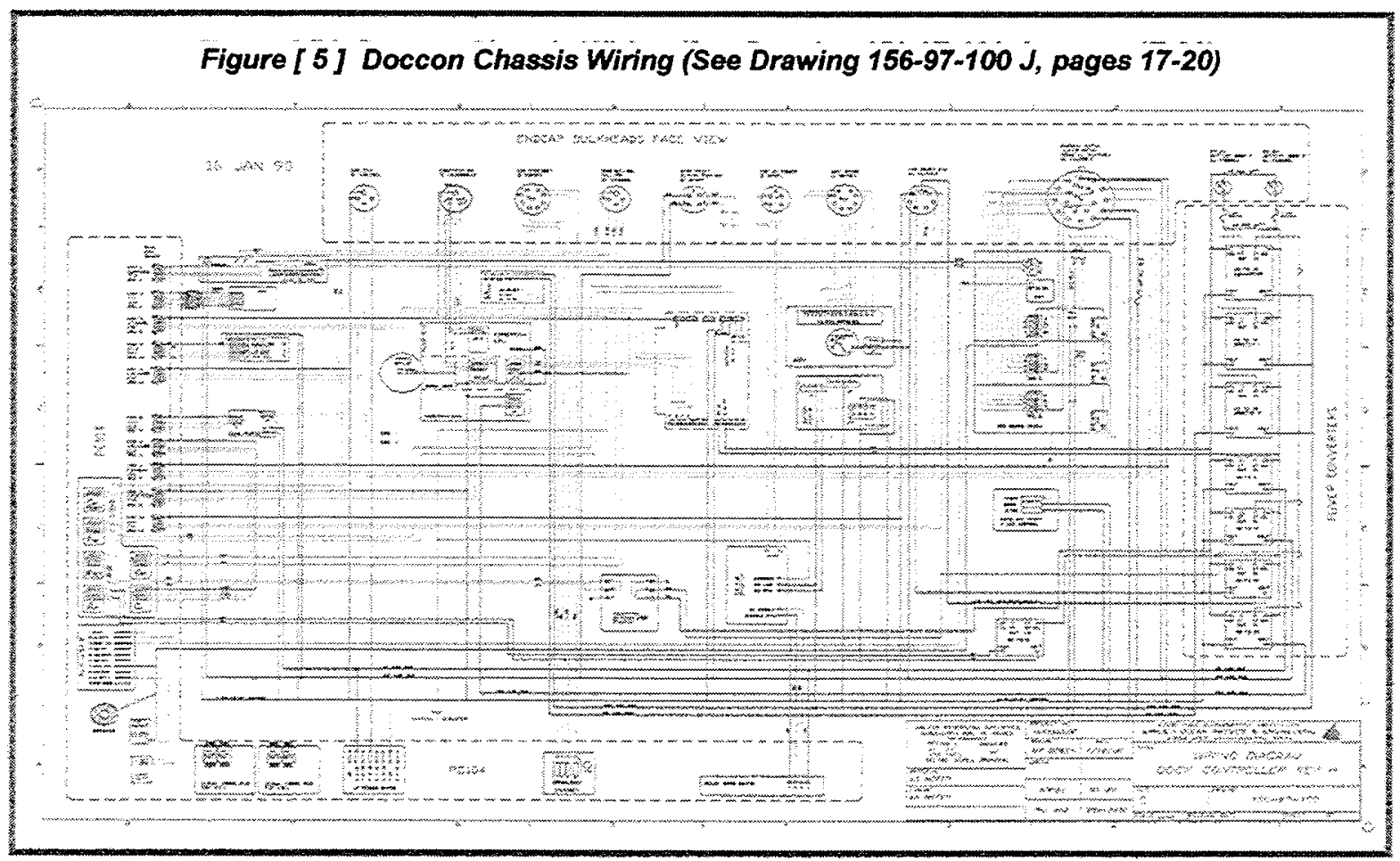

\subsubsection{Chassis Wiring}

The Doccon chassis wiring diagram appears in Figure [5] and as attached Drawing 156-97-100 Rev J. The drawing conveniently details all circuit interconnects, bulkhead feedthroughs, and the design of the power supply buses in a single D-size document.

The Doccon functions as a one-atmosphere enclosure for all integrated electronics associated with the following subsystems: an RS485 to RS232 converter sends and receives signals from the surface expression; an inverter to drive the inductive link resides within an isolated metal chassis; a dc/dc converter supplies the inverter; a PC104 stack with a $80386 \mathrm{CPU}$ and ten serial inputs is assembled with a hard disk drive, parallel port, relay card, video card, Ethernet card, 485 card, utility card, reset circuitry with inverting optoisolator, inverter enabling circuitry; a $\mathrm{KVH}$ digital inclinometer with serial output provides dock pitch and roll data; long-baseline navigation and communications is provided by an Edgetech PS 8000 transceiver, an AM200 modem, and a transducer driver stack; another circuit card stack supports an acoustic Doppler velocimeter probe; and a three-card stack provides an interface for eight magnetic switch channels and reset //O signals. Also included in the chassis are sail to RS 232 converter, disabled watchdog circuitry, and a Vicor-based dc/dc converter power supply bus, which consists of eight modules and boosters. The chassis is densely packaged and secured against cable strumming vibration and shocks caused by ship motion and over the side deployment. All of the chassis components have star-point common returns, which float, with respect to seawater. Only the inverter cage and LBL transducer case are grounded to seawater.

\subsubsection{Wet Harnessing}

A view of the AOSN Doccon external connections and wet hamessing is provided in Figure [6].

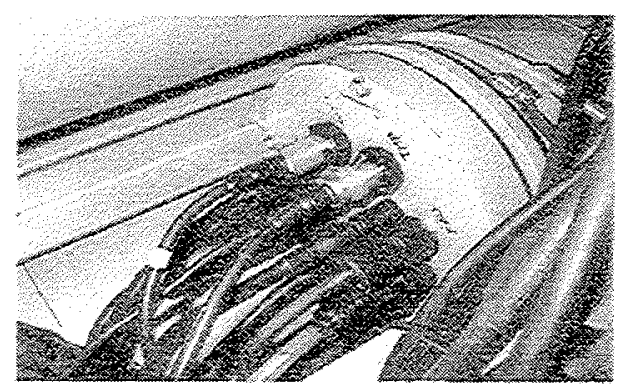

An effort was made to standardize models of pressure-proof connections in procurements from just two manufacturers. We also designed to avoid the pitfalls of interchangeability from bulkhead to bulkhead, which can cause catastrophic interconnection mishaps. The Doccon feedthrough endcap was designed with a $3 \times$ pressure safety margin to help guarantee against deformation and threadlocking. The two endcaps each contain radial and face o-ring seals. 


\subsection{Moving Carriage and Docking Pole}

One and one half meters of a two-inch diameter stainless vertical docking pole are nominally available for the Odyssey AUV to latch onto and be serviced between pre-programmed data gathering missions. The pole has a keyway milled down one side through the dockable length. Inside this keyway rides an alignment key attached to a circular movable carriage. The carriage is designed to force the latched vehicle into a position where the inductive link is mated sufficiently to allow both Ethernet file transfer and power transfer. This is called the docked position. Eight bars of $36.5 \mathrm{lb} . /$ cuft syntactic foam provide the carriage with $4.8 \mathrm{lbs}$. of flotation, making the carriage almost neutrally buoyant in seawater at working depth. Docking pole and moving carriage are labeled in Figure [ 3 ]. Another view is shown in Figure [ 7 ] below.

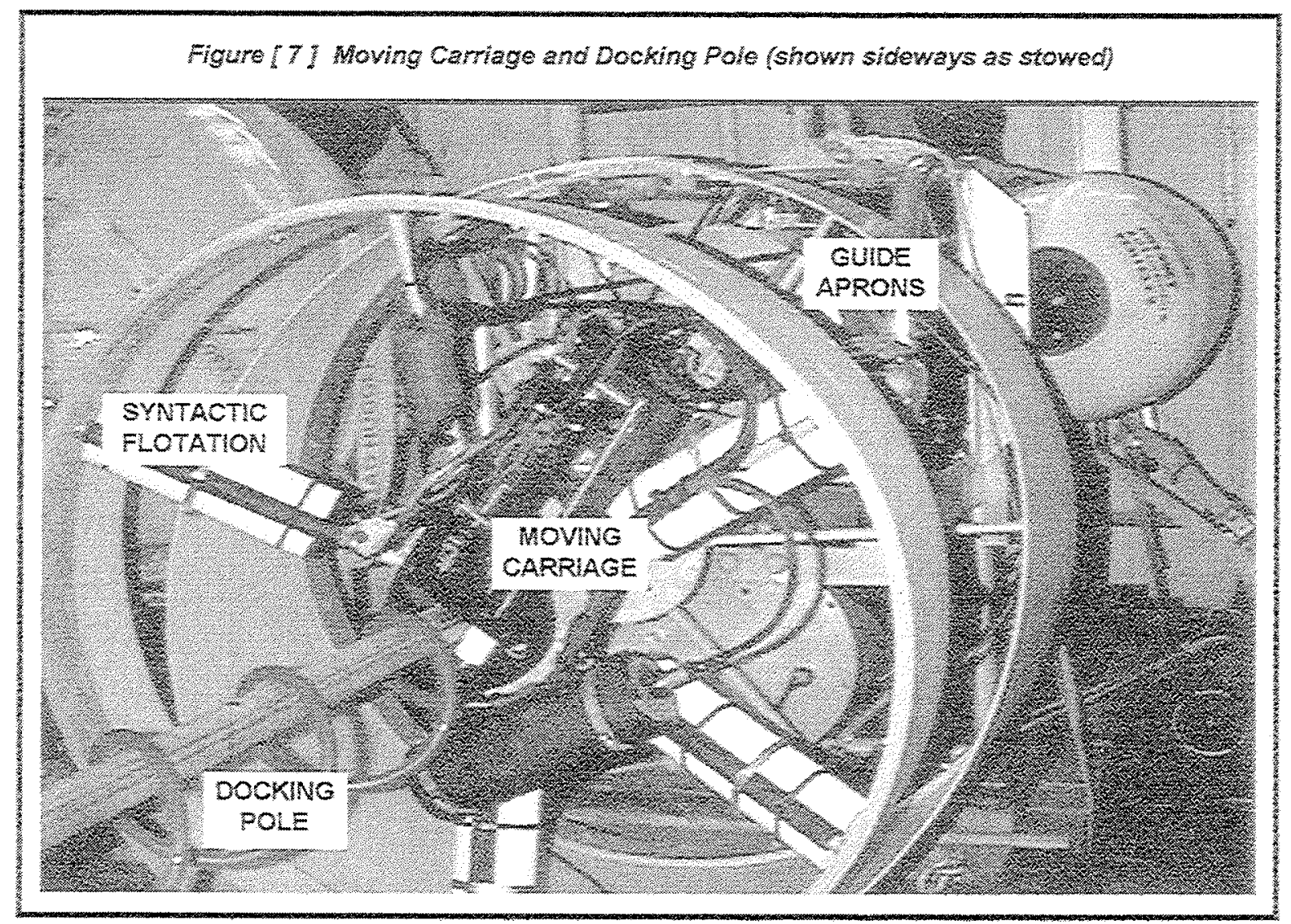

\subsubsection{Drive Mechanism}

The moving carriage is driven up and down the pole by remote control using a motor, a polyurethane veeshaped pinch capstan, a Deirin idler wheel and spring tension. The motor is a brushless DC design from WHOI which contains pressure tolerant electronics, hall effect feedback, thermal protection and a 144:1 gearbox enclosed in a 3 -inch diameter by 10 -inch long plastic housing. The motor, directly coupled to the pinch capstan, is back drivable. The carriage drive mechanism receives $48 \mathrm{VDC}$ and sail commands from the Doccon. It is fused at seven amps.

\subsubsection{Guide Aprons}

The Docking Station carries two cylindrical guide aprons made of aluminum hubs and polyethylene cylinders, see Figure [ 7]. One apron is mounted to the moving carriage. The second apron is fixed at the bottom of the docking pole. This apron has a bilateral inclined edge and a saddle cut into it which directs a docking vehicle into the proper position for power and data servicing. A previous version of this scheme supported three possible docked positions instead of the single one present now. One station reduces overall station costs, reduces maintenance, reduces sensing requirements, and increases system reliability. The resilient poly material can withstand glancing collisions by a moving vehicle which may be approaching just high or low of the targeted point of collision at the pole's center. The aprons, the closed carriage and the vehicle latch prevent all six degrees of AUV movement. 


\subsubsection{Magnetic Switch Harness}

An array of eight pressure-proof magnetic switches (normally open) wired in parallel to Doccon MIO circuitry provide topside indications of the moving carriage state and the degree to which the AUV has docked correctly. Two switches indicate the dock is closed to moving vehicles and that the carriage is down. One switch indicates that the carriage is up and the dock is ready to receive a vehicle. After a vehicle has latched and been squeezed into a fully docked position by the moving carriage, five magnetic switches describe the result. Two switches are located in the center of the inductive core; one is a backup. Three switches surround the circumference of the vehicle's hull at the starboard lower quadrant, the port lower quadrant and the center top. Figure [8] shows approximate magnetic switch locations.

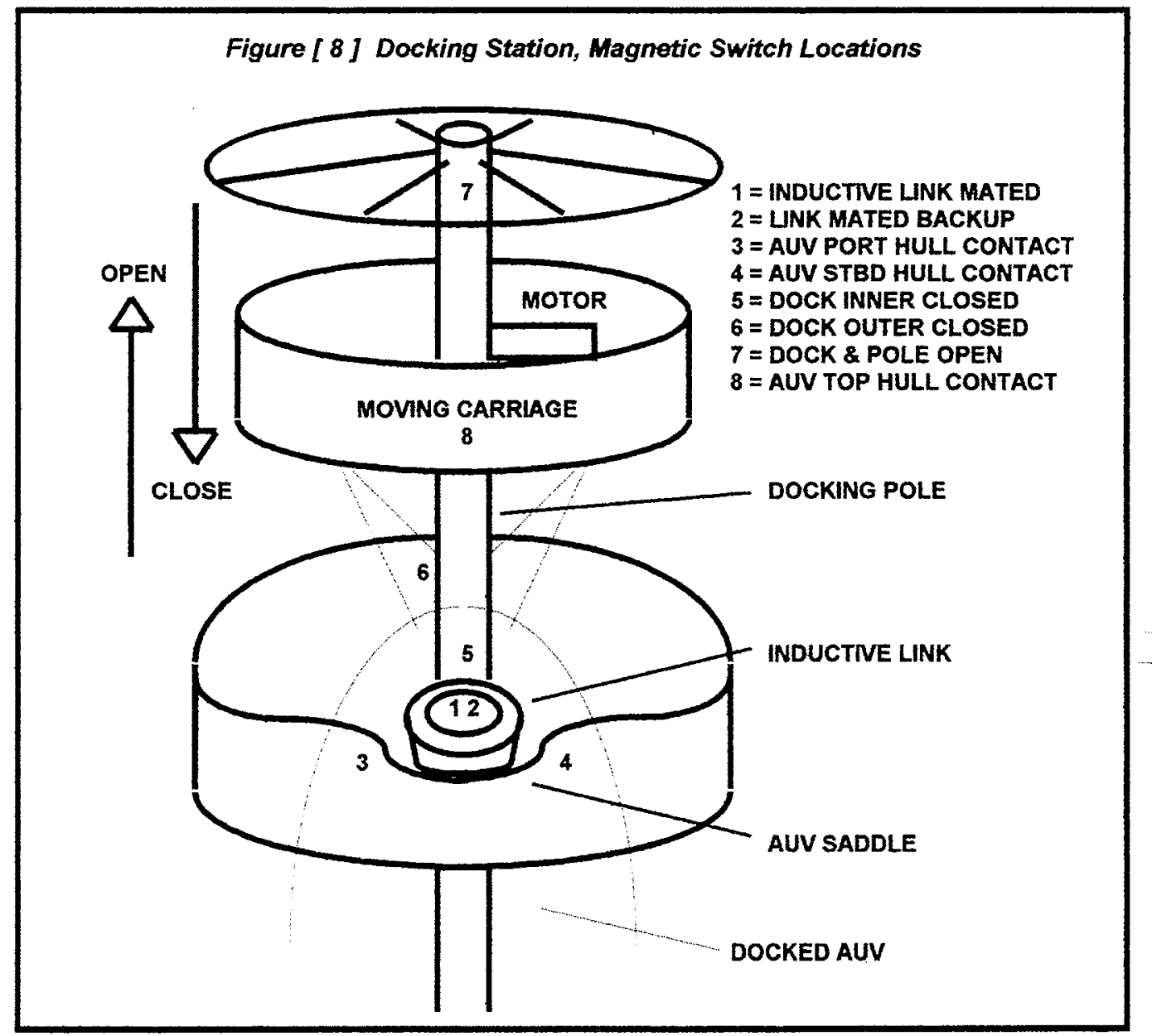

\subsection{Inductive Link}

The inductive link provides AC power into the vehicle for charging batteries and also provides a half-duplex Ethernet file transfer link. Two cores mate underwater with usually less than one-eighth of an inch between their surfaces. The vehicle carries a female core. The dock carries the mating male core. Both cores contain two epoxyencapsulated coils for induction; the outer is Ethernet, and the inner is for AC power. (During transit to the operations site in the Labrador Sea a difficult decision was made that eliminated a previously satisfied requirement for power transfer through the Docking Station, however, this did not necessitate alterations, and the ability to induce Ethemet signals through the link was retained.)

\subsubsection{Male Core Mounting, Docking Station}

The male core is mounted to the Docking Station between the docking pole and the apron saddle. Three threaded stainless rods connect the core mechanically to a six-degree-of-freedom compliant mount. Figure [ 9 ] is a close-up image of the male core mounting arrangement. Total compliance of about one-half inch in all directions ensures that the mating cores have the best possible chance of making close contact. 


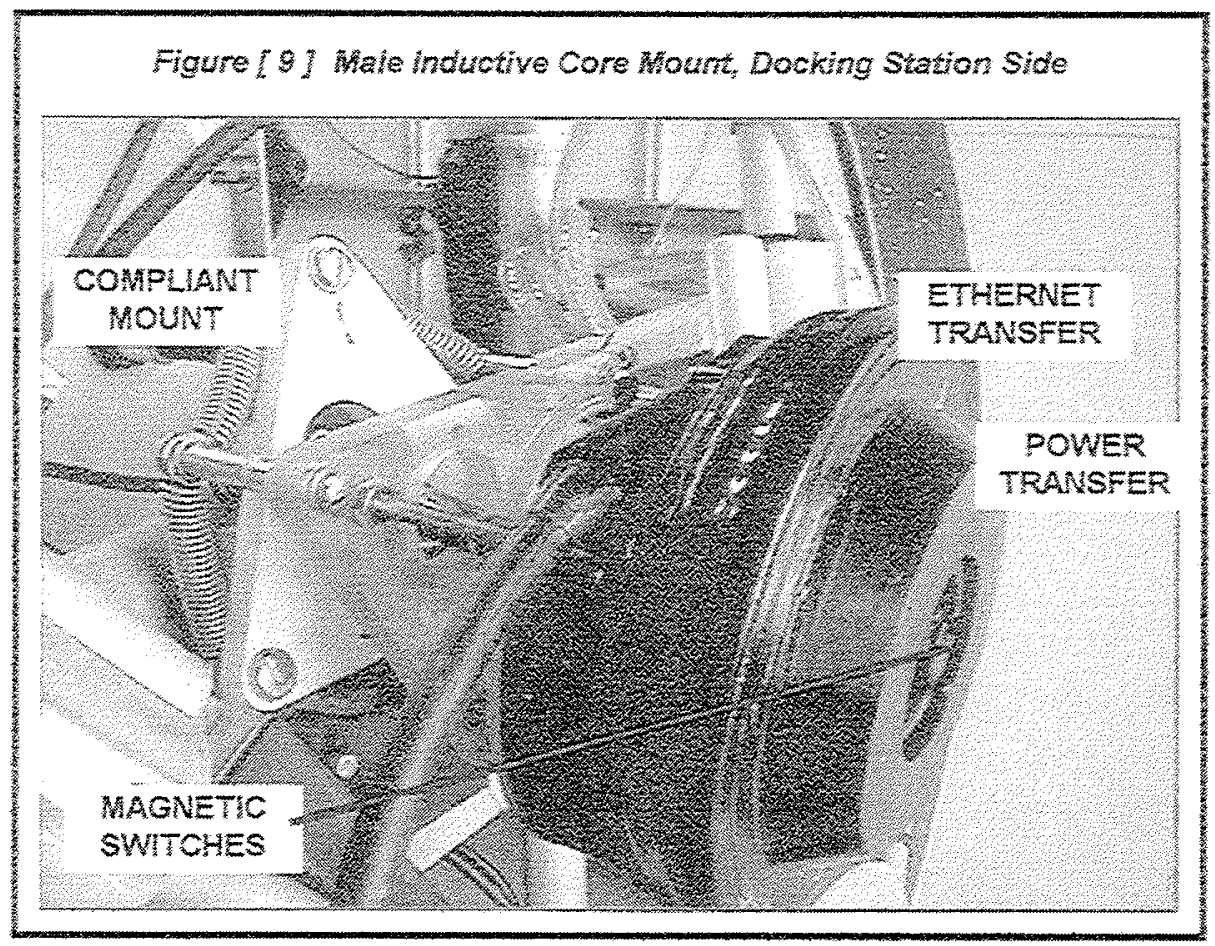

\subsubsection{Female Core Mounting, Vehicle}

Two female inductive cores are currently mounted to the underside (hull) centerline of two Odyssey AUVs behind the docking latch. Three threaded stainless rods connect the core mechanically to a six-degree-of-freedom compliant mount. Figure [ 10 ] is an uplooking image of a female core mounting arrangement. Total compliance of about one-quarter inch in all directions ensures that the mating cores have the best possible chance of making close contact. The female core is slightly more constrained in its alignment compliance due to a space limitation in the bow of the AUVs.

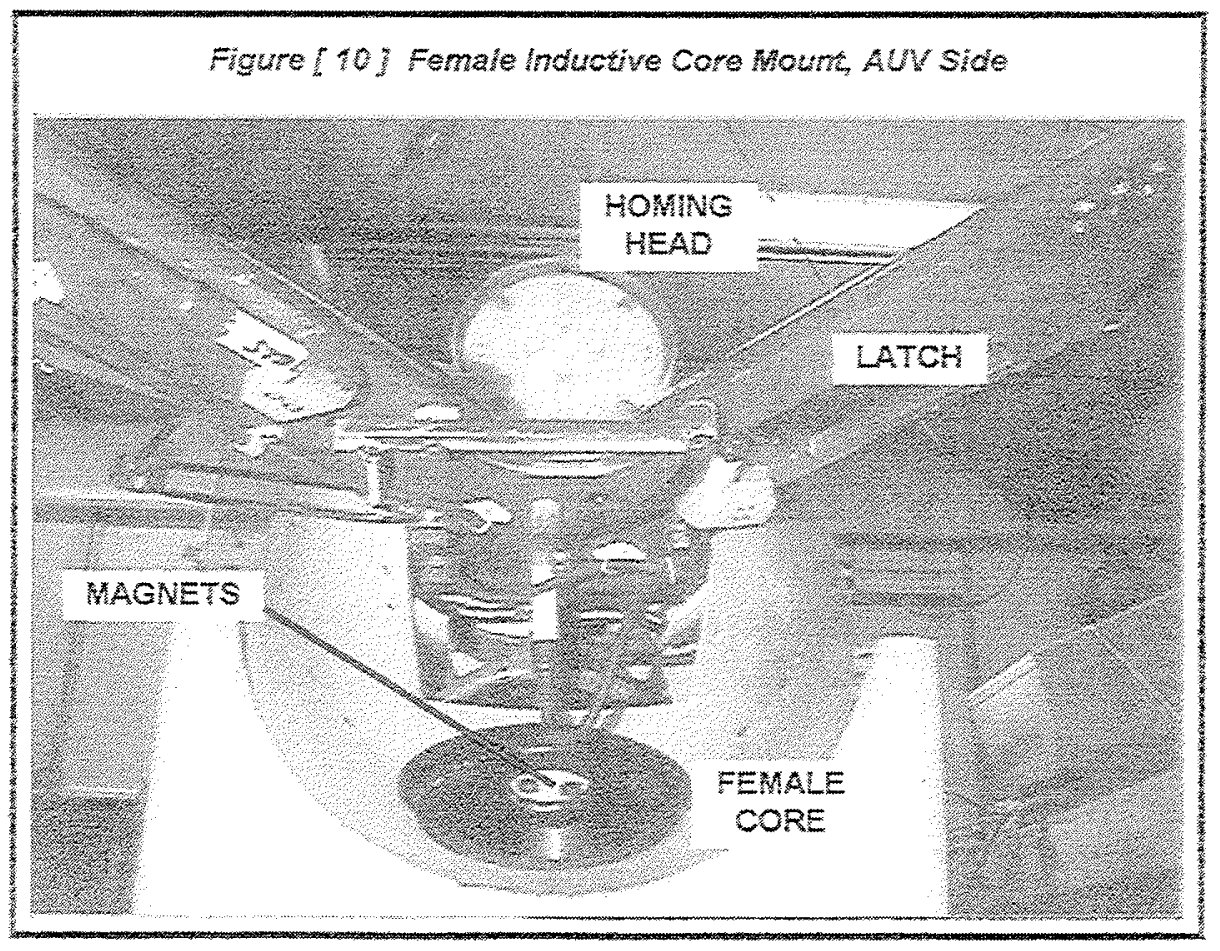




\subsection{Housing Frame}

The housing frame is a welded and sealed (one-atmosphere), tension-bearing device made of schedule forty 6061-T6 aluminum alloy pipe and fittings. It is an integral part of the mooring and is deployed to a depth of 500 meters when the mooring is paid out. The frame contains brackets and mounting hardware that support two large battery housings, the Doccon housing, wet hamessing, external sensors and collapsible flotation. It has a mooring termination at the bottom end. An adjustable lifting bail (yellow paint, see also Figure [ 12 ]) allows operators to move the entire Station from a single pick point whereby the assembled unit is balanced in air. At the top end the frame is bolted to the Docking Station pole. Eight rudder anodes protect the frame from corrosion. The housing frame and battery housings appear in Figures [ 2 ], [ 3 ] and [ 11].

\subsubsection{Battery Housings}

4,960 alkaline D-cells provide a minimum of four months worth of power for the Docking Station components and for vehicle battery bank recharging. The housings provide 65 to $66 \mathrm{VDC}$ nominal output. The Dcells are arranged in pancake packs, stacked and secured inside both battery housings. The packs are diode and fuse protected. Throughout their operational life the housings are cyclically purged of any accumulated explosive gases and resealed with a slight vacuum. The battery assemblies used for the Labrador Sea cruise have been trouble-free. A battery housing, the frame and one polyform float appear in Figure [11].

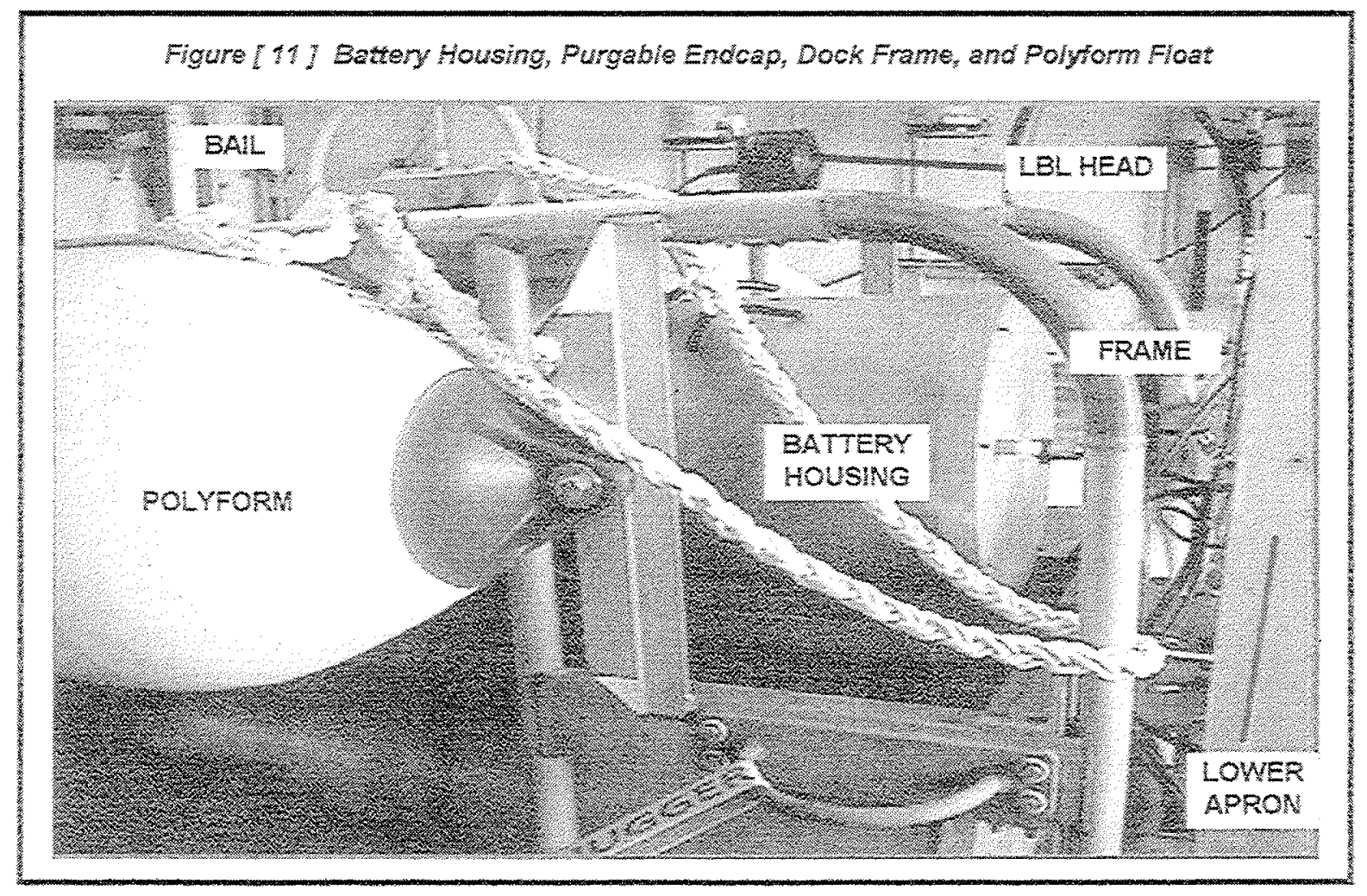

\subsubsection{External Sensors}

Certain integrated subsystems required that specific components be mounted external to the Doccon. These include the UAM, ADV, SBE, LBL and PARO. ADV and LBL have additional electronics that reside in the Doccon one-atmosphere space. UAM, SBE and PARO provide direct serial outputs to the PC104 computer.

\subsubsection{Utility Acoustic Modem (UAM)}

The WHOI designed and built Utility Acoustic Modem provides 9600 baud cableless communication between the Docking Station and an AUV, and between the Docking Station and a support vessel if either is within one kilometer of the mooring. It consists of: a black-anodized aluminum housing; a four-element receiver array which is mounted to the lower Dock frame; and an optional remote head sound source, which was not deployed on the frame for this cruise. The UAM housing appears in Figure [ 12 ]. 


\subsubsection{Acoustic Doppler Velocimeter (ADV)}

The ADV and probe provide AOSN researchers with precise current measurements in 3D space. The primary ADV electronics reside as a three card stack inside the Doccon. The remote probe was situated so that it pointed away from the body of the Station, and it was mounted at right angles to the axis of the mooring. The probe is fairly delicate, so an effort was made to place it away from Station launch and retrieval tag points. The ADV probe and mount appear in Figure [13].

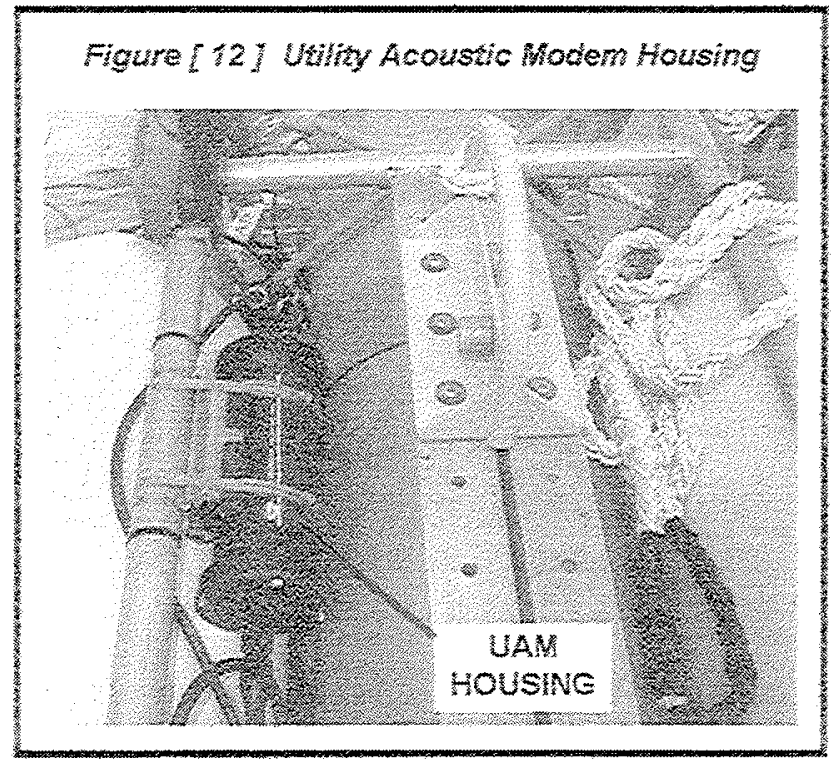

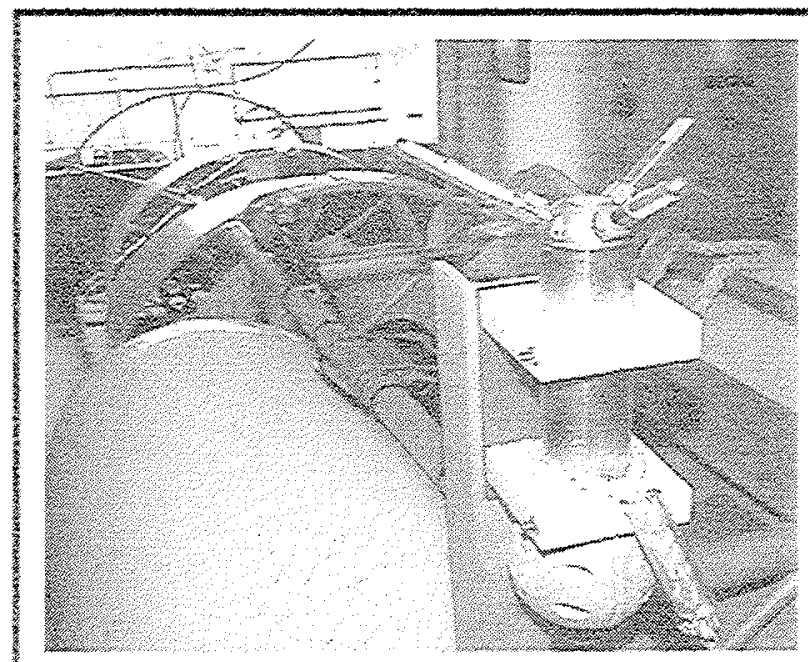

Figure 13 Acoustic Doppier Velocimeter

\subsubsection{Seabird RS232 Temperature Probe (SBE)}

This sensor is one of three Seabird sensors on the AOSN mooring. One is powered from and read at the surface expression. A second is mounted on the subsurface flotation sphere and is read via RS485 link at the Doccon. This middle temperature probe is powered by a self-contained alkaline battery pack mounted to the subsurface sphere. The third sensor is mounted to the Docking Station frame. It has a standard RS232 serial output to the PC104 computer inside the Doccon, which also provides it with a nominal 12 VDC.

\subsubsection{Long-baseline Remote Transducer Head (LBL)}

The remote transceiver head for the Edgetech long-baseline navigation system was mounted to the frame near the lifting bail. It appears at the top of Figure [11].

\subsubsection{Digiquartz Intelligent Depth Sensor (PARO)}

A precision Paroscientific depth sensor was mounted to the movable carriage. Data from the sensor relays not only carriage depth but also whether it is moving vertically with respect to the pole when remotely commanded.

\subsubsection{Collapsible Flotation}

Two large polyform floats were bolted high onto the battery housing frame. When fully inflated, each float provides $465 \mathrm{lbs}$. of positive buoyancy, see Figure [ 14 ] below.

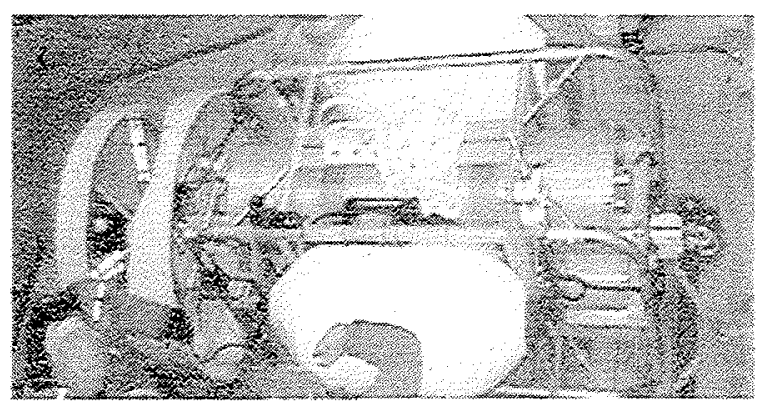

The Docking Station weighs 930 lbs. in seawater. At the sea surface, the two polyforms allow the Station to be neutrally buoyant. This collapsible buoyancy ability increases the chance of deployment without collateral damage, particularly pole bending. As the Station leaves the surface and rotates to become vertical with the axis of the mooring, the polyforms shrink and their influence on the underwater mass is eliminated. One of two floats also appears in Figure [11]. 


\subsection{Performance Analysis}

The station experienced four non-crippling faults in subsystems during its first 1998 immersion: the moving carriage became stuck; a battery connector experienced shallow water intrusion; the long-baseline (Edgetech LBL) navigation transmitter failed; and the carriage drive motor flooded during recovery operations.

\subsubsection{Moving Carriage Fault}

The movable carriage, which aligns a docked AUV into the power transfer position, was stuck in an indeterminate position for the entire deployment. A contingency plan was devised to repair the carriage as soon as the fault became critical to cruise goals. The mooring was recovered after immersion for two weeks for this and other reasons, but was not re-deployed due to constraints of weather and time.

The carriage became unstuck during mooring recovery making fault analysis difficult. An inspection was performed once the system was secured on deck. Our initial impression was that some interference occurred in the pole keyway, however these components had passed all operational tests at WHOl.

The pole was definitely bent during the recovery process while the station barrel-rolled in the water behind the stern and again when it was on the fantail and the rest of the mooring was trailing behind the ship. Conditions were rough. It is possible that the pole was bent earlier, upon deployment, when the dock inverted from a downward slant to an upward slant (see deployment sketch below).

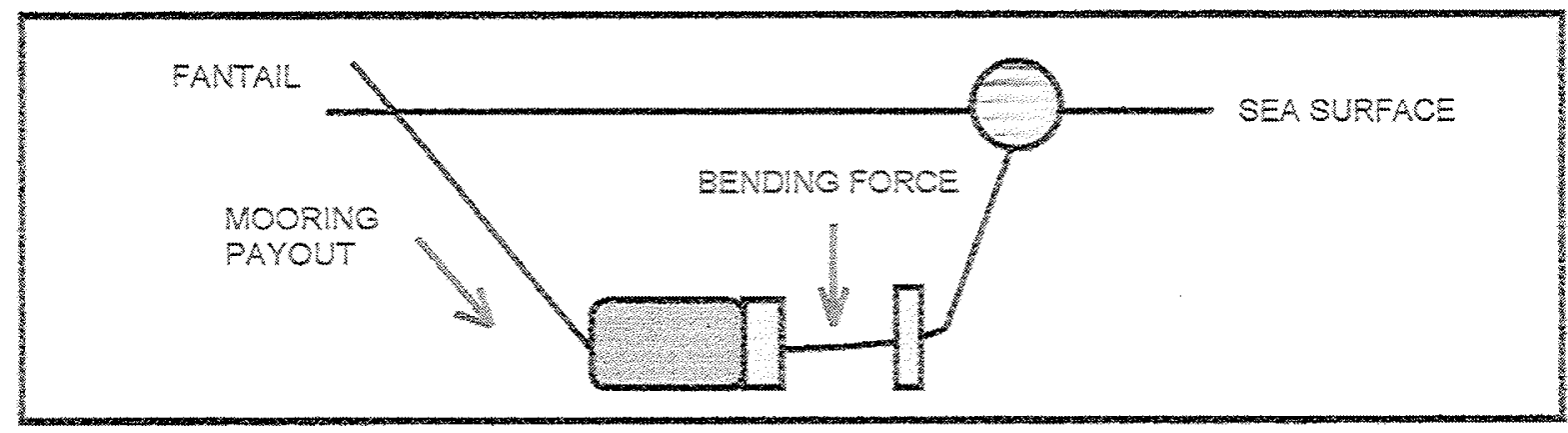

If the pole was bent in this way slightly during deployment then the close tolerance of the moving carriage collar may have interfered with easy sliding on the pole. This theory coincides with depth sensor indications that the carriage was 0.4 meters below the pole center point. In this stuck position none of the three magnetic switches would have been activated.

Mooring tension would not have been sufficient to straighten the pole for normal operations. The moment required to yield the pole in bending is $36,000 \mathrm{in}-\mathrm{lb}$. or $3,000 \mathrm{ft}-\mathrm{lb}$. The mooring tension is $3,000 \mathrm{lb}$. Therefore the moment arm required for mooring tension to cause pole straightening is $3000 \mathrm{ft}-1 \mathrm{~b} . / 3000 \mathrm{lb}$. $=1 \mathrm{ft}$ (deflection in the opposite direction).

After recovery of the dock and mooring system the pole was straightened out on deck using a come-along. Pole concentricity was checked in case it had become deformed or "oblong". The pole was measured to have less than $0.010^{\prime \prime}$ out of round at the top and bottom, so a lack of concentricity was not part of this fault.

\subsubsection{Battery Connector Leak}

Accelerated activity in two sacrificial anodes revealed minor leakage inside a battery bulkhead connector. It is assumed that some minimal amount saltwater (less than a fraction of a drop) entered the connector while it was in shallow water. The connection then sealed completely at depth. It operated properly throughout the deployment. It is unlikely, however, that this connection would have continued operating over a full four-month period of immersion. The battery housings are diode and fuse protected so this housing would not have contributed to dock failure over time, it was designed to shut down instead.

The connector has been cleaned, tested and re-mated. 


\subsubsection{LBL Transmitter Fault}

The Edgetech LBL transmitter located in the Docking Station Controller Chassis (Doccon) did not operate properiy after final testing at WHOI. Some of its intended functions were replaced by adding a separate relay transponder to the mooring wire below the dock.

Both remote heads provided with the Edgetech LBL system leaked compensation oil before they were deployed. One was rebuilt and refilled at WHOI just prior the cruise and it operated without failure. The second was taken as an unreliable deep spare and has not yet been rebuilt. Many of the circuit boards had obviously been used, been reworked poorly or were corroded, and some had salt crystals between components.

The Edgetech system as delivered to MIT engineers included substandard commercial hardware and interface efforts with other subsystems of the Doccon were difficult from the beginning.

\subsubsection{Carriage Motor Flooding}

The carriage motor, which is compensated with non-toxic Carnation mineral oil, was partially flooded when the station reached the surface. It had been working properly throughout the two-week deployment. The motor was disassembled while we were on site. There was evidence that intense cable strumming had caused at least three screws to back out. One of them was critical; the seal screw that holds the whole housing together, end to end. This screw was not Loctited. It is estimated that the strumming occurred during the long recovery process and not during the two week immersion. A carriage motor and a compensation bottle appear in Figure [ 15 ].

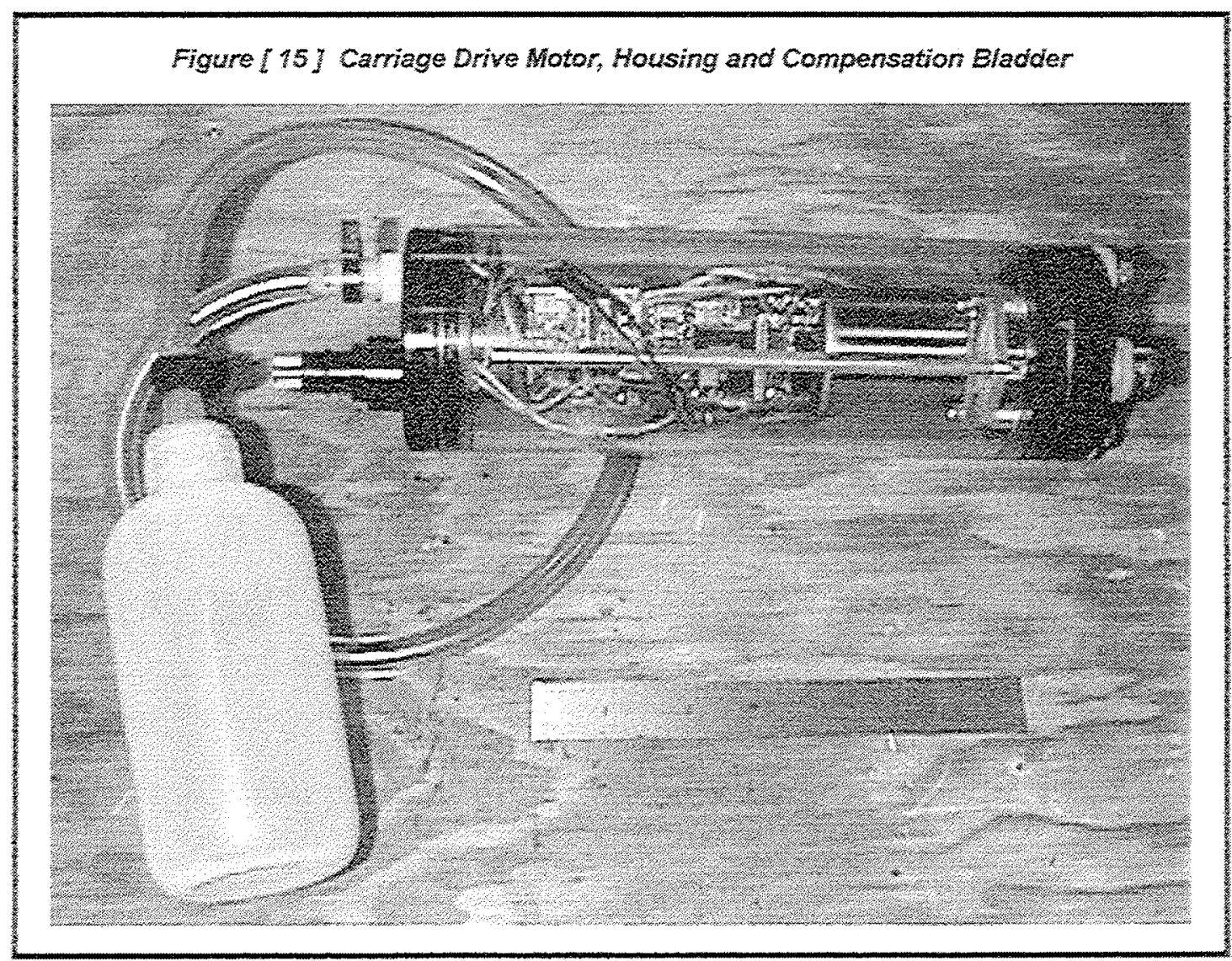

\subsection{Proposed Improvements}

All of the recommendations made below for the improvement of each subsystem mentioned can be implemented before the next AOSN cruise. The Docking Station System as described in this report has performed well under adverse conditions. The existing design, along with minor changes, will provide a timely and successful demonstration of a fully autonomous AOSN Docking Station for our sponsors at ONR and MIT. 


\subsubsection{Split Station Modification}

I recommend that the docking station housing frame be separated from the juicer by fifty meters of fourconductor EM cable, see Figure [ 16 ]. WHOI mooring expert John Kemp agrees with this idea. A two-part Docking Station would be shorter, more easily handled, and less prone to pole bending.

The square base of the existing docking pole has a pattem of eight bolt holes. To these we can attach a triple-purpose clamp, which will: 1) support the Doccon housing across the bottom of the juicer, 2) support the ADV probe, UAM housing, UAM array, and LBL head; and 3) provide a new termination point. The batteries will remain in the existing station frame. This change requires the design of a stainless, triple-purpose clamp and an extra shot of terminated electro-mechanical (EM) cable for power transfer.

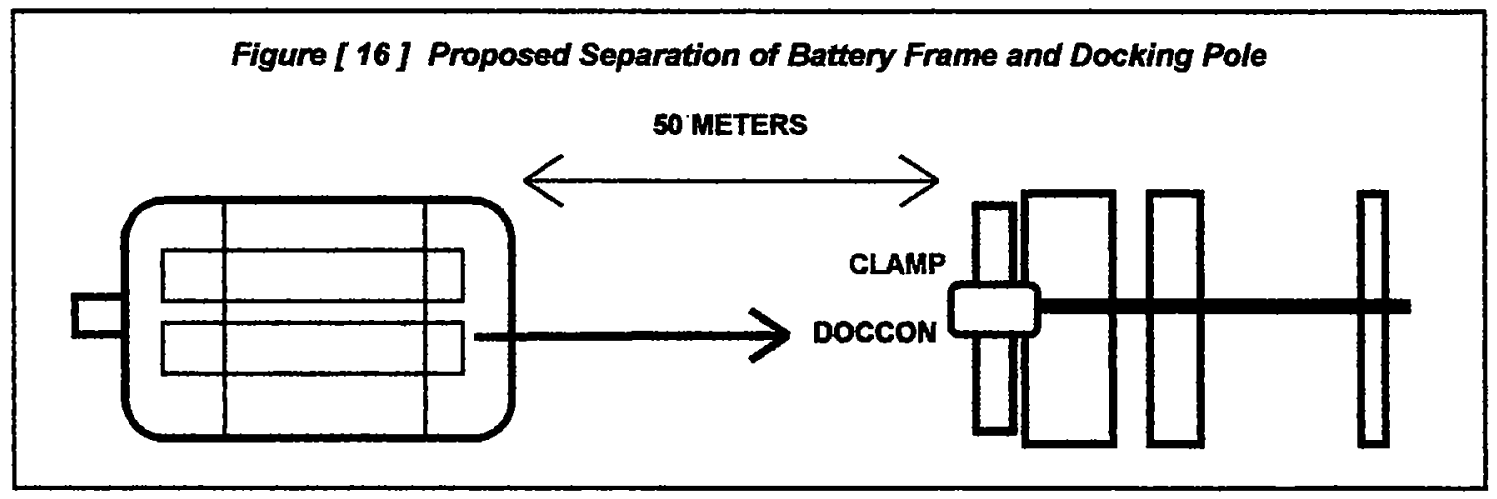

\subsubsection{Pinch Capstan Modification}

The designer of the pinch capstan assembly, WHOl's Don Peters, has been consulted about the sticking fault. He recommends that the design be changed to a totally roller-guided carriage rather than using a sliding collar and clamp arrangement. There is a tradeoff to consider between looseness of a sliding carriage to accommodate slight pole bending and situations whereby a loose key and keyway cause binding will increase. A newly proposed design implements a triad of guide wheels at both the top and bottom of the moving carriage, all of which have a large-OD-ridge that run in grooves in the pole. This way one could tighten the wheel to groove tolerances and still not hinder carniage movement on a curved pole. (The redesign suggested above is a work in process as of 10 June 1998.)

\subsubsection{Edgetech Correction}

A solution to the Edgetech LBL receiver fault will be discussed under a separate cover (MIT).

\subsubsection{Carriage-Motor Compensation}

The motor compensation bladder should be pressurized to 2-3 psi above ambient rather than simply kept at ambient. Screws should be Loctited or secured in some manner. Costs and effort for this change are minimal.

\subsubsection{Slow Scan Video System Addition}

It was difficult to imagine the situation at $\mathbf{5 0 0}$ meters when the vehicle and the station were joined. It is recommended that a snapshot, slow scan video processor and CPU be added to the Doccon and tap into the 485 link to the surface. Also add a hi-resolution camera and $100 \mathrm{w} / \mathrm{sec}$ flash to the station carriage, looking downward. An interrupt from the surface or a timer fires off one shot which is reassembled at the surface as soon as the link can manage; however hi-speeds are not crucial. In this way operators will be able to look in on the dock situation without a demand for increased bandwidth from the as-built system.

The idea of a snapshot video system setup to look down the docking pole would satisfy a question raised in early 1997 regarding how the Station would be able to detect the presence of a docked vehicle if the carriage was not closed and the appropriate magnetic switches were not activated. 
Figure [ 17] Odyssey Labrador Sea Mooring Detail, AEL Revision 4

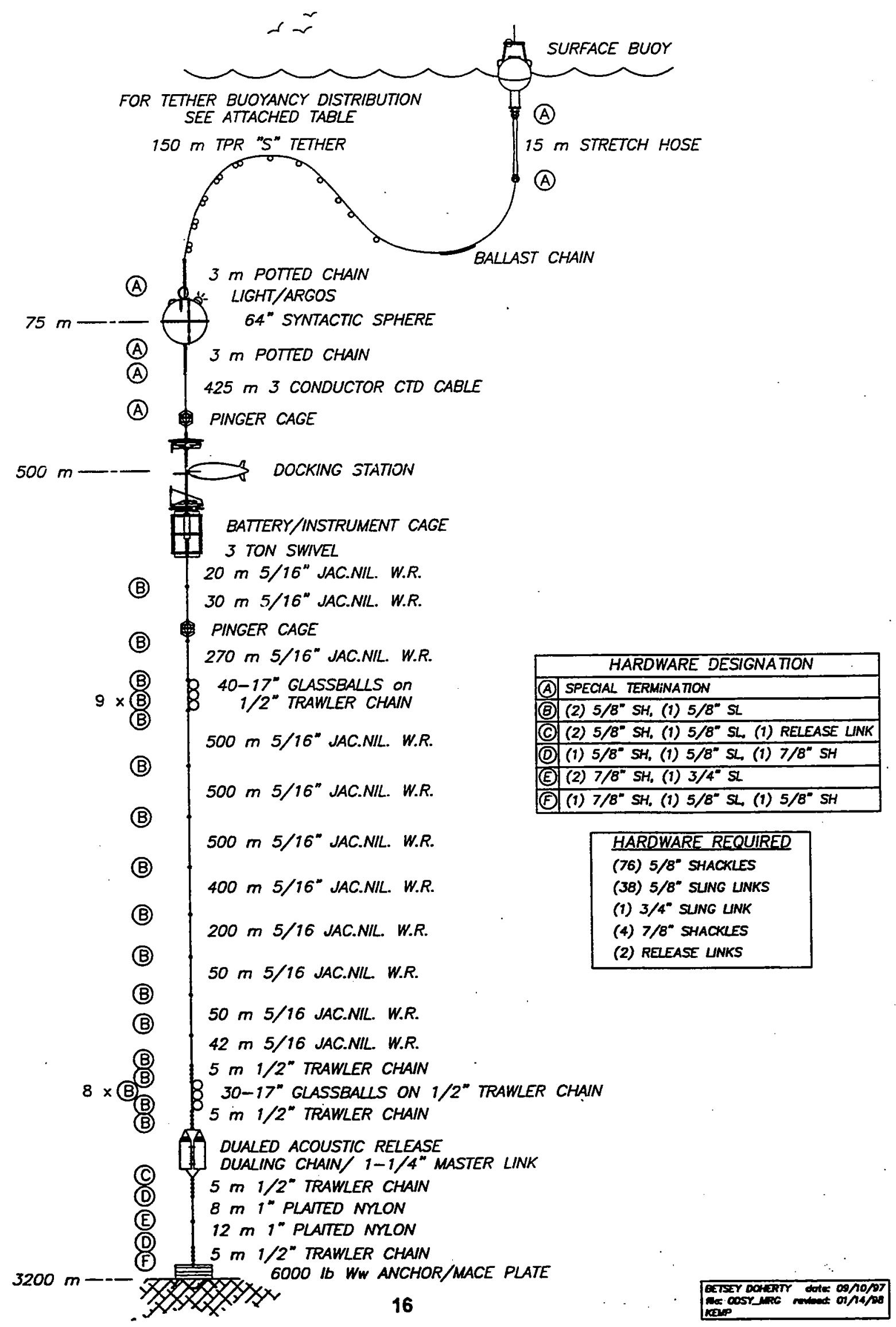




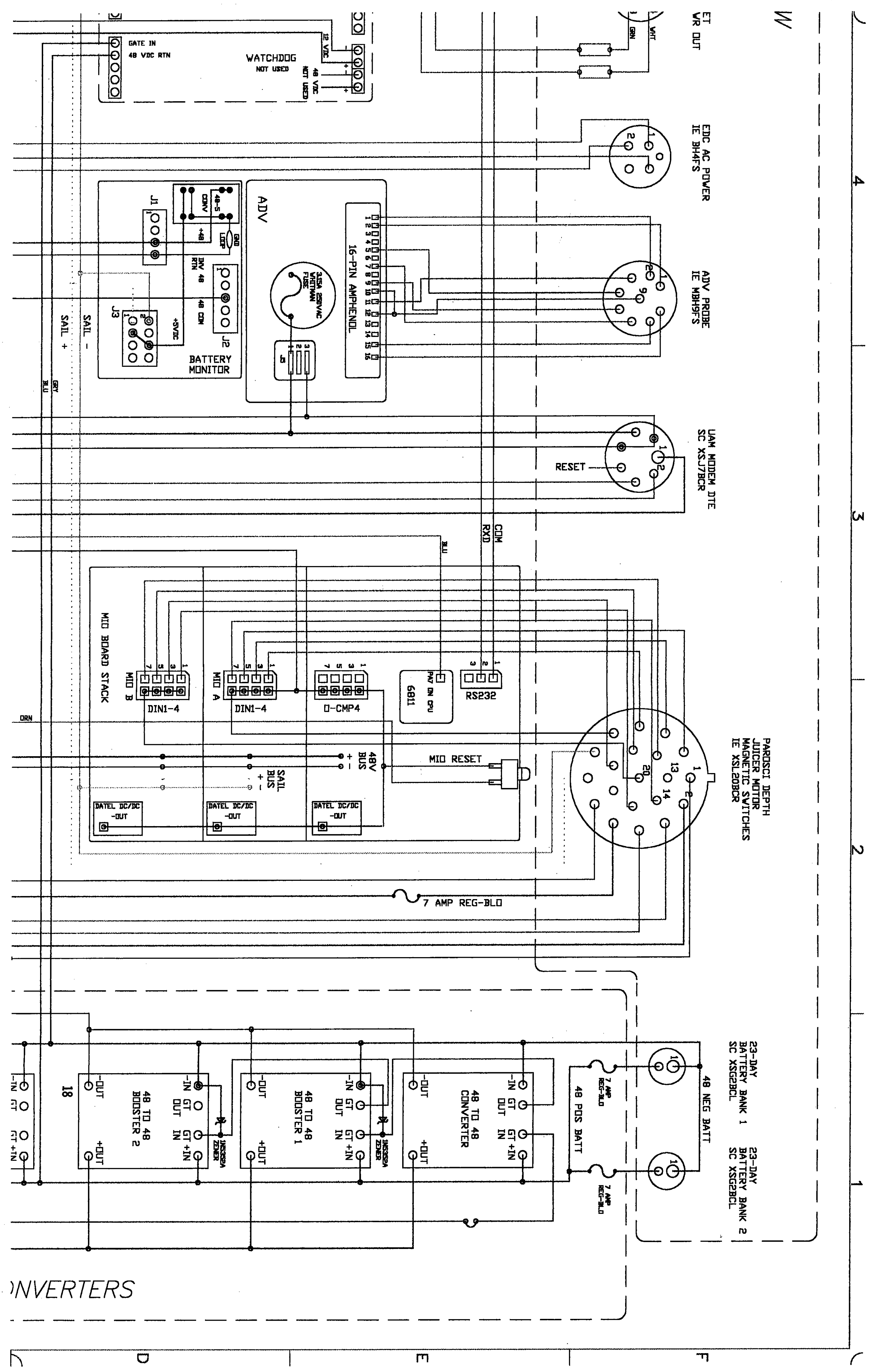


AOSN Lab Sea Vehicle Dock Drawing Numbers

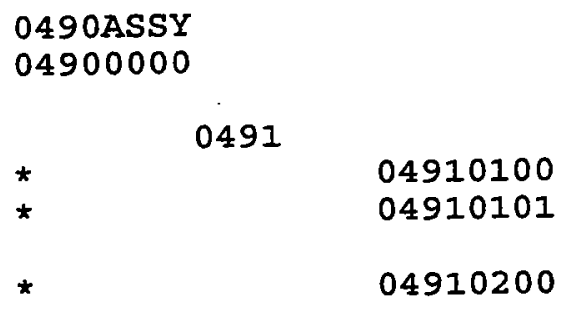

04910100

04910101

04910200

0492

04920100

04920101

04920200

04920300

obs $\quad 04920301$

04930000

04930101

04930102

04930103

04930104

04930105

04930200

04930201

04930301

04930302

obs $\quad 04930400$

obs $\quad 04930402$

obs 04930403

04930500

04930501

04930502

04930503

04930504

04940000

04940100

04940200

04940201

04940202

04940301

04940302

04940401

04940501 obs 04930401
Vehicle Dock and Battery Frame Assembly Vehicle Dock Assembly

Pole Structure
Pole Weldment

Pole Anode

Pole Top Bumper

Hoop/Skirts

Upper Hoop

Hoop Center Plate

Lower Hoop

Hoop Clamp, Lower

Hoop Clamp, Carriage

Dock Carriage

Mount Plate

Bearing Block 1

Bearing Block 2

Motor Mount Block

Spring Post

Friction Drive wheel

Idler Wheel

Drive shaft

Idler shaft

Slider Assembly

slider sleeve

Slider Flange

slider Key

slider Assembly

slider Upper Attachment

slider Lower Attachment

slider shaft

slider Key

Battery Frame Assembly

Frame Weldment

Spine

Upper Crosspiece

Lower Crosspiece

Pickup Bale

Bottom Tang

Battery Case strap

Instrument Housing Bracket 
0495

*

$\star$

$\star$

$\star$

$\rightarrow$

\section{Battery Case}

Tube

Bulkhead

Endcap

Endcap Penetrations

Endcap Penetration Detail

Mounting Tab Location

Mounting Tab 


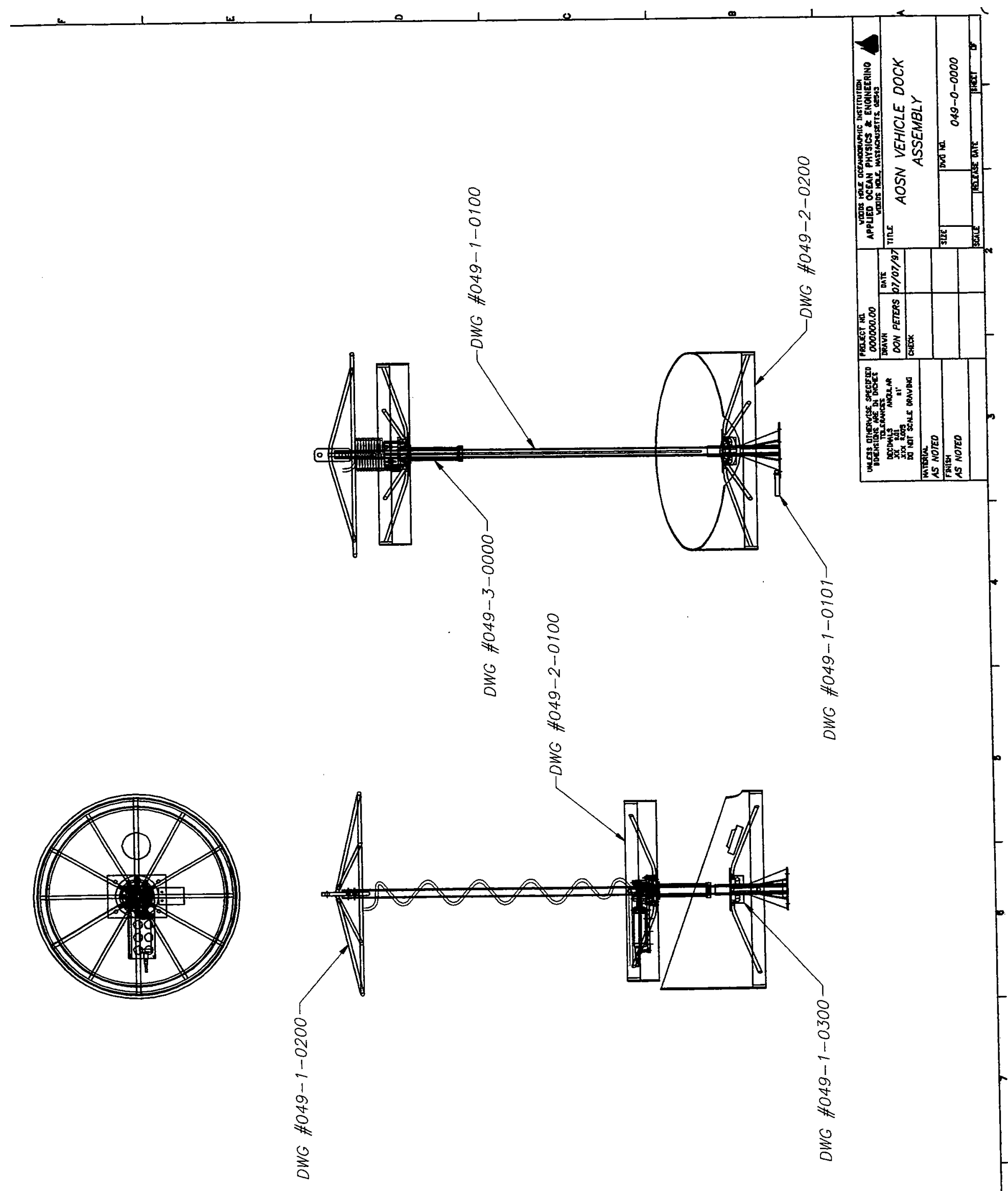




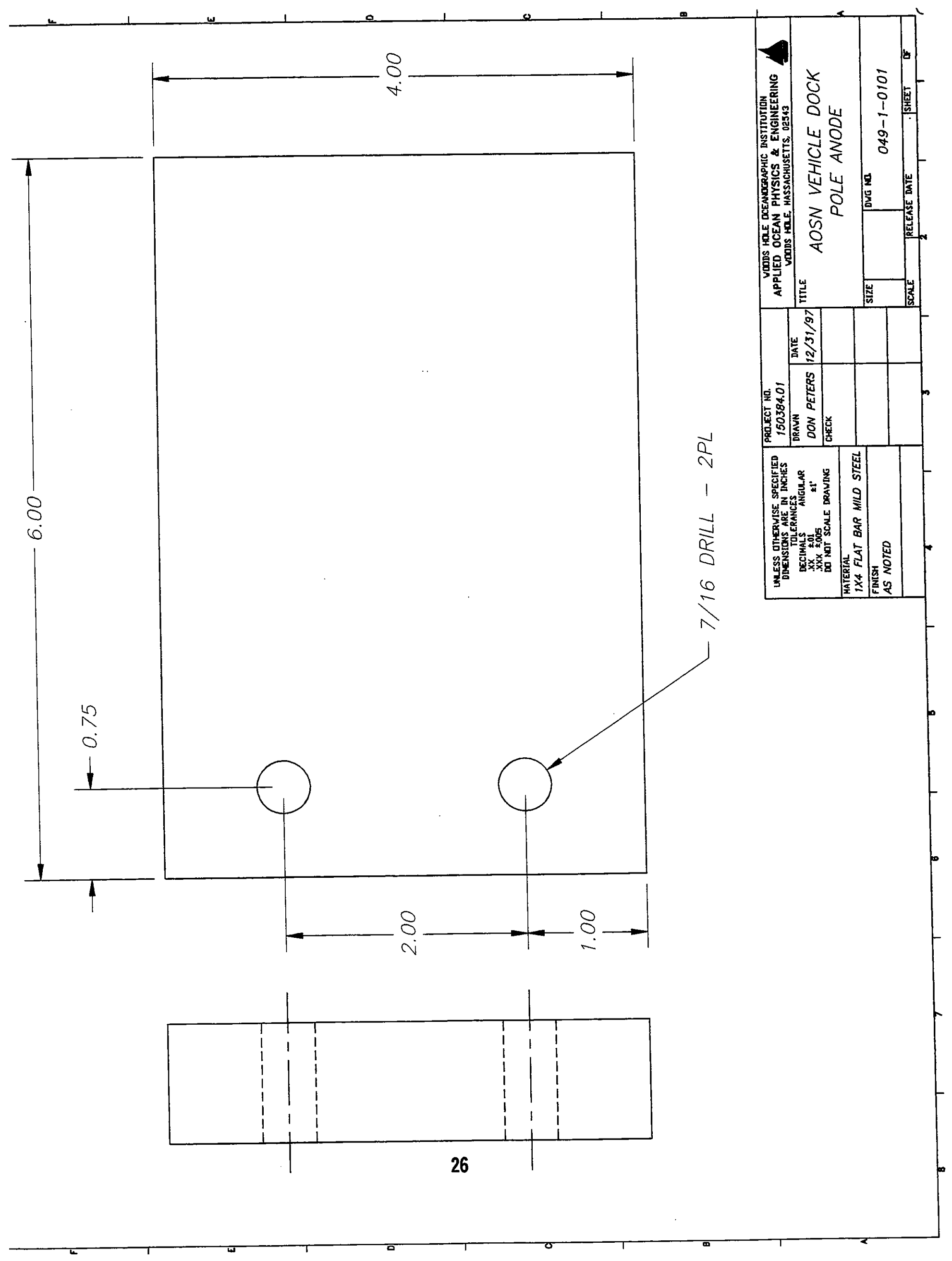



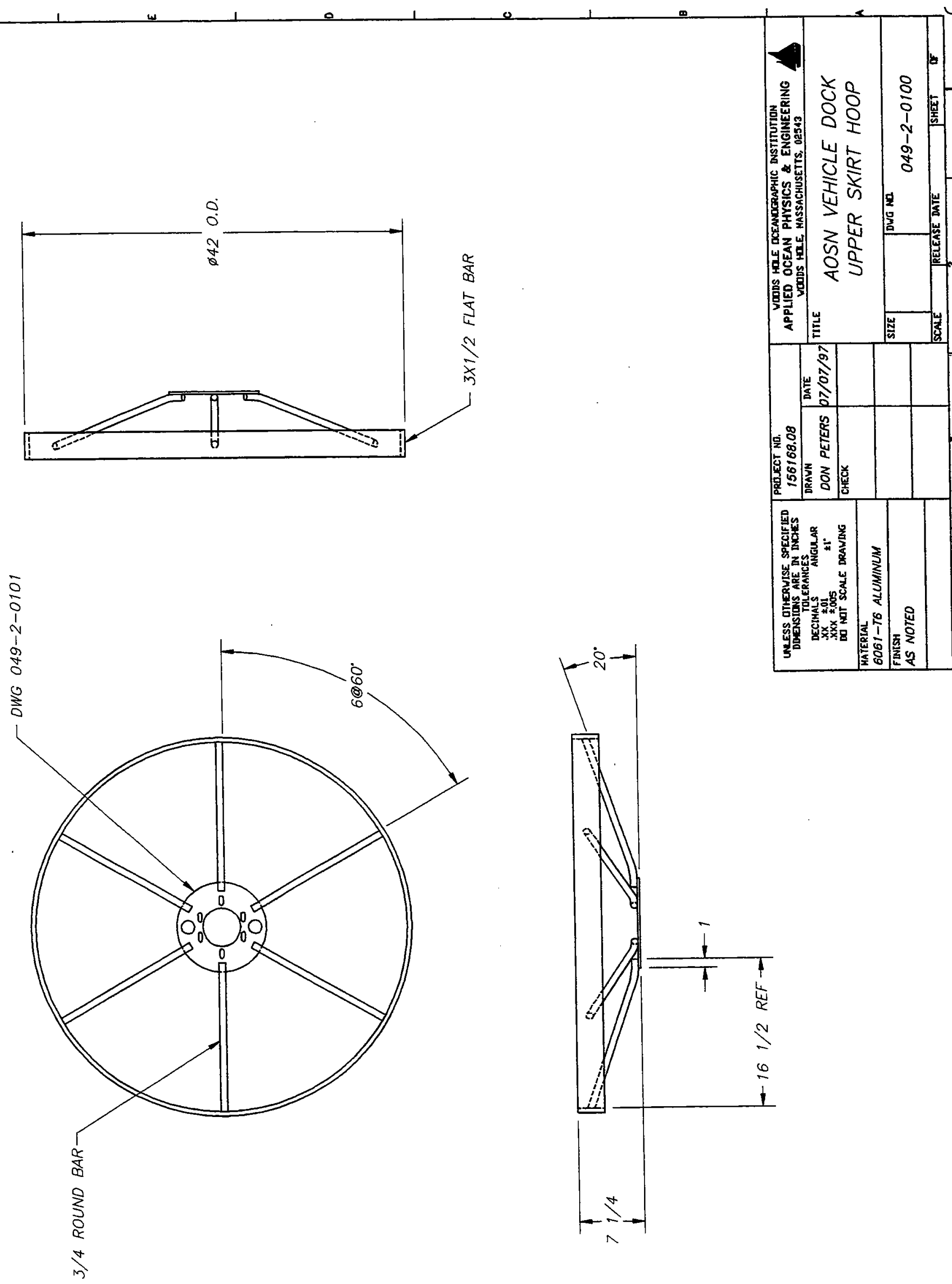


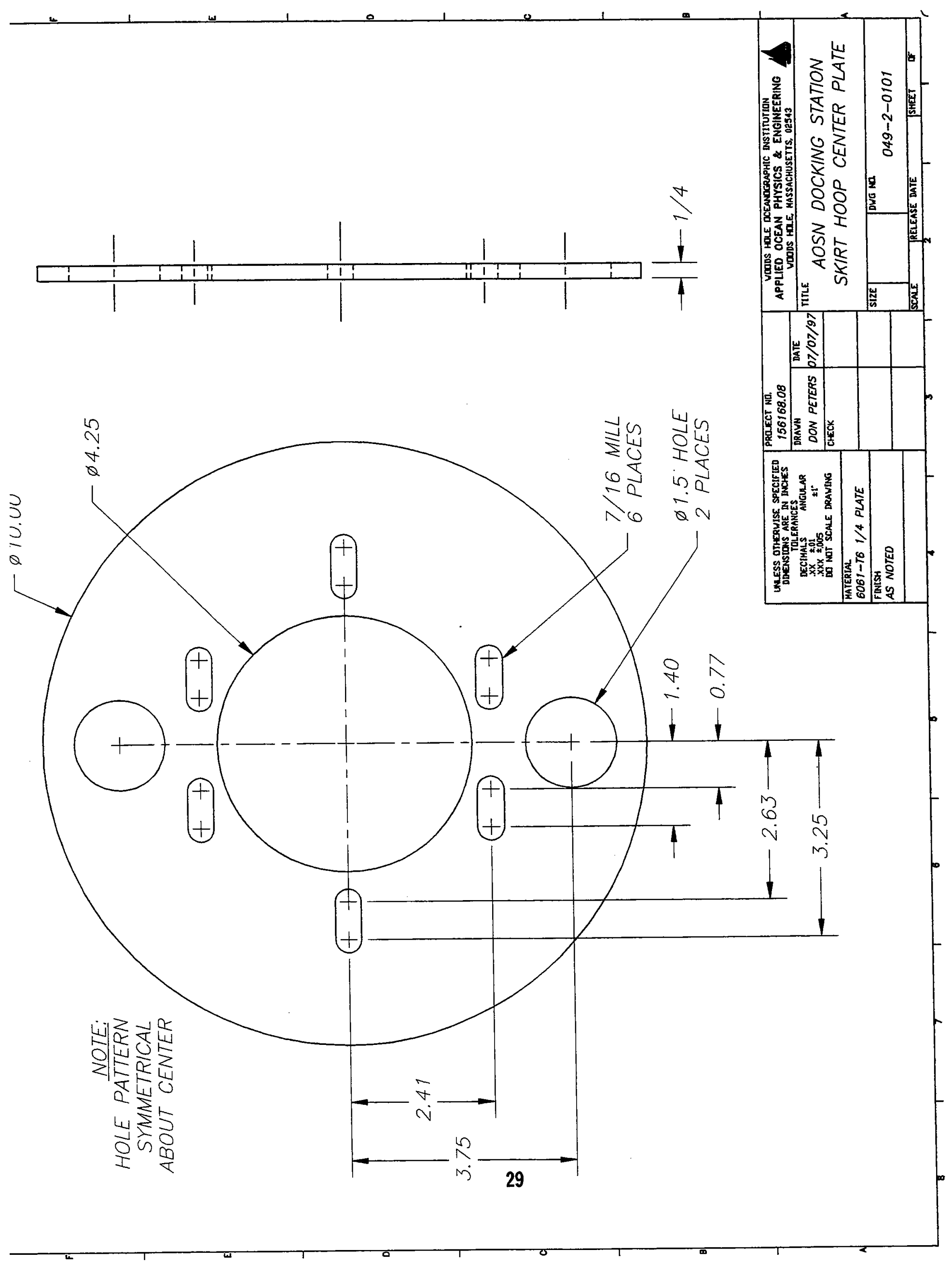



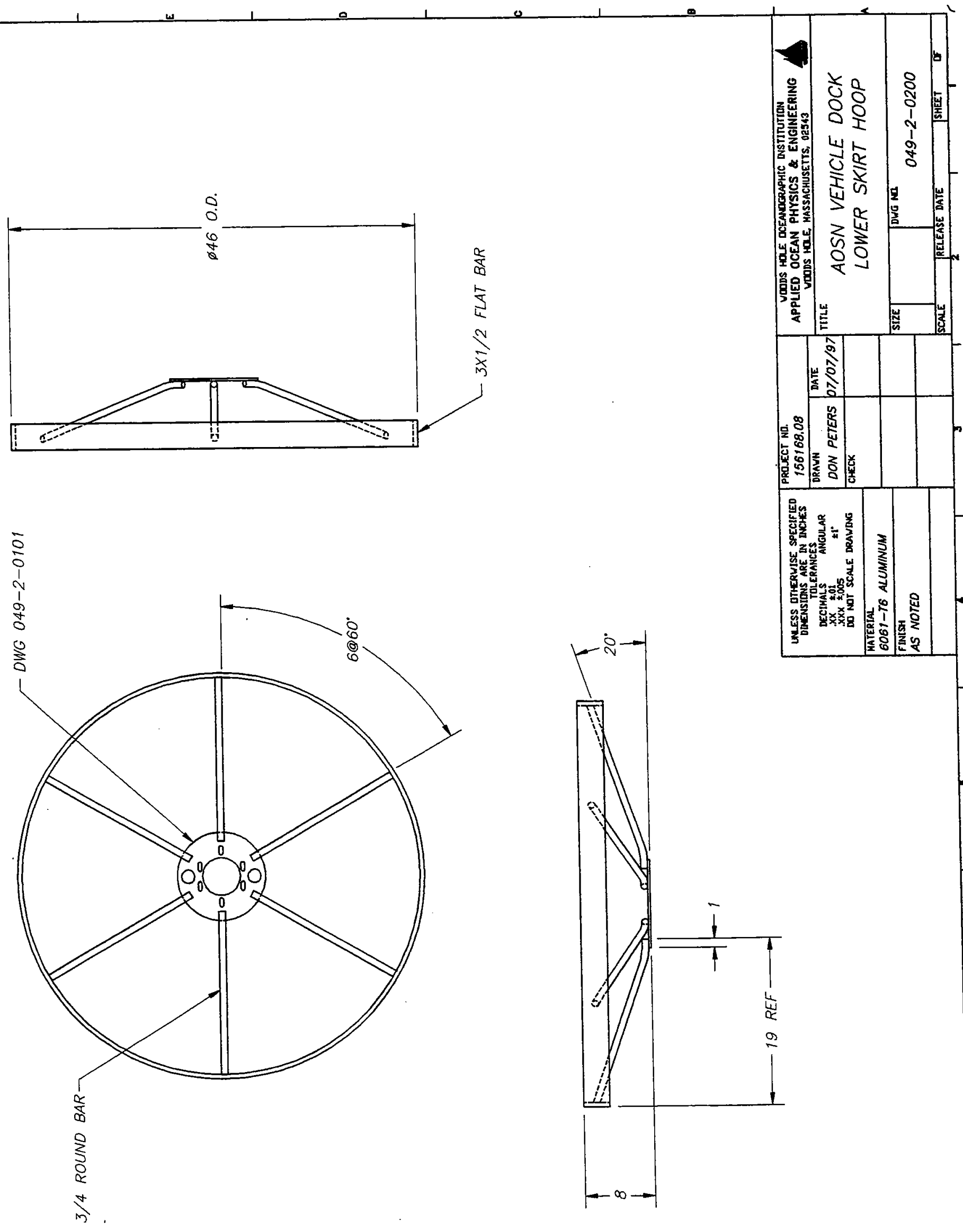


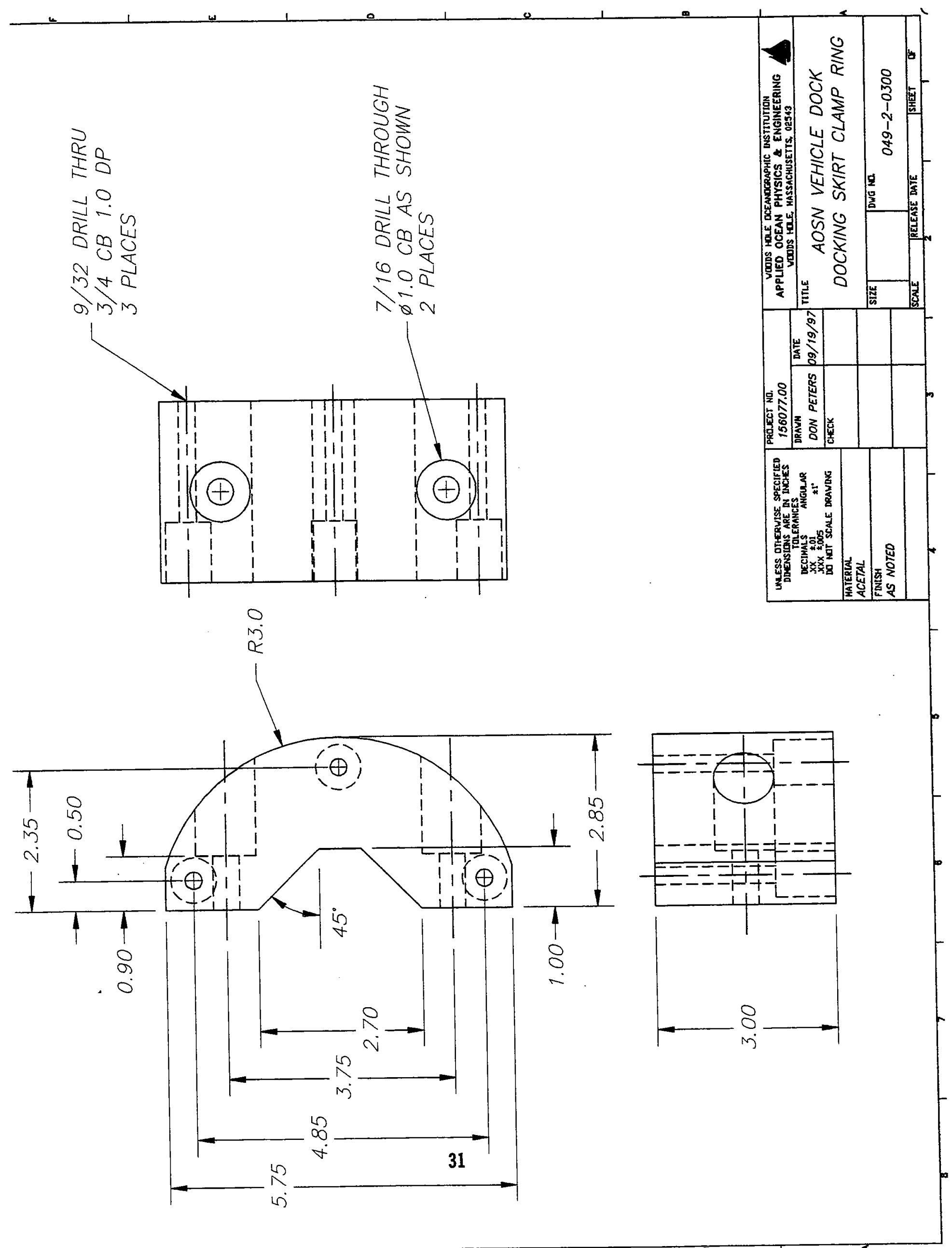




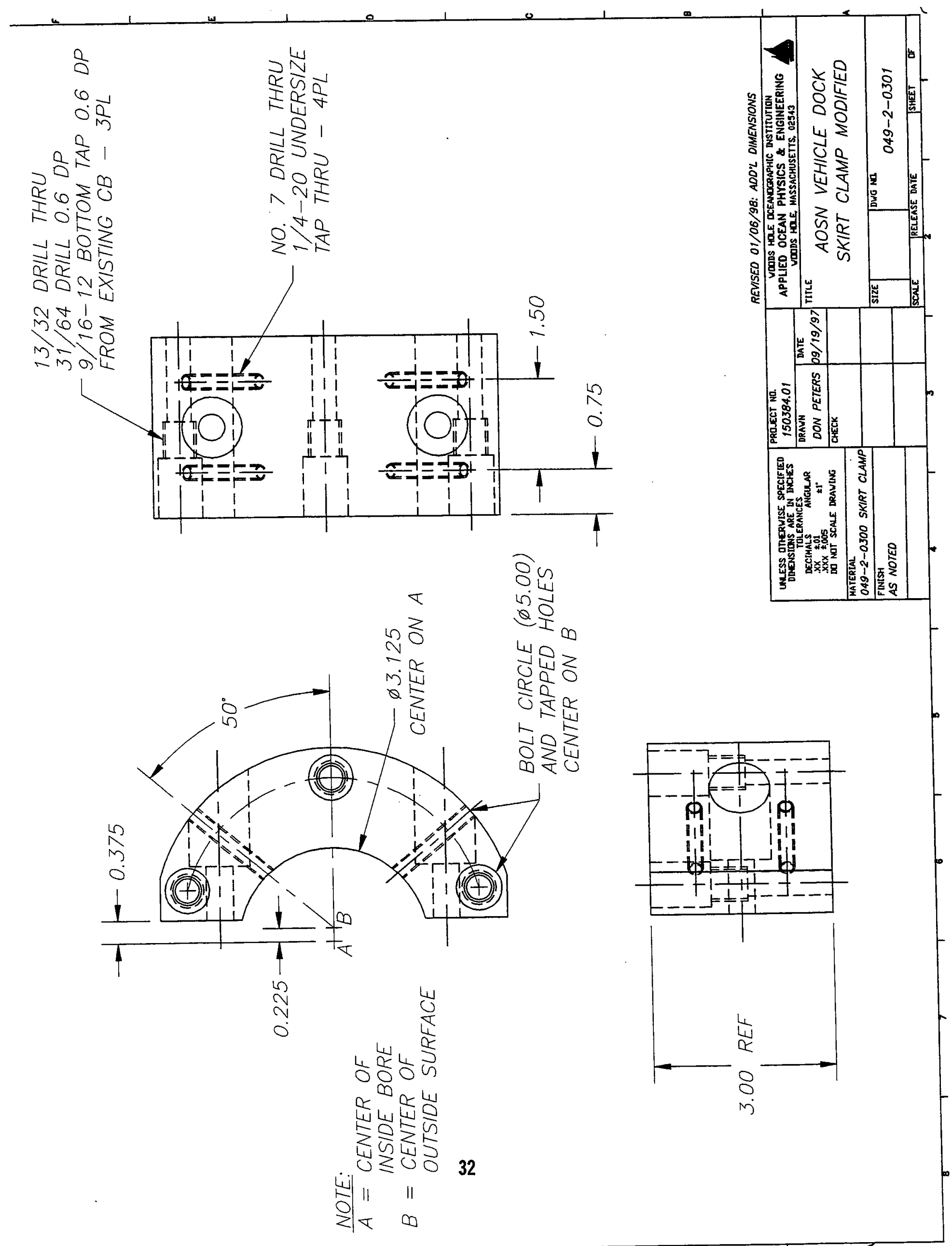



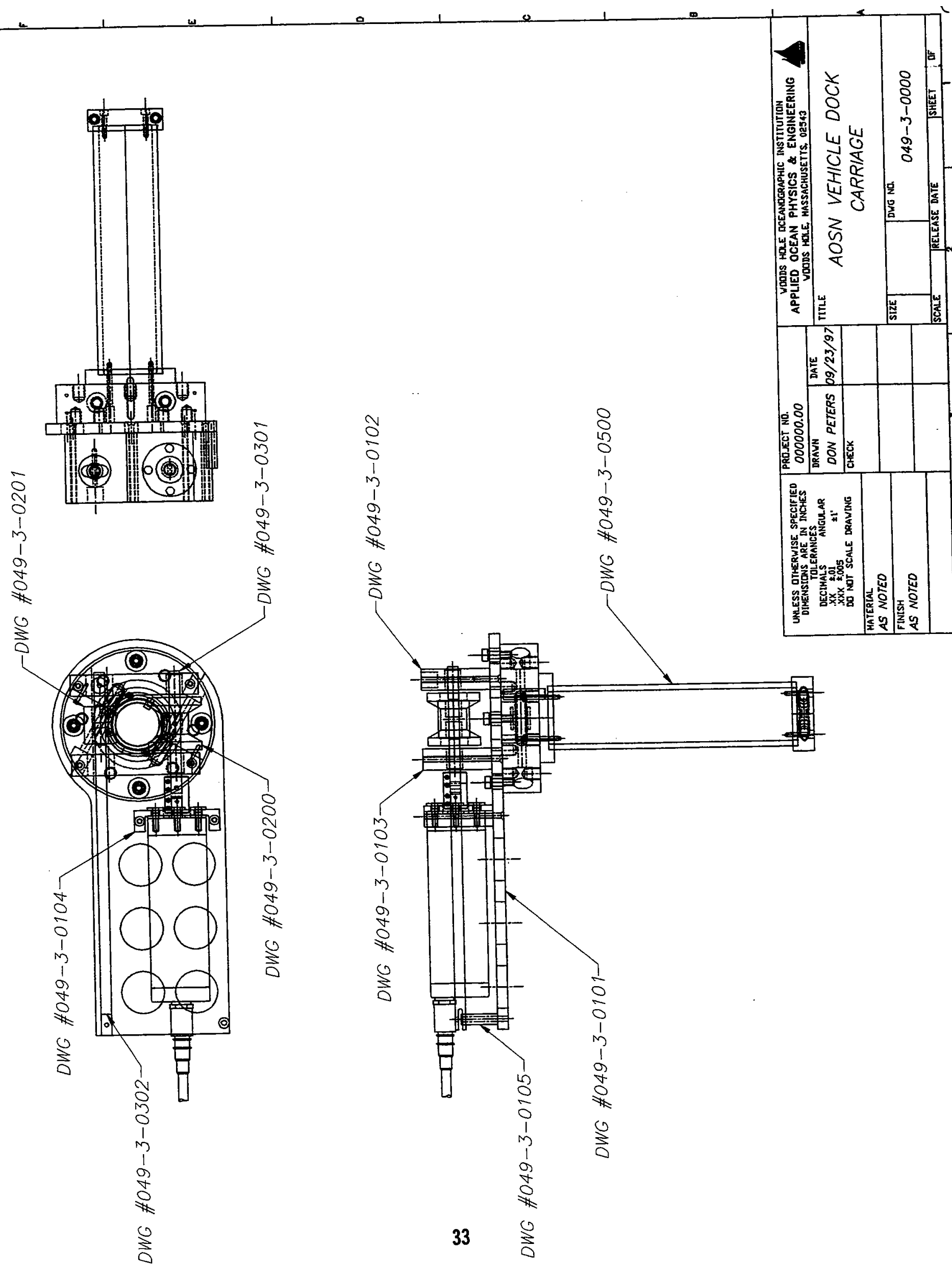


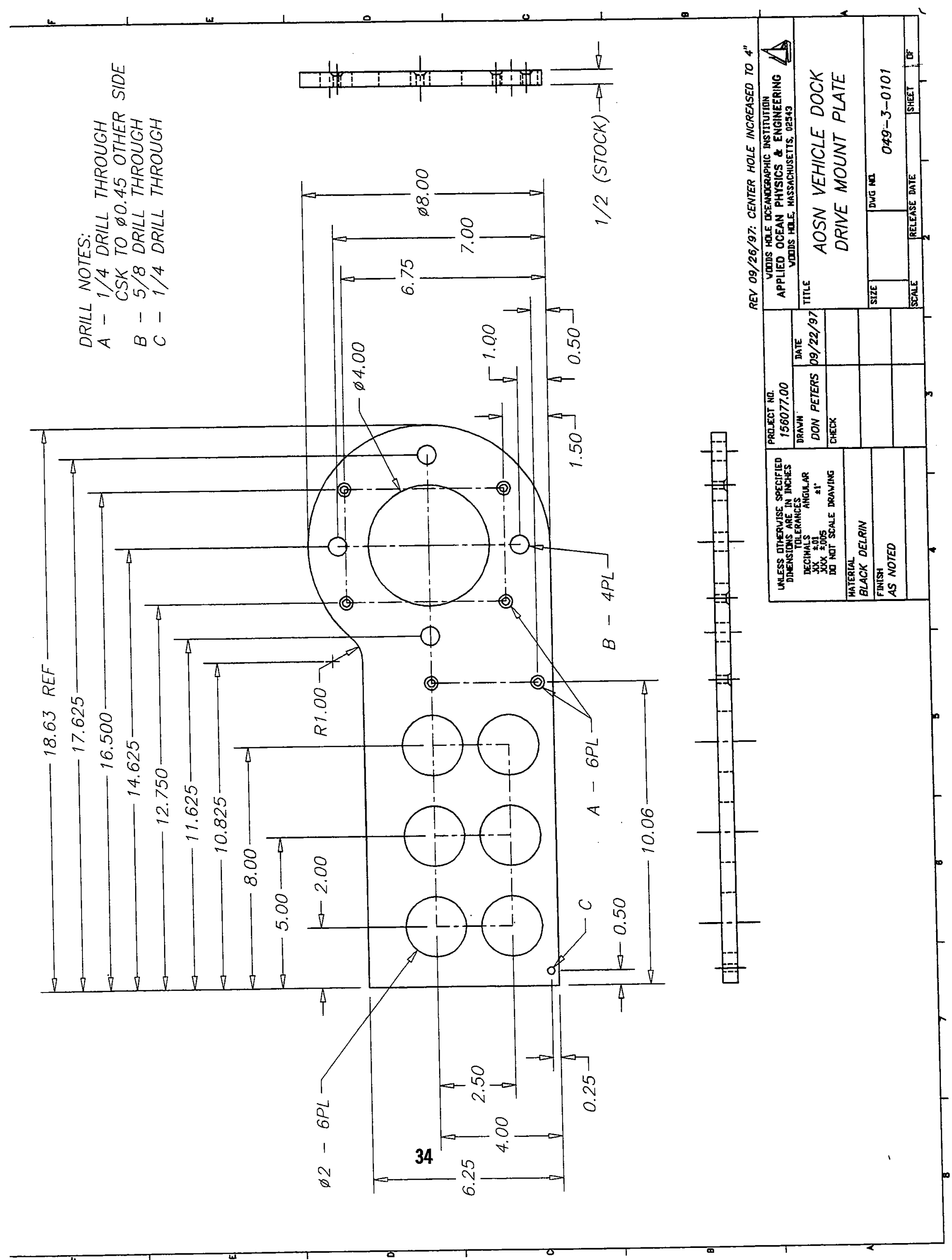




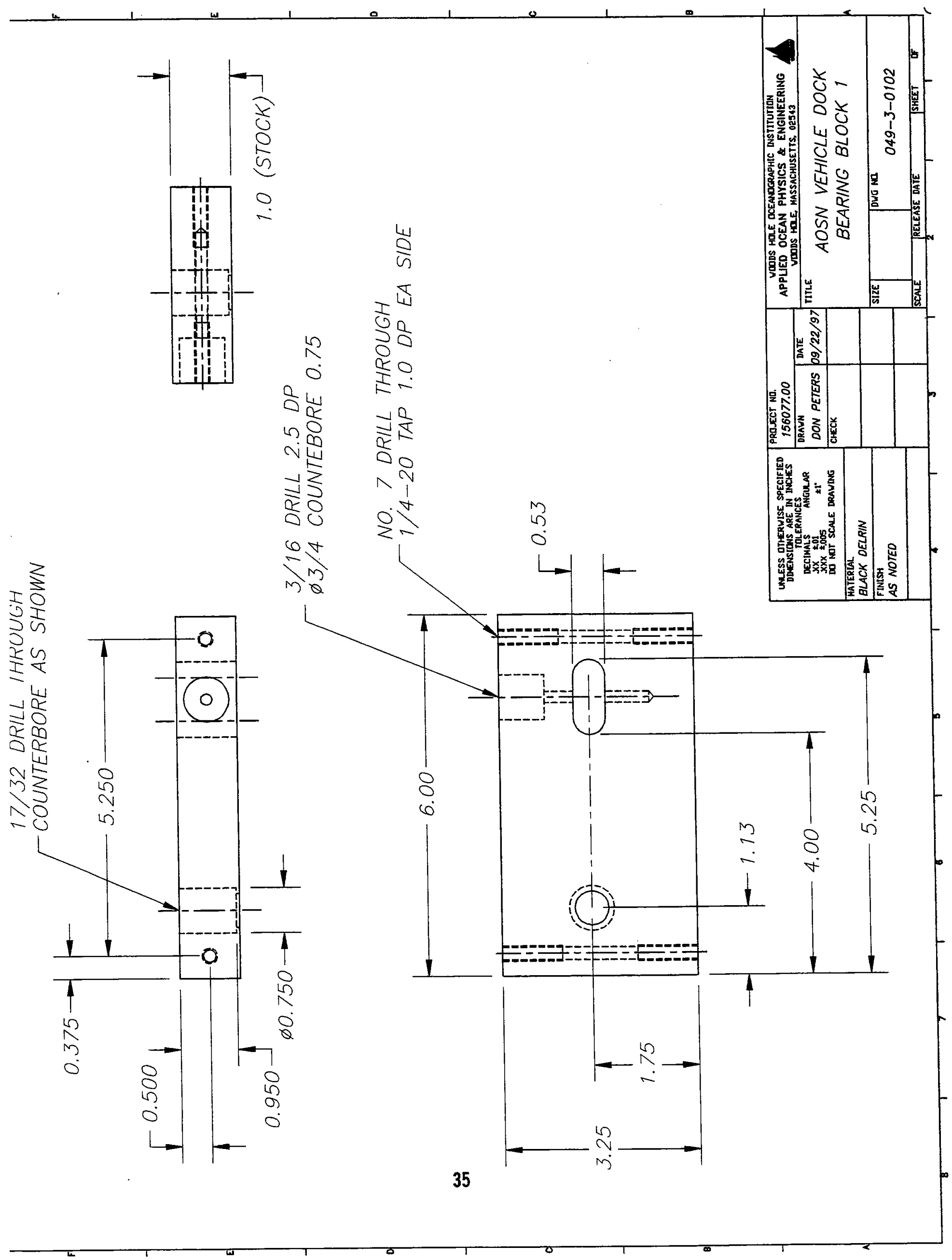




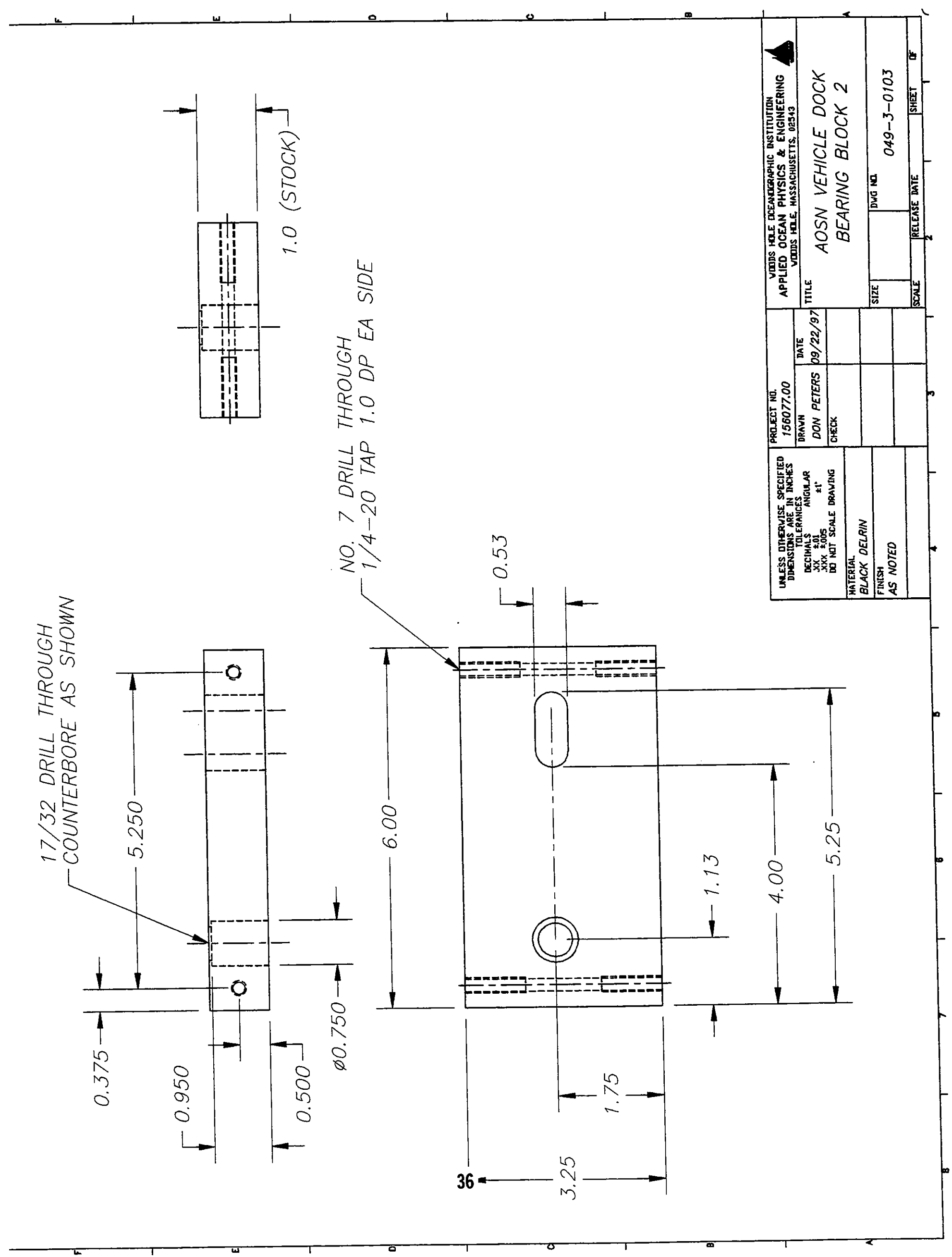



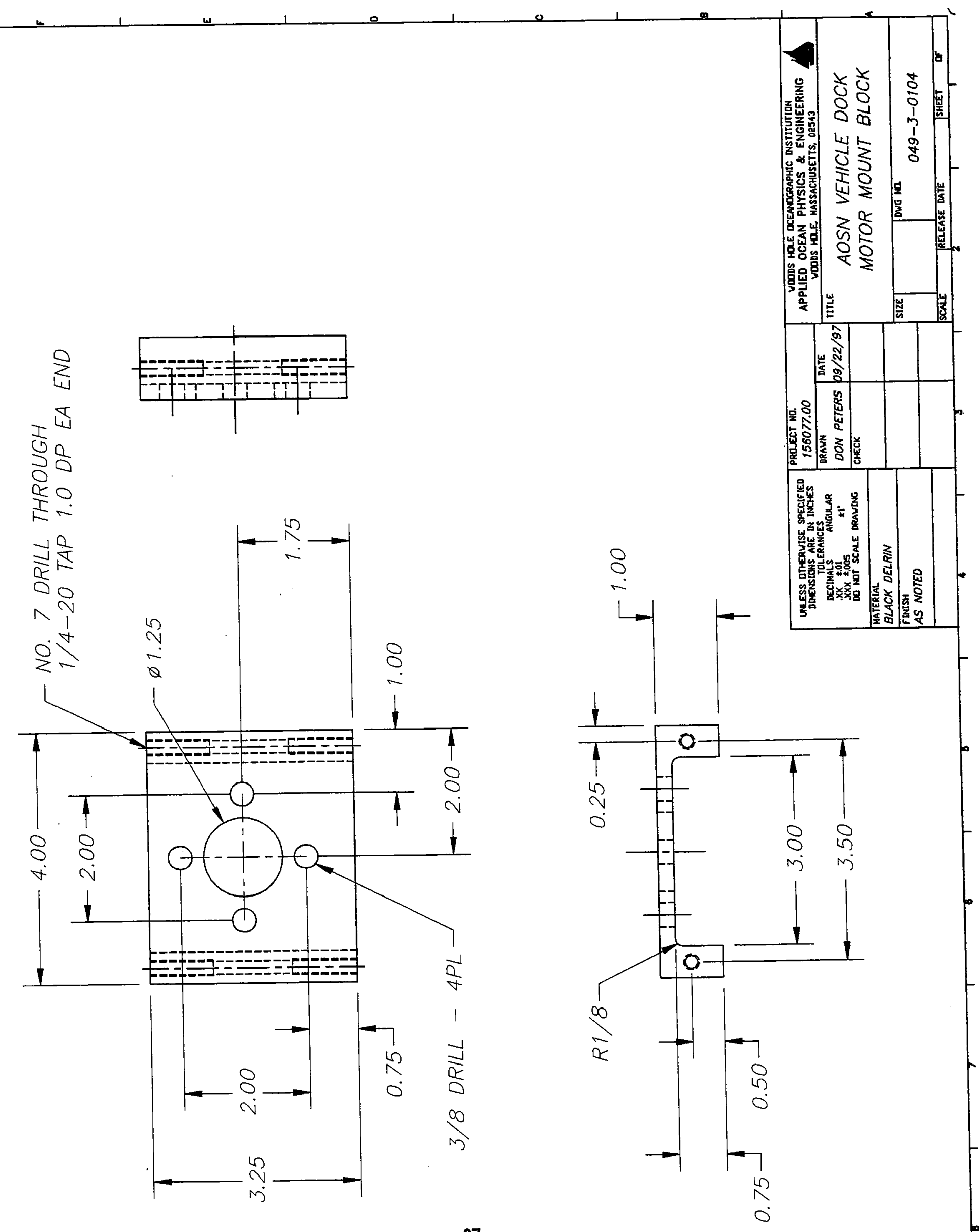

37 


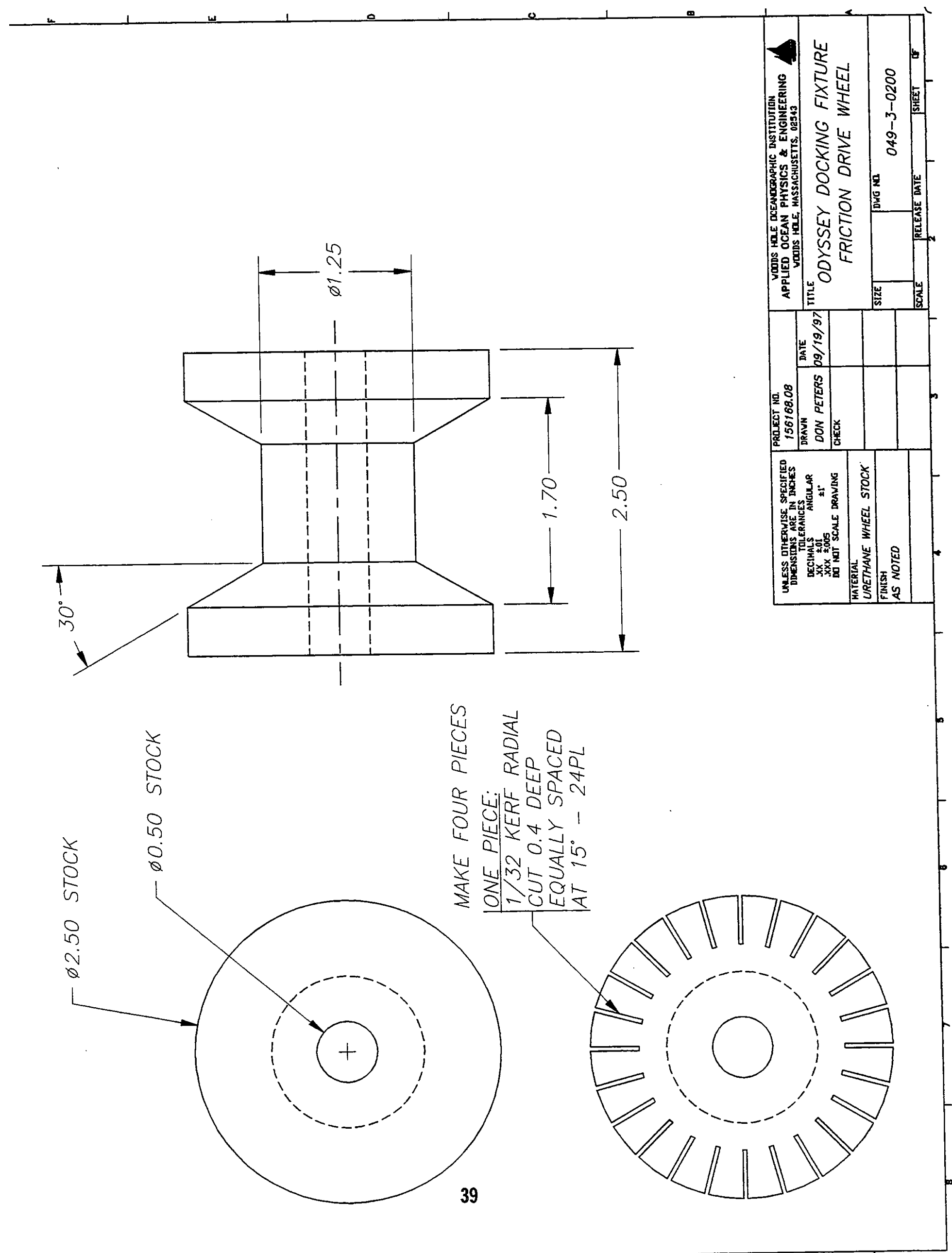



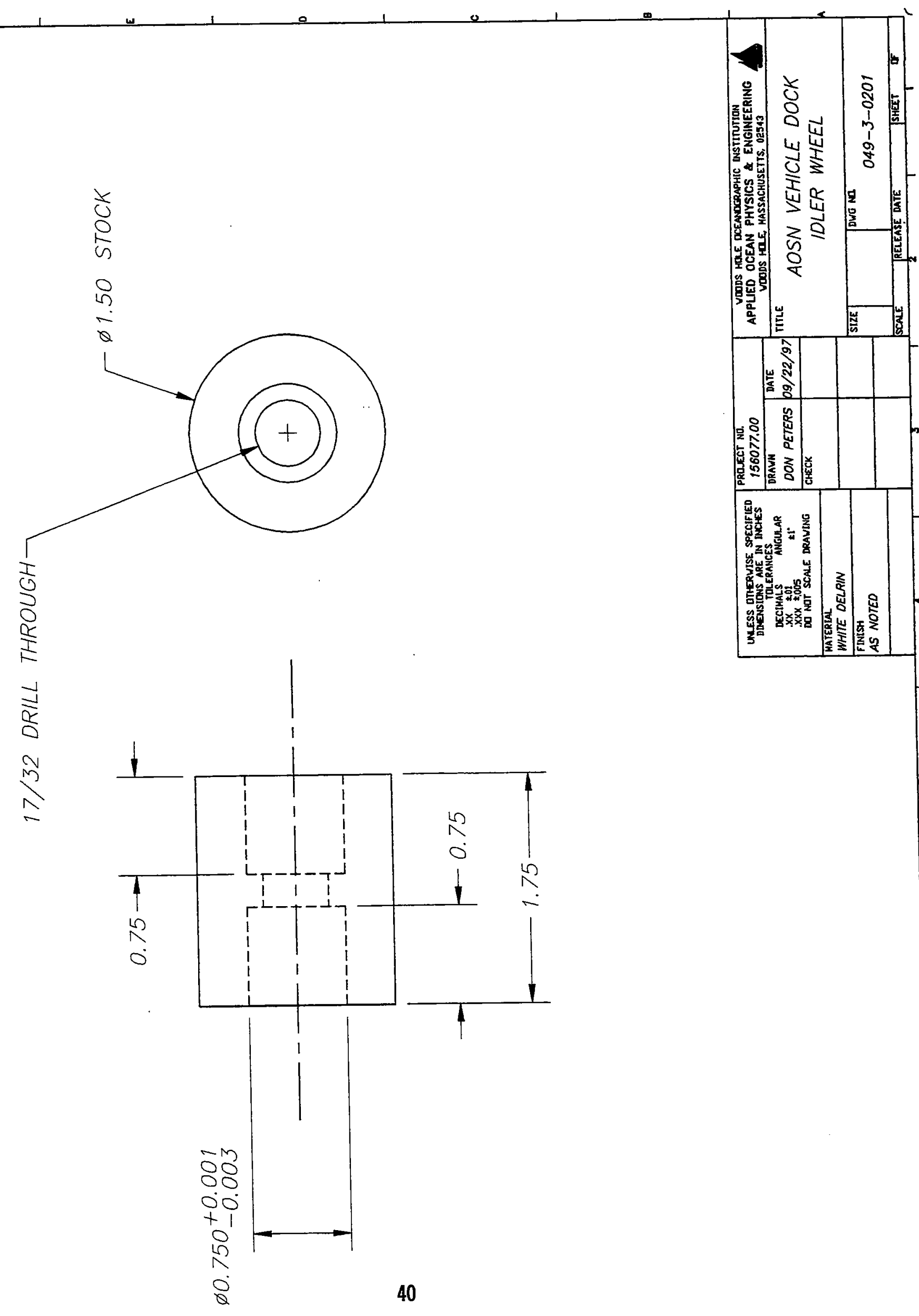


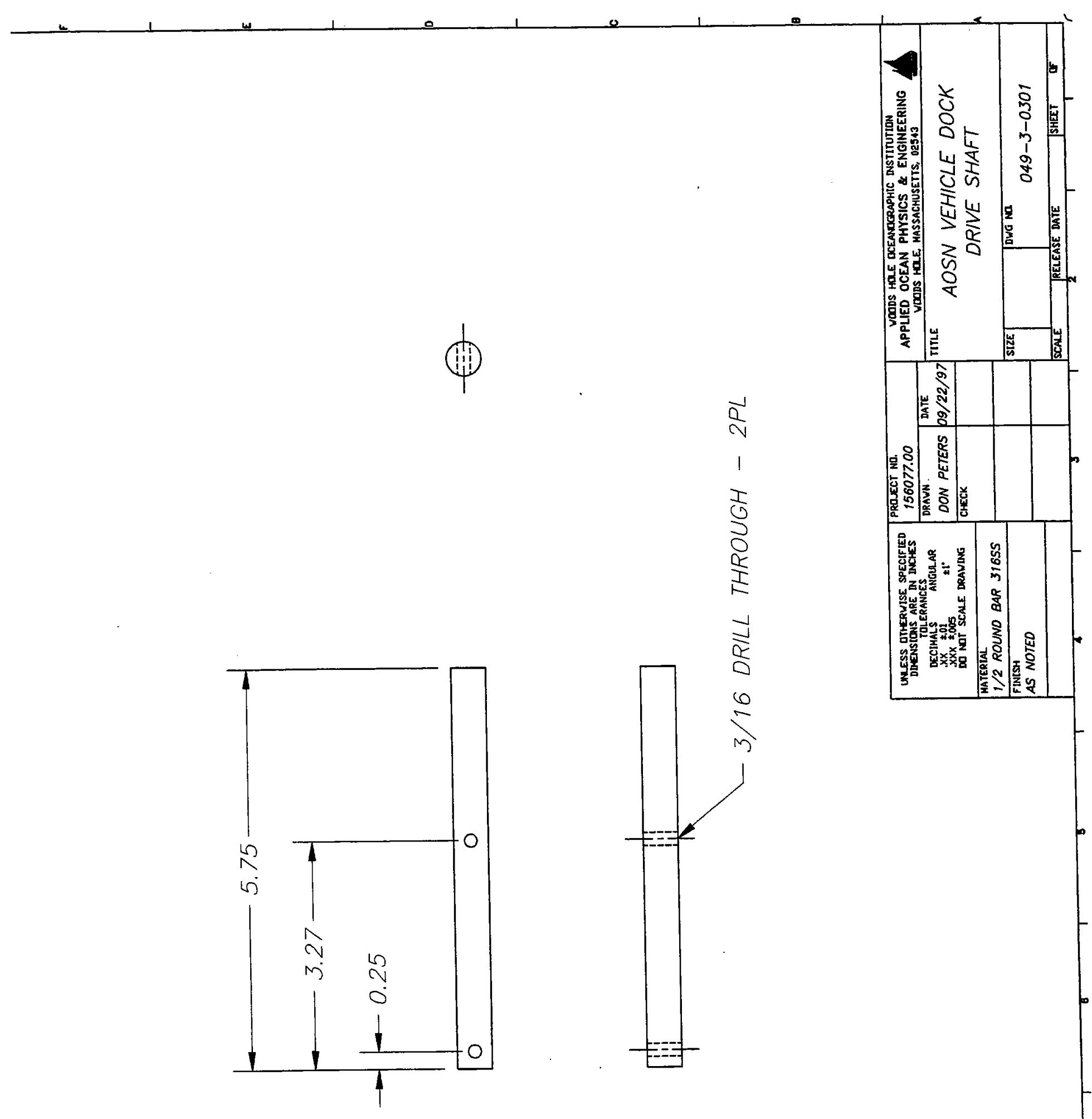




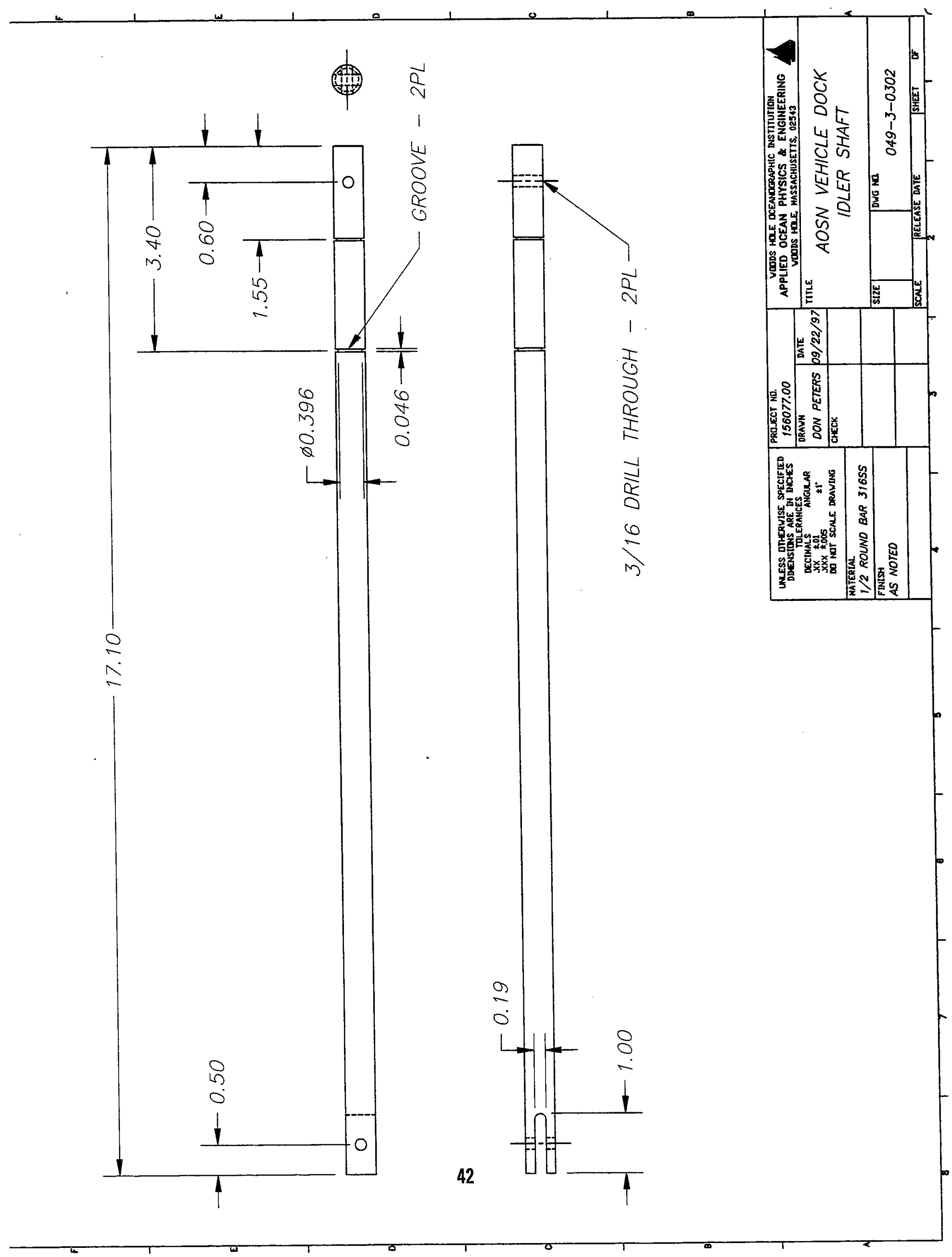



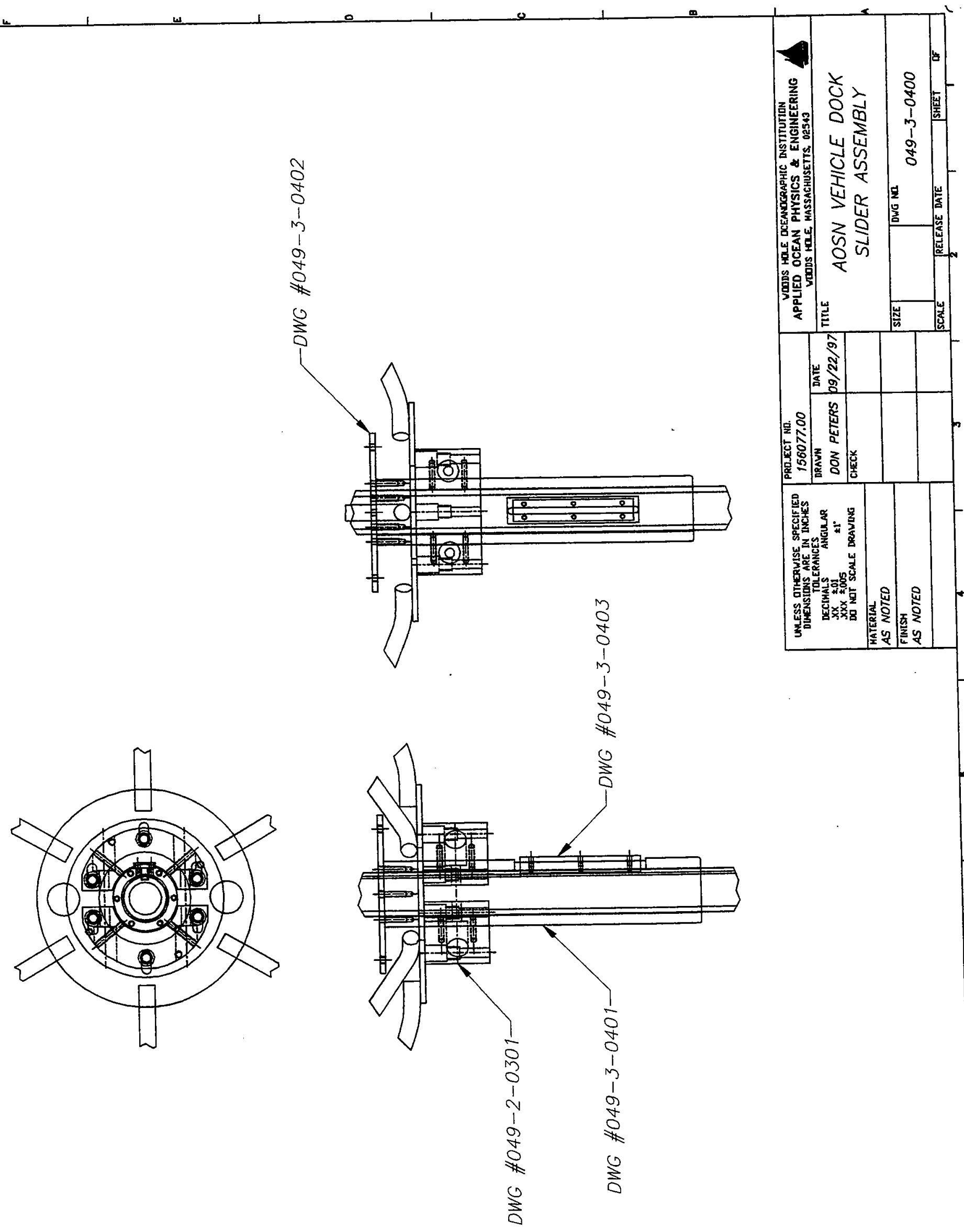


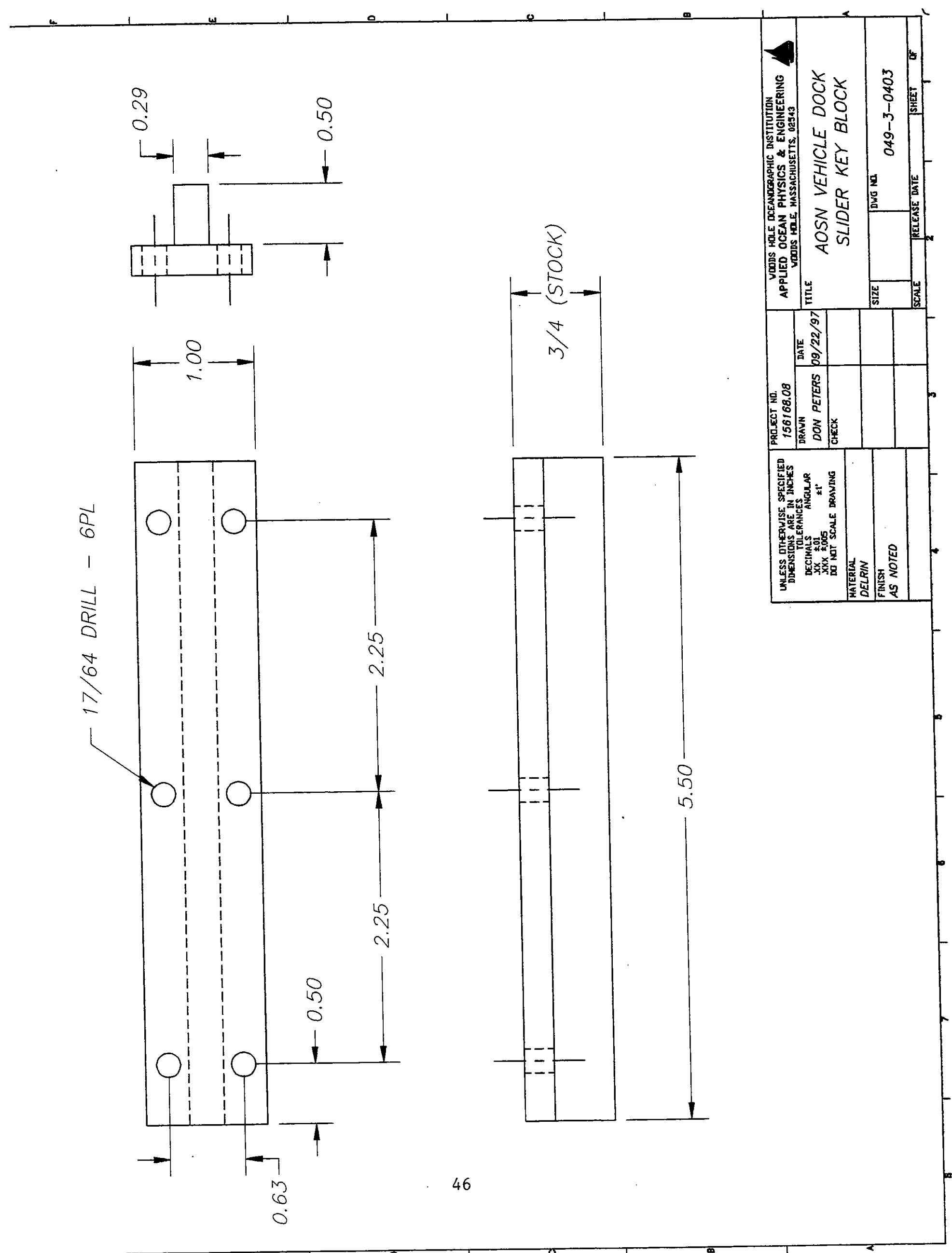



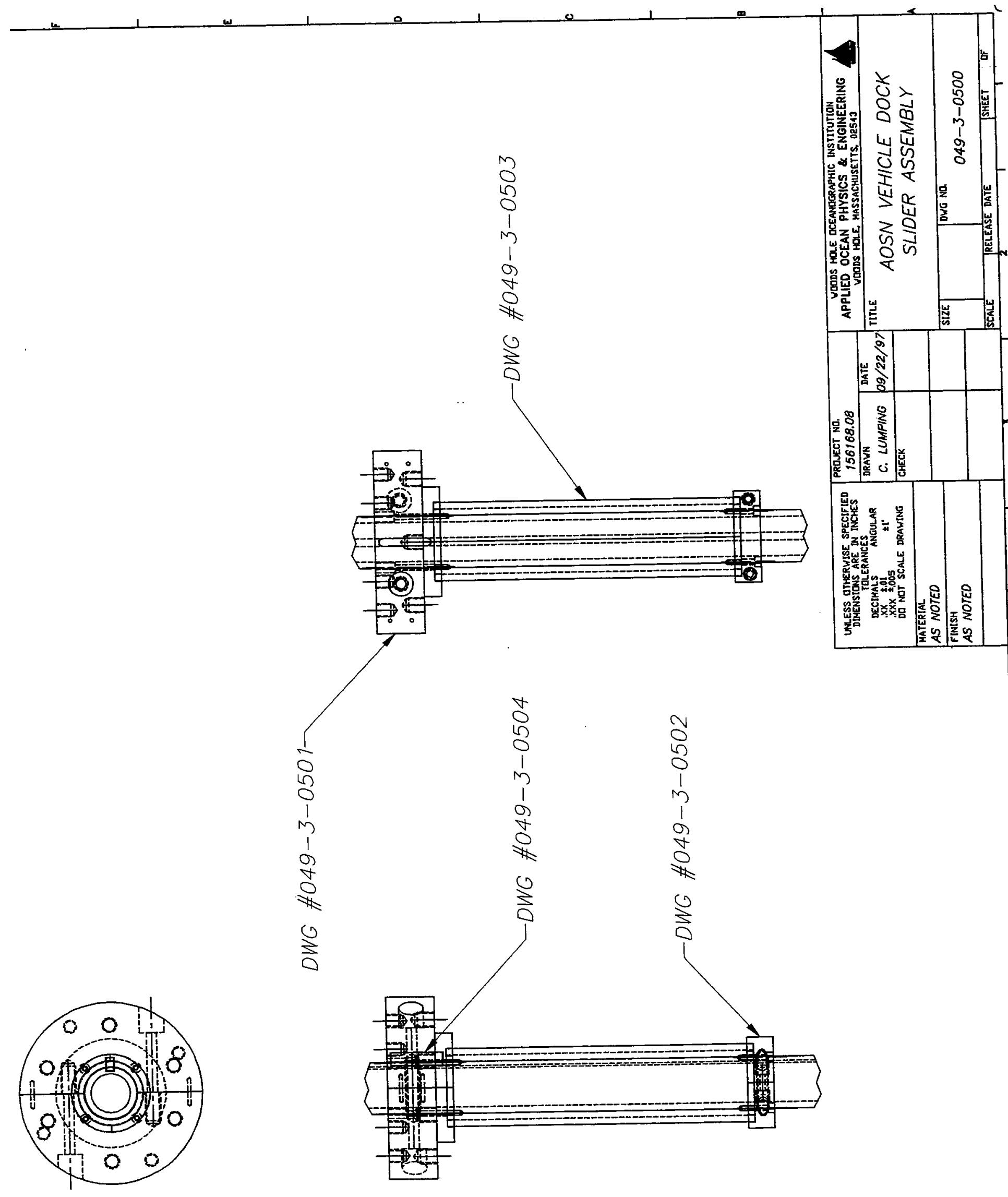


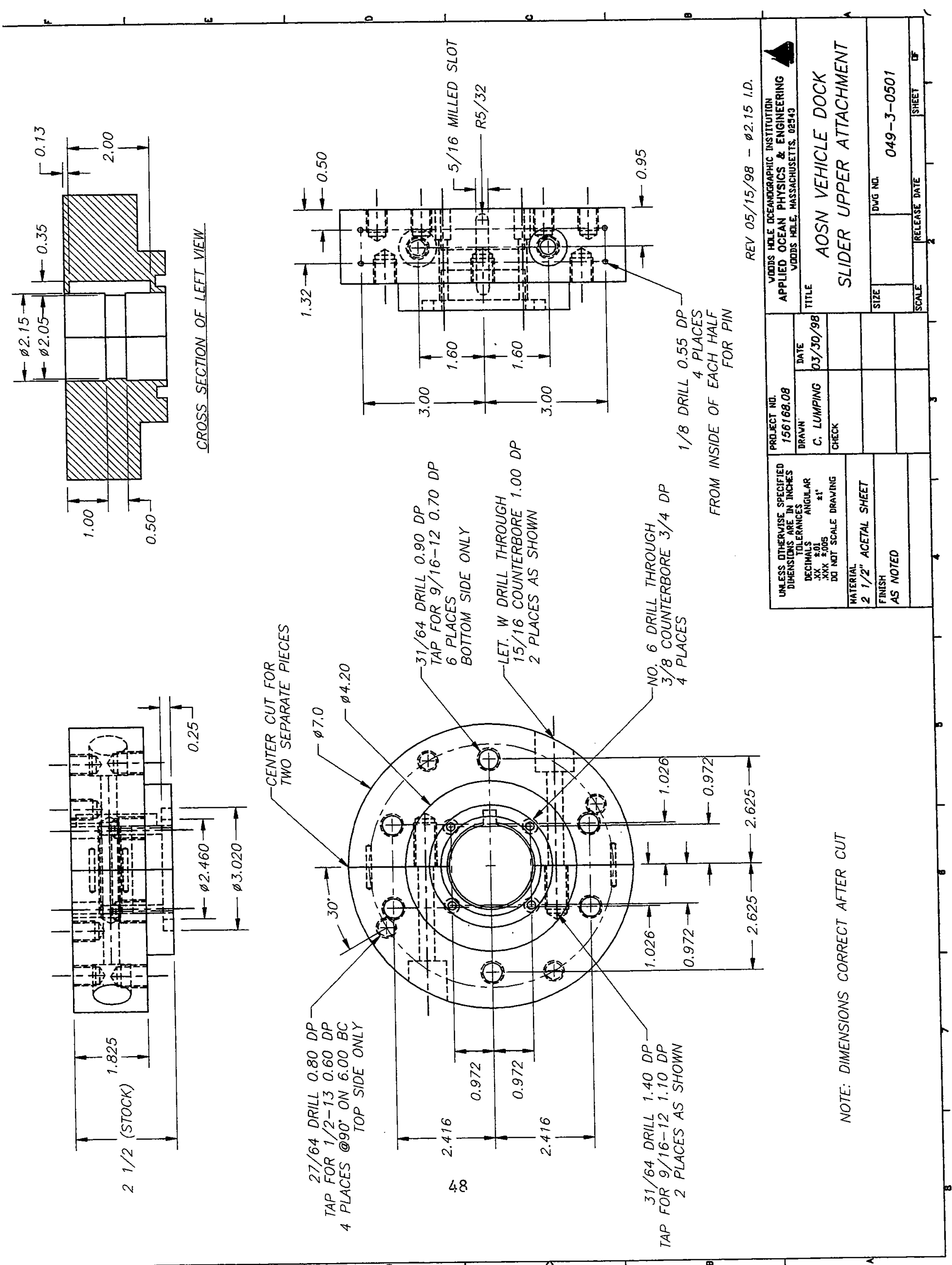




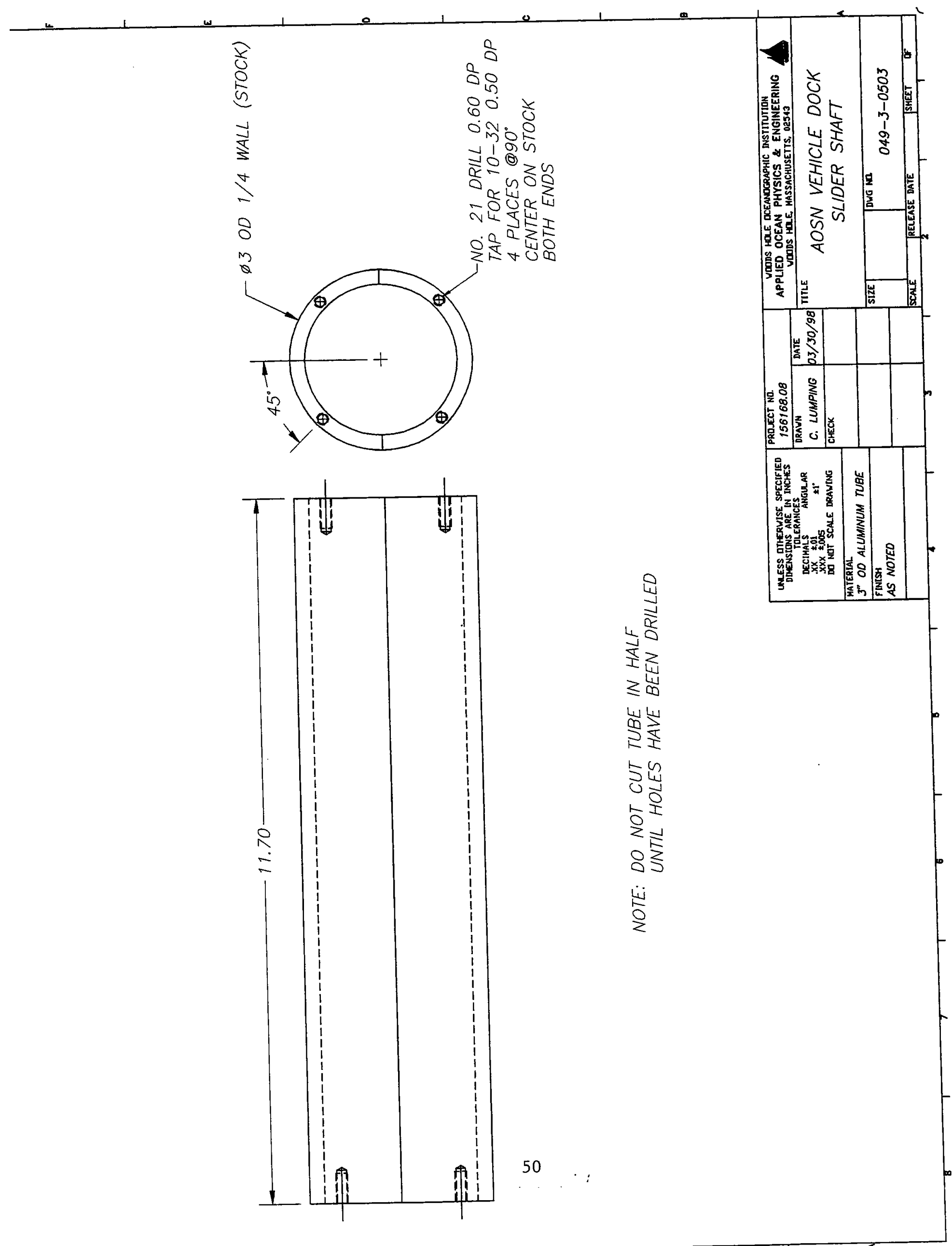




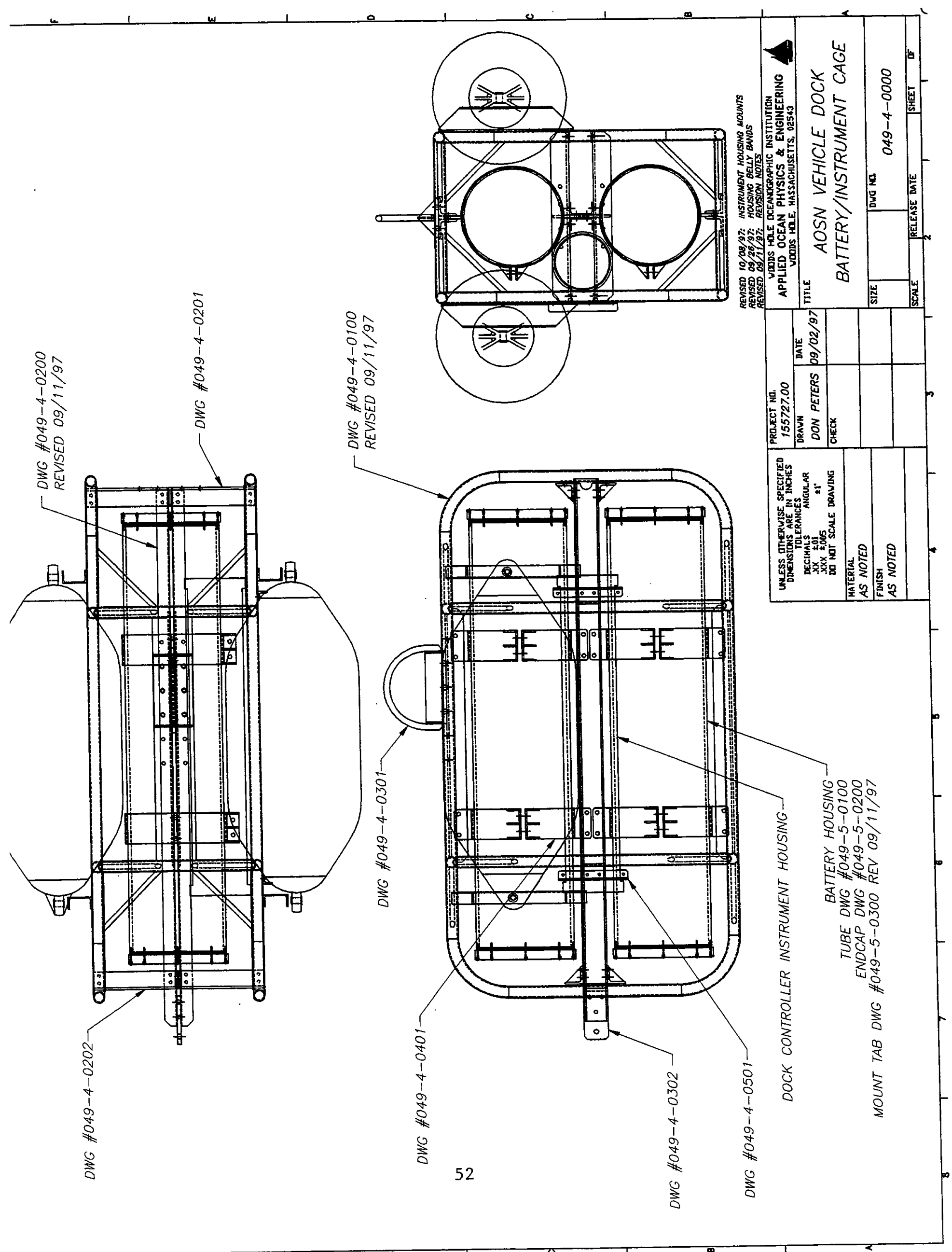




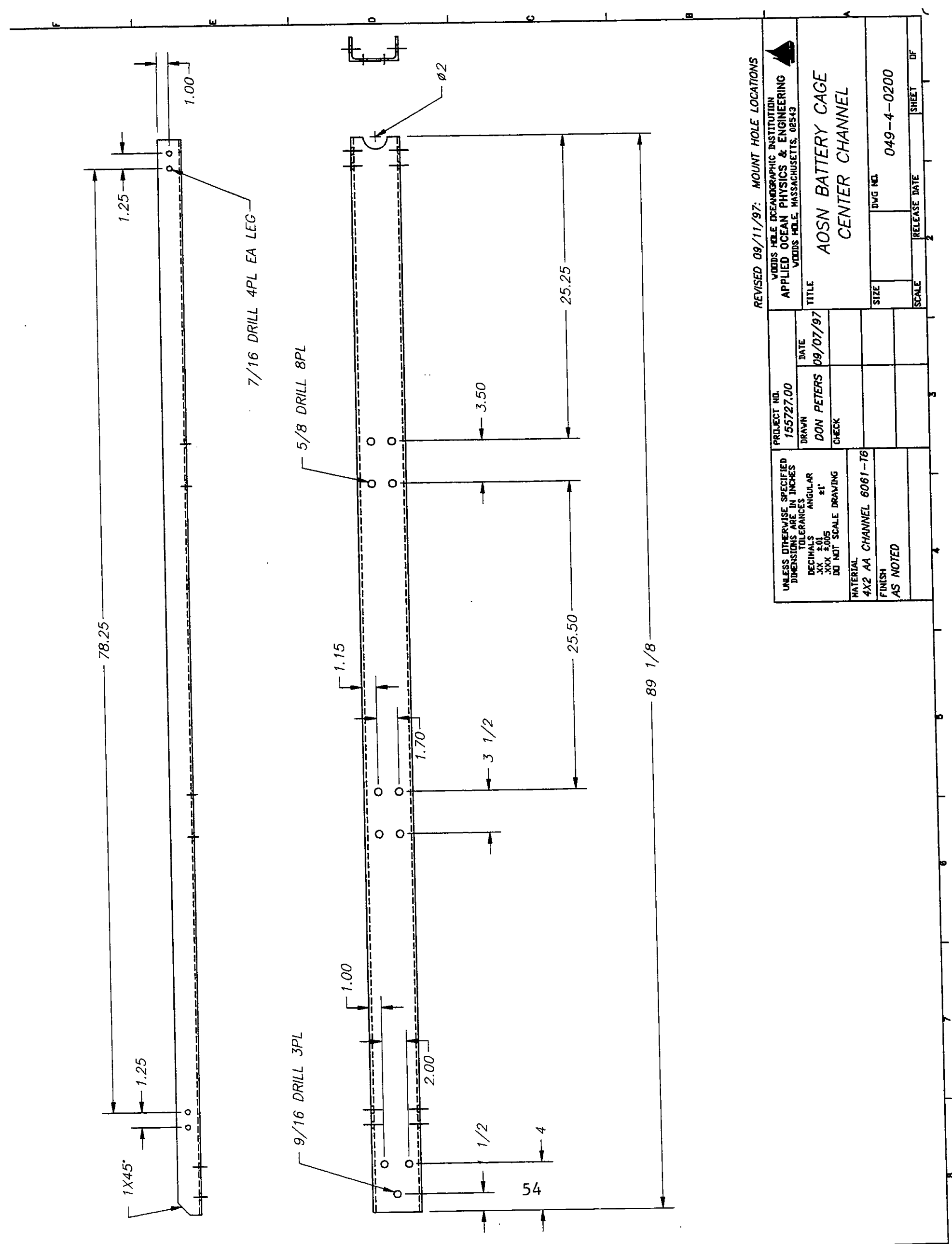




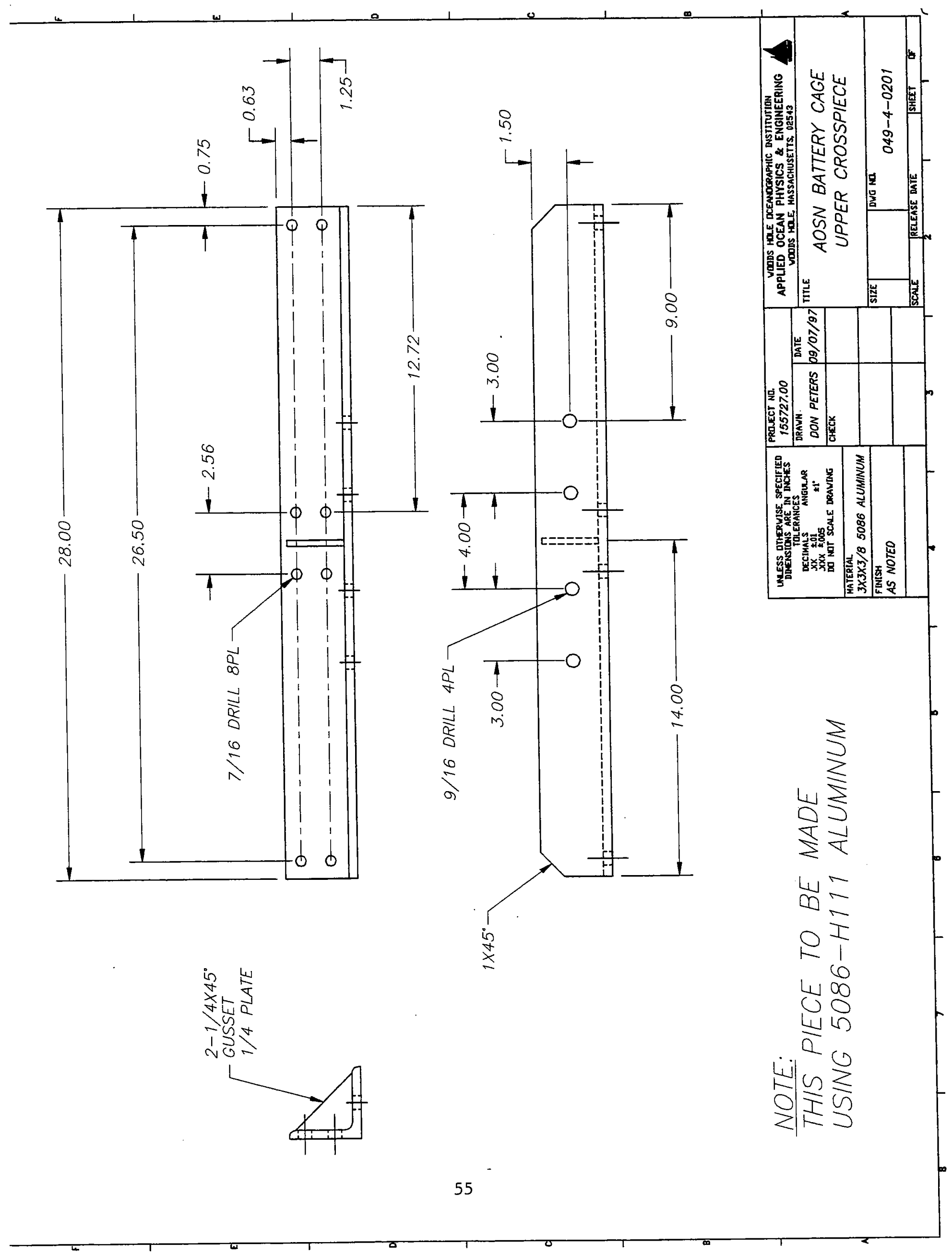



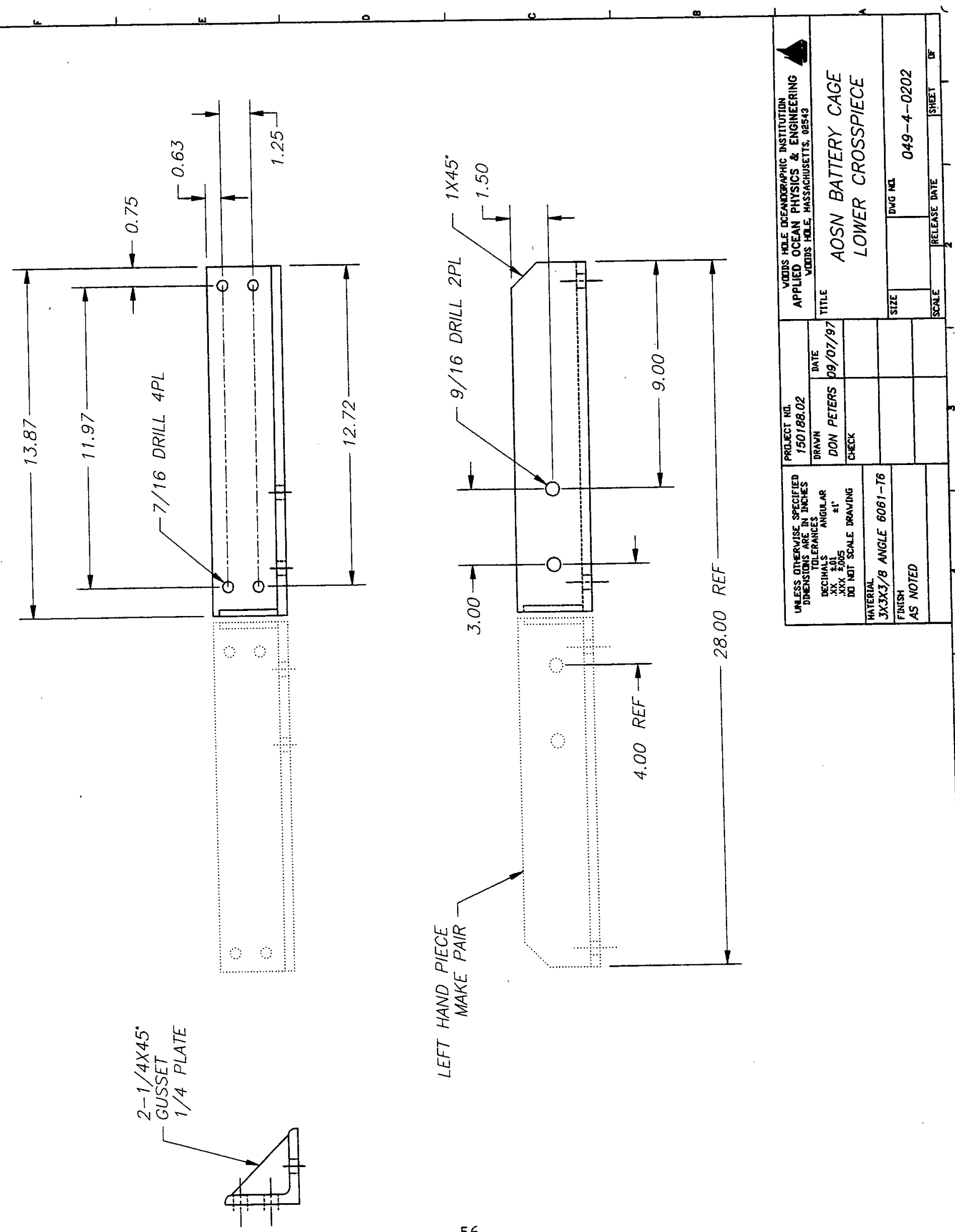


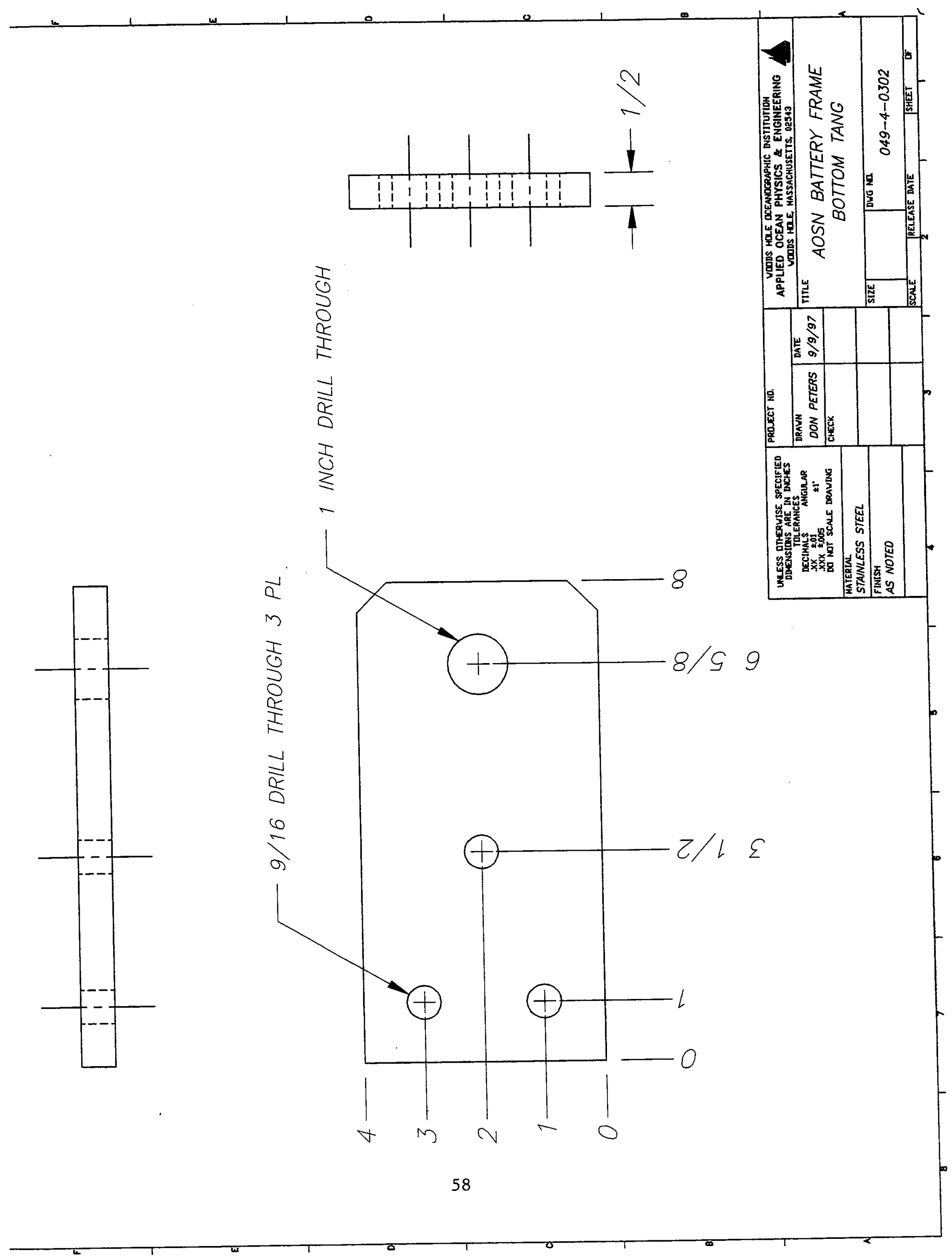




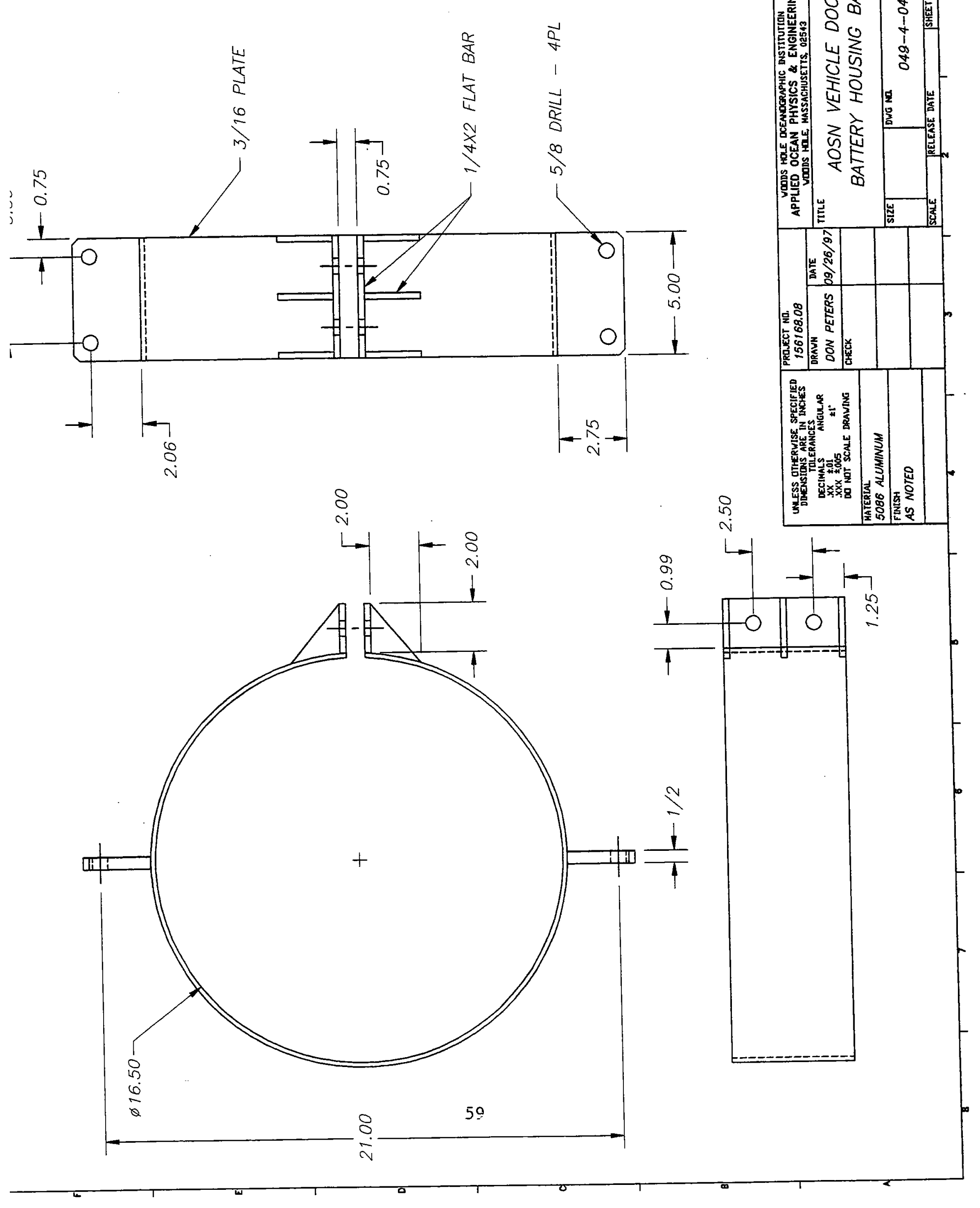




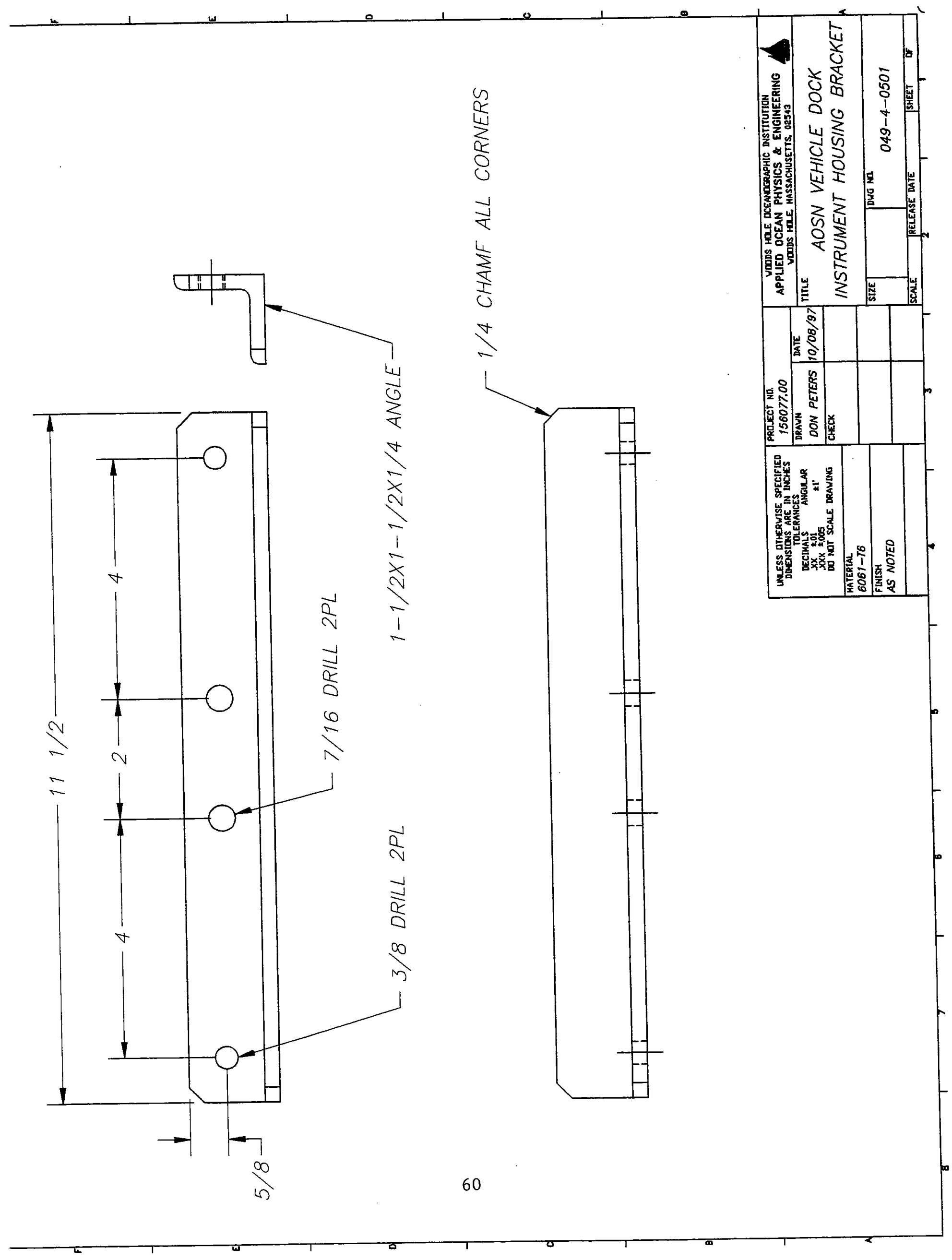



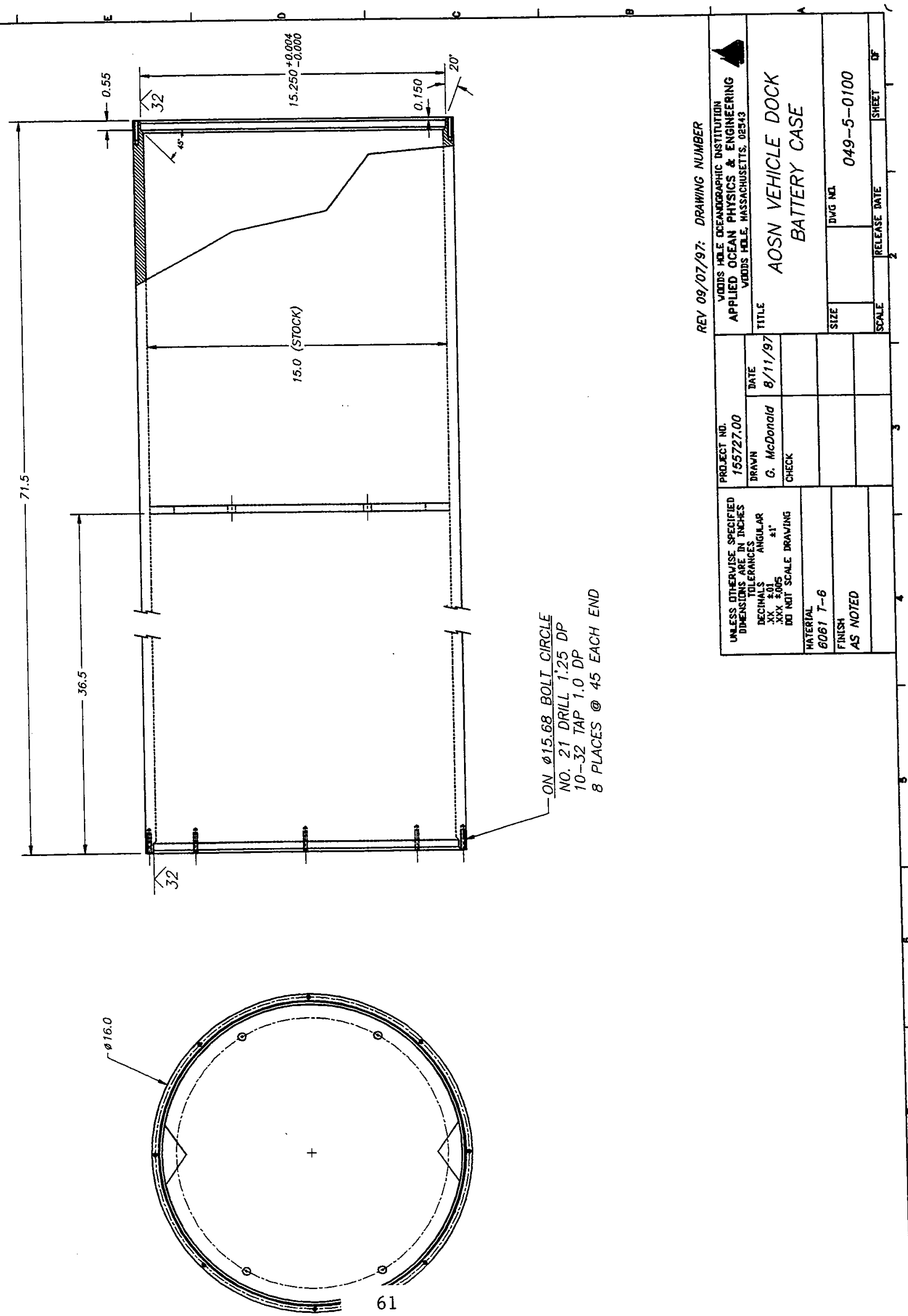


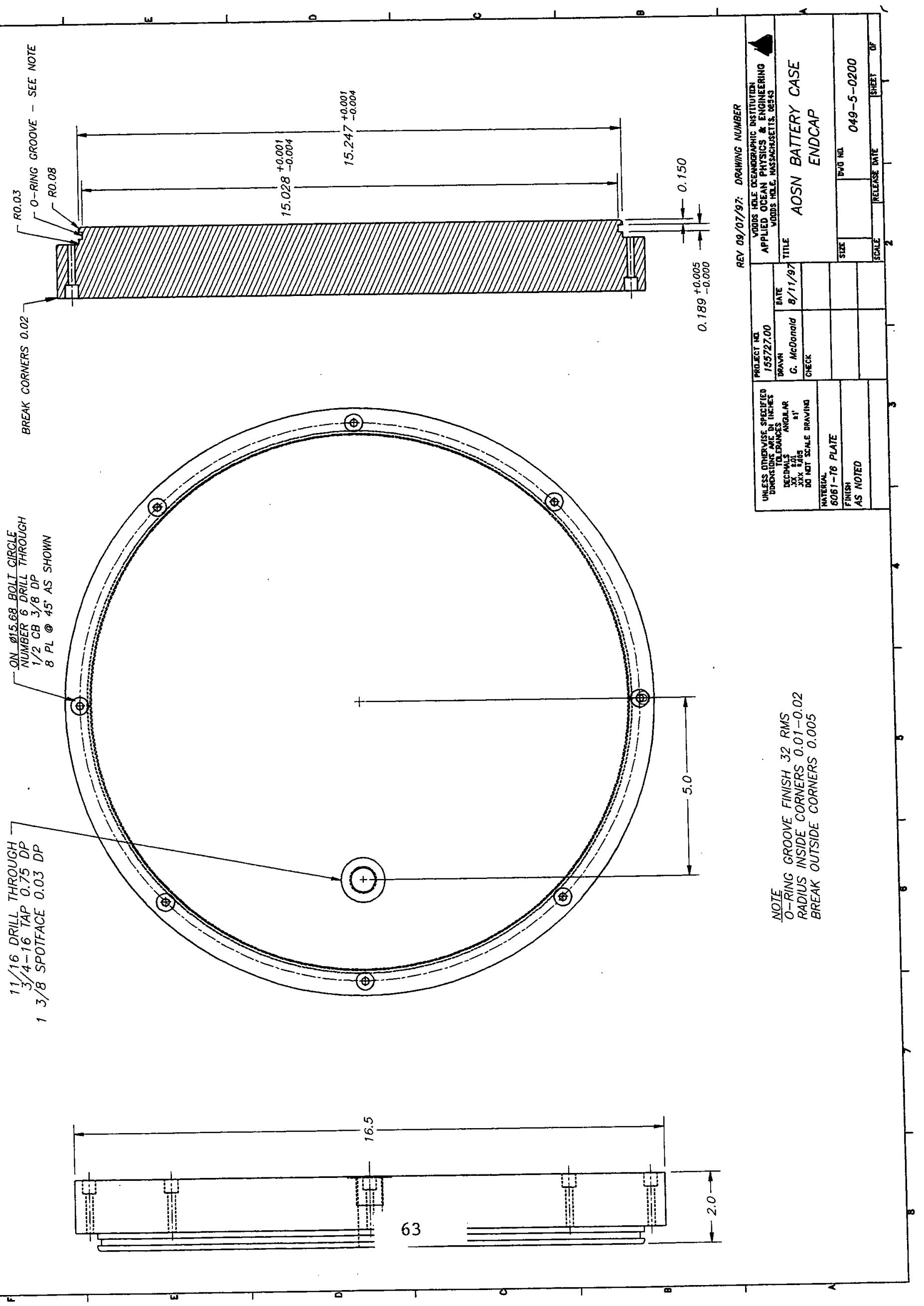




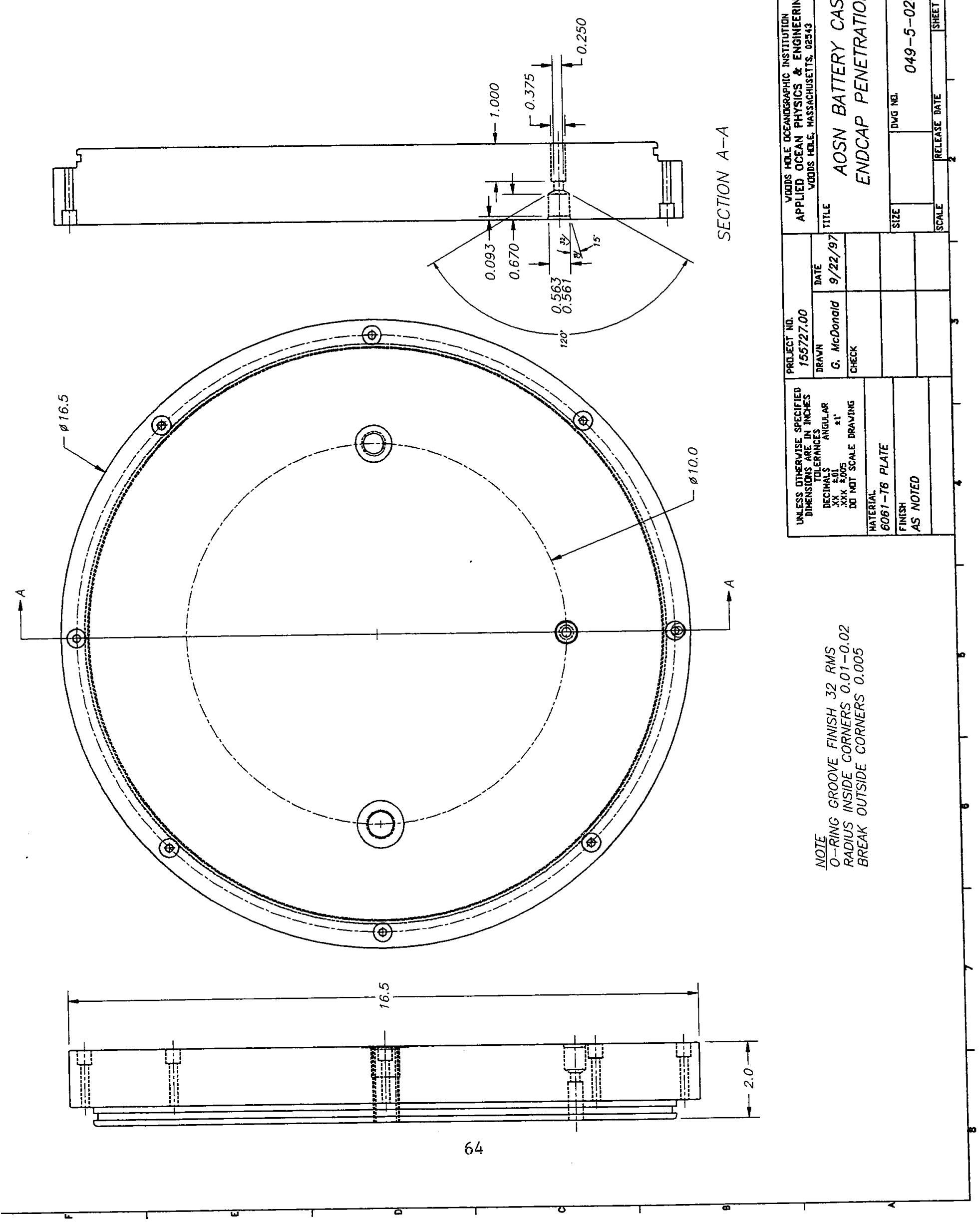




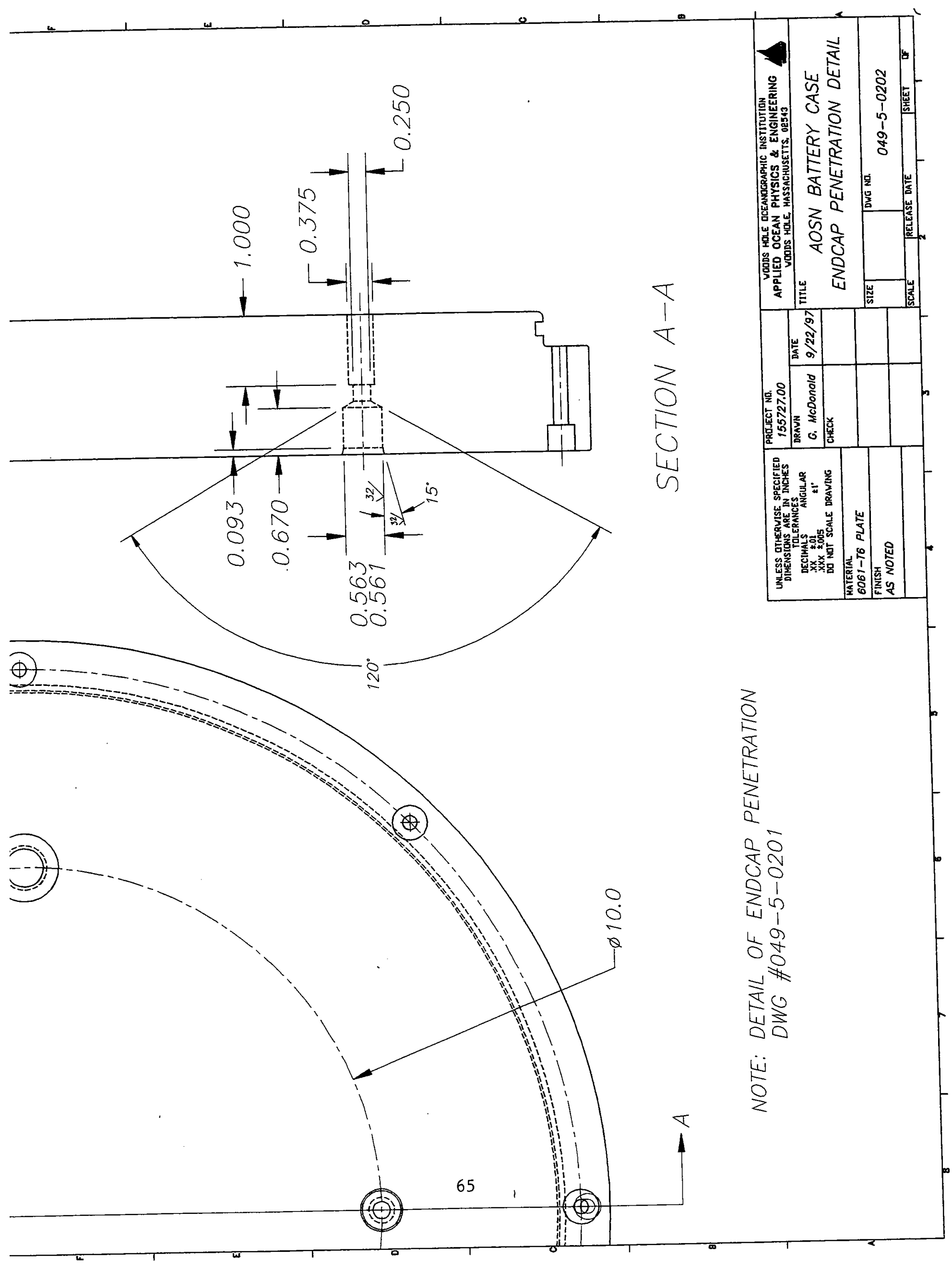




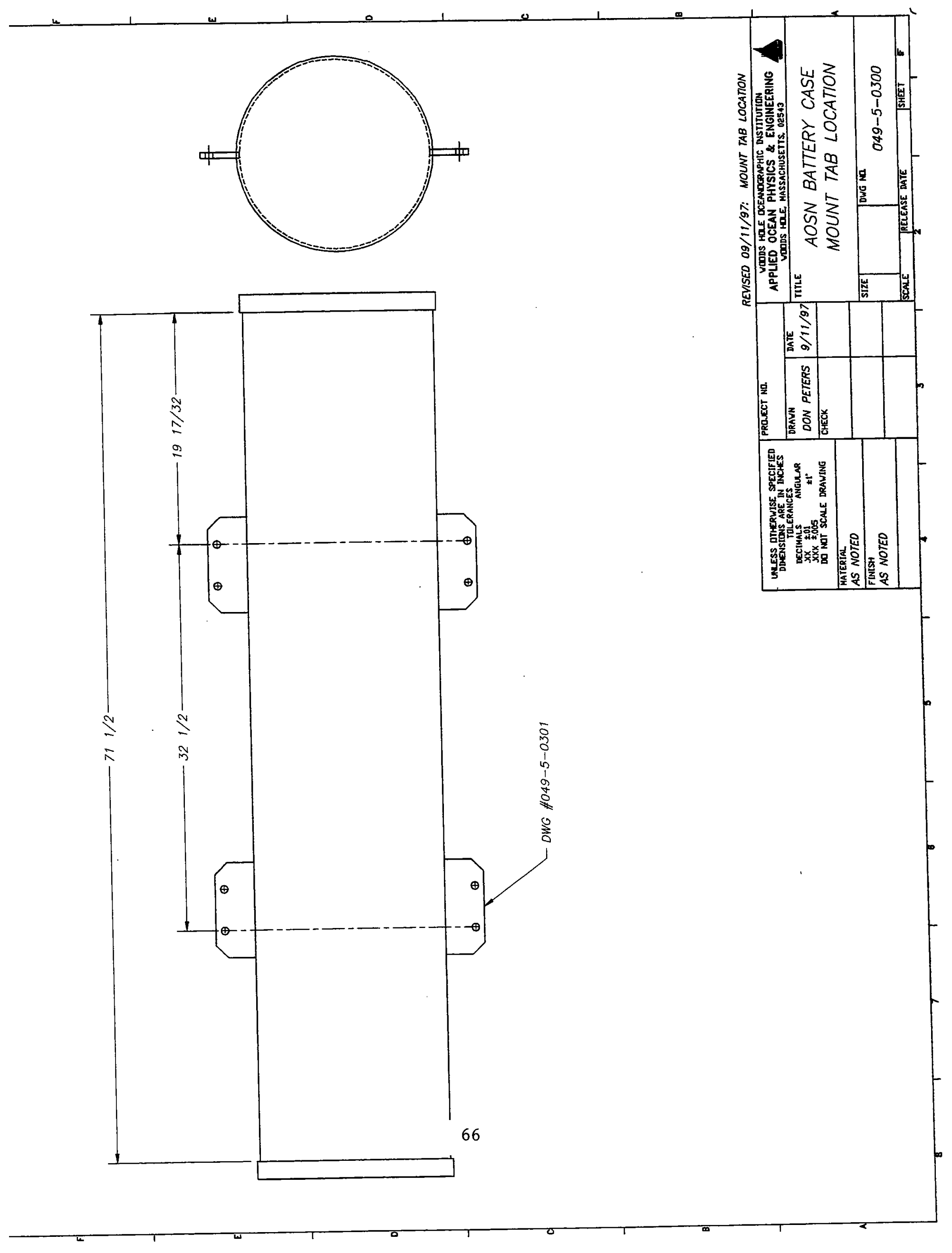




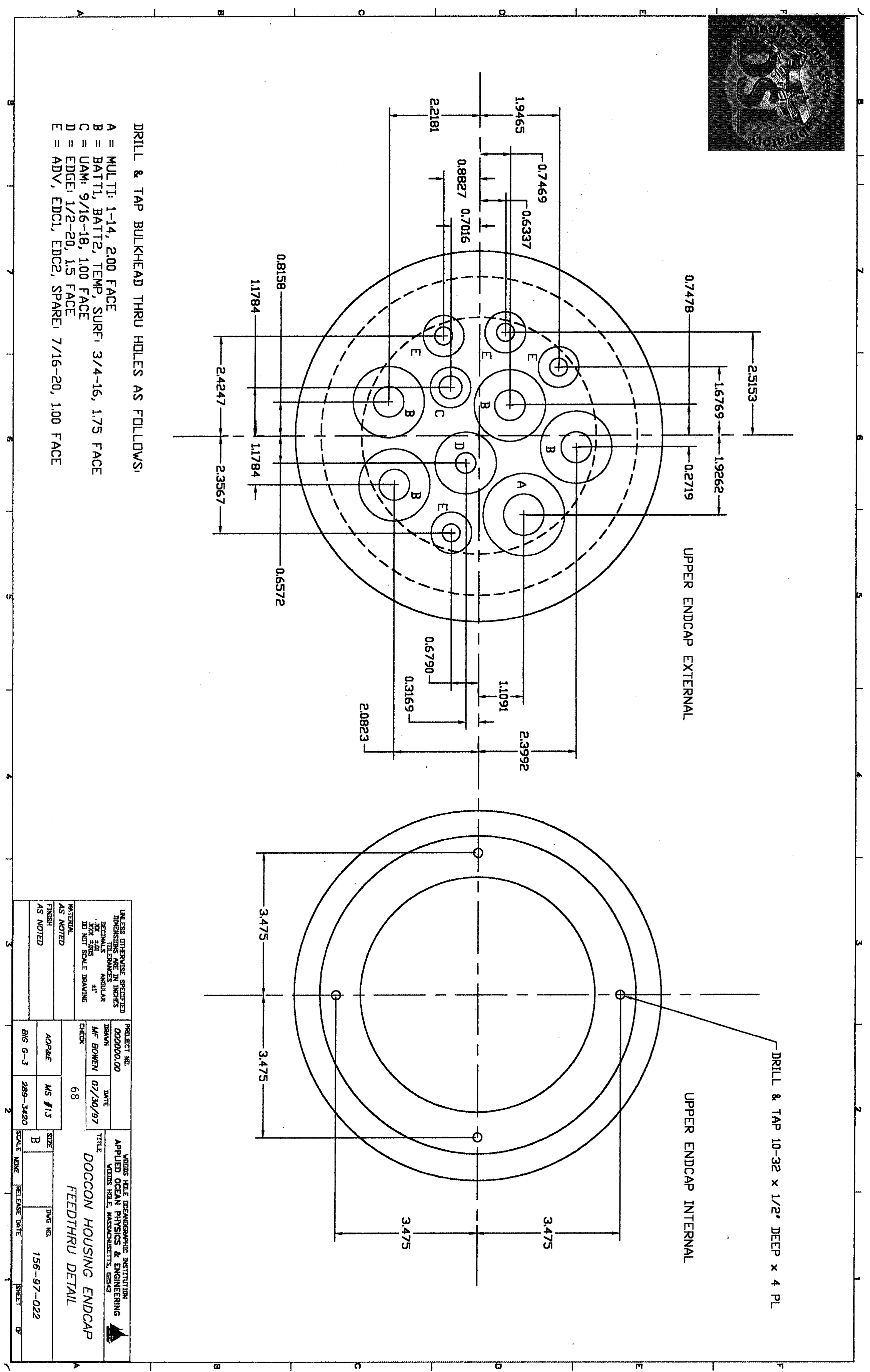




\subsection{References}

1. Bowen, M.F., A Passive Capture Latch for ODYSSEY Class AUVs, Woods Hole Oceanographic Institution, Woods Hole, MA, Blue Cover Technical Report WHOI-98-12, forthcoming, 1998.

2. Den Hertog, J.P., Advanced Strength of Materials, Dover Publications, Inc., New York, NY, pp. 90-99, 1952.

3. Dexter, S.C., Handbook Of Oceanographic Engineering Materials, Robert E. Krieger Publishing Company, Malabar, FL, 1985.

4. Impulse Enterprises, Technical Manual and Connector Selection Guide, rev 0192, San Diego, CA, 1997.

5. Parker Seal Group, Q-Ring Seals Handbook, U.S. Government Manufacturing Code Identification Number 02697, Lexington, KY, 1992.

6. Pittman, Elcom, Guide to Brushless DC Motors and Planetary Gearheads, Penn Engineering and Manufacturing Corporation, Technical Bulletin 3000, Harleysville, PA, 1987.

7. Shigley, J.E., Mischke, C.R., Mechanical Engineering Design, $5^{\text {th }}$ Edition, ISBN 0-07-056899-5, McGrawHill, Inc., New York, NY, 1989.

8. Stock Drive Products, Handbook of Shafts, Bearings and Couplings, Publication D200-4, Sterling Instrument, New York, NY, 1995. 


\section{DOCUMENT LIBRARY}

\section{Distribution List for Technical Report Exchange - July 1998}

University of California, San Diego

SIO Library 0175C

9500 Gilman Drive

La Jolla, CA 92093-0175

Hancock Library of Biology \& Oceanography

Alan Hancock Laboratory

University of Southern California

University Park

Los Angeles, CA 90089-0371

Gifts \& Exchanges

Library

Bedford Institute of Oceanography

P.O. Box 1006

Dartmouth, NS, B2Y 4A2, CANADA

NOAA/EDIS Miami Library Center

4301 Rickenbacker Causeway

Miami, FL 33149

Research Library

U.S. Army Corps of Engineers

Waterways Experiment Station

3909 Halls Ferry Road

Vicksburg, MS 39180-6199

Marine Resources Information Center

Building E38-320

MIT

Cambridge, MA 02139

Library

Lamont-Doherty Geological Observatory

Columbia University

Palisades, NY 10964

Library

Serials Department

Oregon State University

Corvallis, OR 97331

Pell Marine Science Library

University of Rhode Island

Narragansett Bay Campus

Narragansett, RI 02882

Working Collection

Texas A\&M University

Dept. of Oceanography

College Station, TX 77843
Fisheries-Oceanography Library 151 Oceanography Teaching Bldg.

University of Washington

Seattle, WA 98195

Library

R.S.M.A.S.

University of Miami

4600 Rickenbacker Causeway

Miami, FL 33149

Maury Oceanographic Library

Naval Oceanographic Office

Building 1003 South

1002 Balch Blvd.

Stennis Space Center, MS, 39522-5001

Library

Institute of Ocean Sciences

P.O. Box 6000

Sidney, B.C. V8L 4B2

CANADA

National Oceanographic Library

Southampton Oceanography Centre

European Way

Southampton SO14 3ZH

UK

The Librarian

CSIRO Marine Laboratories

G.P.O. Box 1538

Hobart, Tasmania

AUSTRALIA 7001

Library

Proudman Oceanographic Laboratory

Bidston Observatory

Birkenhead

Merseyside L43 7 RA

UNITED KINGDOM

IFREMER

Centre de Brest

Service Documentation - Publications

BP 7029280 PLOUZANE

FRANCE 


\begin{tabular}{|c|c|c|c|}
\hline $\begin{array}{l}\text { REPORT DOCUMENTATION } \\
\text { PAGE }\end{array}$ & $\begin{array}{l}\text { 1. REPORT NO. WHOI-98-11 } \\
\text { WH }\end{array}$ & 2. & 3. Recipient's Accession No. \\
\hline \multirow{2}{*}{\multicolumn{3}{|c|}{$\begin{array}{l}\text { 4. Title and Subtitle } \\
\text { A Deep Sea Docking Station for ODYSSEY Class Autonomous Underwater } \\
\text { Vehicles }\end{array}$}} & $\begin{array}{l}\text { 5. Report Date } \\
\text { June } 10,1998\end{array}$ \\
\hline & & & 6. \\
\hline \multicolumn{3}{|c|}{ 7. Author(s) M. F. Bowen, D. B. Peters } & $\begin{array}{l}\text { 8. Performing Organization Rept. No. } \\
\text { WHOI-98-11 }\end{array}$ \\
\hline \multirow{2}{*}{\multicolumn{3}{|c|}{$\begin{array}{l}\text { 9. Pertorming Organization Name and Address } \\
\text { Woods Hole Oceanographic Institution } \\
\text { Woods Hole, Massachusetts } 02543\end{array}$}} & 10. Project/TaskWork Unit No. \\
\hline & & & $\begin{array}{l}\text { 11. Contract(C) or Grant(G) No. } \\
\text { (C) NO00-14-95-1-1316 } \\
\text { (G) }\end{array}$ \\
\hline \multirow{2}{*}{\multicolumn{3}{|c|}{$\begin{array}{l}\text { 12. Sponsoring Organization Name and Address } \\
\text { Office of Naval Research }\end{array}$}} & $\begin{array}{l}\text { 13. Type of Report \& Period Covered } \\
\text { Technical Report }\end{array}$ \\
\hline & & & 14. \\
\hline
\end{tabular}

15. Supplementary Notes

This report should be cited as: Woods Hole Oceanog. Inst. Tech. Rept., WHOI-98-11

\section{Abstract (Limit: 200 words)}

Under subcontract to the Massachusetts Institute of Technology's (MIT) Sea Grant Autonomous Ocean Sampling Network (AOSN) program, engineers and researchers at the Woods Hole Oceanographic Institution (WHOI) designed, fabricated and operated a deep sea Docking Station for ODYSSEY-class autonomous underwater vehicles (AUVs). The docking station provides shelter as well as power transfer and data exchange services for an AUV that is between autonomous midwater missions. The Station is integrated into the main tension member of a deep sea mooring system. A large subsea flotation sphere supports the mass of the Station above the seafloor. A surface expression connected by an umbilical to the Station was capable of bi-directional satellite or radio frequency communications. Primary subsystems of the Docking Station described in this report include a dock controller with multi-sensor support, long-duration battery packs, a docking pole with a moving carriage, an inductive link for power and data transfer, and information about how the Station was deployed, operated and recovered.

17. Document Analysis a. Descriptors
AUV
Docking
Mooring

b. Identifiers/Open-Ended Terms

\section{c. COSATI Field/Group}

18. Availability Statement

Approved for public release; distribution unlimited.

\begin{tabular}{|l|l|}
\hline $\begin{array}{c}\text { 19. Security Class (This Report) } \\
\text { UNCLASSIFIED }\end{array}$ & $\begin{array}{c}\text { 21. No. of Pages } \\
73\end{array}$ \\
\hline 20. Security Class (This Page) & 22. Price \\
\hline
\end{tabular}

